\title{
The legal protection of farmed fish in Europe - analysing the range of EU legislation and the impact of international animal welfare standards for the fishes in European aquaculture
}

\author{
Marita Giménez-Candela \\ Full Professor, Autonomous University of Barcelona (UAB) Faculty of Law, Spain \\ Director of ICALP and of the Master in Animal Law (UAB) \\ ORCID: https://orcid.org/0000-0002-0755-5928
}

Joao L. Saraiva

CCMAR

Fish Ethology \& Welfare group

University of Algarve, Portugal

ORCID: https://orcid.org/0000-0002-8891-8881

\author{
Helena Bauer \\ Master in Animal Law (UAB) \\ Project Assistant, Animals' Angels e.V., Germany
}

Received: October 2019

Accepted: February 2020

Recommended citation. GIMÉNEZ-CANDELA, M., M., SARAIVA, J.L., BAUER, H., The legal protection of farmed fish in Europe - analysing the range of EU legislation and the impact of international animal welfare standards for the fishes in European aquaculture, dA. Derecho Animal (Forum of Animal Law Studies) 11/1 (2020). - DOI https://doi.org/10.5565/rev/da.460

Acknowledgement. This article was adapted from the Master's thesis defended by Ms. Helena Bauer (Master in Animal Law and Society, UAB, 6th ed.), and supervised by Dr. Anne Peters (Max-Planck Institute for Comparative Public Law and International Law, Heidelberg). Ms. Helena Bauer and Dr. Anne Peters deserve credit for having provided an excellent basis for this publication.

\section{Abstract}

Nowadays, fishes are one of the most exploited 'farm' animals. They are reared in marine and freshwater aquaculture farms, which represent one of the fastest growing food-producing industries worldwide. The numbers of fishes farmed, transported and slaughtered every year are enormous, with more than 100 billion fishes estimated to be killed per year, solely in aquaculture industries. They are kept in high densities, fattened for fast growth and slaughtered, just like in factory farming of terrestrial 'farm' animals. 'Farmed' fishes are regularly handled and transported according to their life stages between different farming systems and cages. In some cases, fishes are deprived of food up to 14 days prior to their slaughter, and commonly their killing is done either without prior stunning or using stunning methods, like CO2-stunning, causing pain and suffering. Despite the fact that a huge number of individuals is involved and that many farming practices impose pain, stress and suffering on the fishes, fish welfare only takes a back seat in public awareness. Fishes are sentient beings, and as such recognised by the EU in Article 13 of the Treaty on the Functioning of the European Union (TFEU). Especially taking into account that the EU has implemented a newly reformed Common Fisheries Policy (CFP) and is making great efforts to increase its aquaculture production within the next years, the present study deals with the question to what extent a 'farmed' fish in Europe is currently protected by EU law and if the international animal welfare standards set out by the World Organisation of Animal Health (OIE) are actually met. 
Keywords: fishes; aquaculture; farm animals; farmed fishes; sentient beings; art. 13 TFUE; Common Fisheries Policy; CFP; OIE.

Resumen - La protección jurídica de los peces de piscifactoría en Europa: análisis del conjunto de la legislación de la UE y de las repercusiones de las normas internacionales de bienestar animal para los peces de acuicultura en Europa

A día de hoy los peces son algunos de los animales de "granja" más explotados. Se crían en granjas acuícolas marinas y de agua dulce, las cuales figuran entre las industrias de producción de alimentos que han experimentado un crecimiento más rápido en todo el mundo. El número de peces que se cultivan, transportan y sacrifican cada año es enorme y se estima que, sólo en la industria acuícola, se sacrifican más de 100.000 millones de peces al año. Se mantienen en altas concentraciones, se engordan para un crecimiento rápido y se sacrifican, al igual que se hace en la cría industrial de animales de "granja" terrestres. Los peces "de granja", a tenor de la época de su desarrollo, se manipulan y transportan regularmente mediante diferentes sistemas de cultivo y diferentes tipos de jaulas. En algunos casos, los peces permanecen privados de alimento incluso hasta 14 días antes de su sacrificio y, comúnmente, tal sacrificio se realiza sin aturdimiento previo o utilizando métodos de aturdimiento, como el aturdimiento con $\mathrm{CO} 2$, que causa dolor y sufrimiento. A pesar del hecho de estar involucrados un gran número de peces -individualmente considerados- y de que muchas de las prácticas de cría imponen dolor, estrés y sufrimiento a los peces, sin embargo, en la conciencia pública el bienestar de los peces solo interesa de forma secundaria. Los peces son seres sentientes y, como tales, están reconocidos por la UE en el artículo 13 del Tratado de Funcionamiento de la Unión Europea (TFUE). Lo que ha de tenerse especialmente en cuenta, ya que la UE ha implementado una Política Pesquera Común (PPC), que ha sido reformada recientemente y que además está haciendo grandes esfuerzos para aumentar la producción acuícola. El presente estudio, aborda la cuestión de hasta qué punto un pez "de piscifactoría" en Europa está actualmente protegido por la legislación de la UE y si se cumplen realmente las normas internacionales de bienestar animal establecidas por la Organización Mundial de Sanidad Animal (OIE).

Palabras clave: peces; acuicultura; animales de granja; peces de cultivo; seres sentientes; Art. 13 TFUE; Política Pesquera Común; PPC; OIE
Abbreviations
CAP
CETS
CFP
COE
EC
EFSA
EU
FAO
OIE
SME
UK
VER
VOR
Common Agricultural Policy
Council of Europe Treaty Series
Common Fisheries Policy
Council of Europe
European Commission
European Food Safety Authority
European Union
Food and Agricultural Organisation of the United Nations
World Organisation for Animal Health
Small- and medium-sized enterprises
United Kingdom
Visual evoked response
Vestibulo-ocular reflex 


\section{Contents}

I. Introduction

II. Aquaculture in the European Union

III. Animal Welfare Legislation in the European Union

IV. International Animal Welfare Standards - The World Organisation for Animal Health (OIE)

V. Fish ethology, cognition and sentience

VI. Comparison of EU legislation versus OIE's Aquatic Animal Health Code concerning fish welfare VII. Conclusion

\section{Introduction}

'Farmed' fishes are the most exploited 'farm' animals. They are reared in marine and freshwater aquaculture farms in numbers exceeding by far any terrestrial 'farm' animals. ${ }^{1}$ In 2010 alone, it was estimated that up to 120 billion fish individuals were killed, solely in aquaculture industries. ${ }^{2}$

The world's largest importer for these products is the EU, with $65 \%$ of 'seafood'imports found on the EU market in 2010. ${ }^{3}$ Since EU politics continue to promote the consumption of fish meat as "an important part of our diets, keeping us healthy", ${ }^{4}$ like the recent EU Commission's campaign 'Farmed in the EU' ${ }^{5}$ is demonstrating, new strategies have been and are urgently searched for in order to compensate the depletion of the oceans.

As stated by the World Food and Agriculture Organisation (FAO), "aquatic food production has transitioned from being primarily based on capture of wild fish [es] to culture of increasing numbers of farmed species". ${ }^{6}$ Indeed, aquaculture is one of the fastest growing industries worldwide. ${ }^{7}$ Only between 2005 and 2014 , aquaculture industries ${ }^{8}$ have increased by about $6 \%$, with finfish production having by far the biggest increase with partly up to $65 \% .{ }^{9}$ Compared to the rest of the world, the EU performs relatively poorly regarding its contribution of aquaculture products. Currently, 'only' $20 \%$ of the total fish production in the EU comes from EU aquaculture. ${ }^{10}$ To change this and take part in the so-called 'Blue Revolution', in 2013 a new Common Fisheries Policy (CFP) was introduced with Regulation (EU) No 1380/2013 - apparently with positive results for the industry. As recently announced, the CFP has achieved its first successes, since "after more than a decade of stagnation, EU aquaculture is finally showing signs of recovery" 11 in terms of growth $(+4 \%)$ and value $(+8 \%)$ between 2014 and $2015 .{ }^{12}$ The development of the aquaculture sector is pushed forward by EU policy, but what part do the fishes and their well-being actually play within this aquaculture policy?

Following the definition of the World Organisation for Animal Health (OIE), "[a]nimal welfare means how an animal is coping with the conditions in which it lives ${ }^{13}$. An animal is in a good state of welfare if (as indicated by scientific evidence) it is healthy, comfortable, well nourished, safe, able to express innate

\footnotetext{
${ }^{1}$ BERGQVIST, J., GUNNARSSON, S., Finfish Aquaculture: Animal Welfare, the Environment, and Ethical Implications. Journal of Agricultural and Environmental Ethics 26 (2013) 76s.

${ }^{2}$ http://fishcount.org.uk/published/std/fishcountstudy2.pdf, (25.05.2018) N.B.: Fishes are still counted in 'tonnes live weight', instead of numbers of individuals. Obviously due to the enormous numbers of fishes caught, it would be very difficult to count them on board a trawler, for example. However, I find it noteworthy that also for aquaculture only statistics on 'tonnes live weight' exist, without considering the single animal (e.g. https://ec.europa.eu/fisheries/facts_figures_en?qt-facts_and_figures=4, 12.06.2018).

${ }^{3}$ EU Commission (2013) Strategic guidelines for sustainable development of EU aquaculture. COM (2013) 229 final. 2.

${ }^{4} \mathrm{https}$ ://ec.europa.eu/fisheries/inseparable/en/know (25.05.2018).

${ }^{5}$ The campaign 'Farmed in the EU' is a project by the European Union promoting fish farmed in European aquaculture as "a healthy, fresh and local alternative". It is embedded in the European Commission's Inseparable initiative on sustainable fisheries. See: https://ec.europa.eu/fisheries/inseparable/en/farmed-eu.

${ }^{6}$ FAO (2016) The State of World Fisheries and Aquaculture 2016. Contributing to food security and nutrition for all. Rome.

${ }^{7}$ See http://www.fao.org/aquaculture/en/ (25.05.2018).

${ }^{8}$ Including finfishes, invertebrates as well as algae production.

${ }^{9}$ FAO, cit., 22.

${ }^{10}$ EU Commission (2017c) Welfare of farmed fish: Common practices during transport and at slaughter. Final report. 21.

${ }^{11}$ https://ec.europa.eu/fisheries/recovering-industry-and-valuable-source-healthy-food- $\% \mathrm{E} 2 \% 80 \% 93$-european-commission-callsregions-embrace_el, 25.05.2018.

${ }^{12}$ Ibid.: ,(...) profits exceeding 400 million euro, the sector is generating more value than ever before."

${ }^{13}$ This definition is not originally from the OIE. It is from BROOM, D.M., Indicators of poor welfare. The British Veterinary Journal $142 / 6$ (1986) 524-526.
} 
behaviour and it is not suffering from unpleasant states such as pain, fear and distress. Good animal welfare requires disease prevention and veterinary treatment, appropriate shelter, management, nutrition, humane handling and humane slaughter/killing" 14 .

However, the focus of the OIE on the health aspect of welfare may be considered incomplete. In fact, the conceptual framework underlying animal welfare is well established and should encompass a functionbased ${ }^{15}$ as well as feelings-based approaches. ${ }^{16}$

These two perspectives should be combined with a nature-based approach, and the ethical concerns regarding the quality of life of animals should therefore reflect 1) that the animals are healthy and physiologically normal, 2) that the animals fell well and are free from pain, fear and other chronic negative emotional states and 3) that the animals are able to express their natural behaviour and adaptations. ${ }^{17}$

The resulting combination should define welfare in a longer term, as a balance between positive and negative subjective experiences. ${ }^{18}$ This combination is obviously difficult, because the function-based approach is clearly insufficient to assess mental states (fear, anxiety, etc. - see section $\mathrm{V}$ of this manuscript) and the feelings-based approach is clearly too broad to be readily measurable. Furthermore, severe knowledge gaps exist concerning in the biology of farmed fishes. ${ }^{19}$ The information that does exist is focused primarily on production traits rather than welfare. In fact, research has pushed the physiological limits of many fish species in growth, fertility and size, as a consequence of (or resulting in) highly artificial conditions. ${ }^{20}$ This creates an obvious issue regarding welfare: Fish are sentient beings ${ }^{21}$ and each species has evolved for millennia in natural contexts, developing adaptations, behaviours and coping mechanisms which are relevant for those contexts. ${ }^{22}$ The artificial conditions of captivity, particularly in industrial aquaculture, pose a whole new category of stimuli, for which the animals are seldom equipped to deal with: Space restraints, unnatural aggregations, barren environments, handling and other frequent artificial stressors, etc. ${ }^{23}$ Artificial selection may not necessarily be an answer to the issue, because (1) the domestication of fish is very recent and (2) selected or 'domesticated' strains may be far from their welfare optima as a consequence of their domestication processes. ${ }^{24}$

A welfare assessment of farmed fishes is publicly available in the FishEthoBase (www.fishethobase.net), an open-access database that aims to provide information on the welfare of all fish species currently farmed worldwide. The database is based on common risk assessment protocols and delivers a score on the Likelihood that the species is farmed under good welfare, the Potential to be farmed under good welfare and Certainty of the findings for the scoring. Presently approaching the top 45 species, this database is directed to all stakeholders in the field and targets not only to bridge the gaps between them but also to provide scientific information to improve the welfare of fish. Analysing the available information in the FishEthoBase, it is clear that (i) the general welfare state of farmed fishes is poor, (ii) there is some potential for improvement and (iii) this potential is related to research on species' needs, but (iv) there are many remaining knowledge gaps and (v) current fish farming technologies do not seem to fully address welfare issues. ${ }^{25}$

Since 2009, fishes are also recognised as sentient beings by the EU in Article 13 of the Treaty on the

\footnotetext{
${ }^{14}$ Article 7.1.1 of Terrestrial Animal Health Code.

${ }^{15}$ DUNCAN, I.J., Science-based assessment of animal welfare: Farm animals. Revue scientifique et technique (International Office of Epizootics) 24/2 (2005) 483.

${ }^{16}$ DUNCAN, I., DAWKINS, M., The problem of assessing "well being" and "suffering" in farm animals. In Indicators Relevant to Farm Animal Welfare (Dordrecht 1983) 13-24.

${ }^{17}$ FRASER, D., WEARY, D.M., PAJOR, E.A., MILLIGAN, B.N., A scientific conception of animal welfare that reflects ethical concerns. Animal welfare, 6 (1997) 187-205.

${ }^{18}$ SPRUIJT, B.M., VAN DER BOS, R., PIJLMAN, F.T., A concept of welfare based on reward evaluating mechanisms in the brain: Anticipatory behaviour as an indicator for the state of reward system. Applied Animal Behaviour Science 72/2 (2001)145-171.

${ }^{19}$ SARAIVA, J. L., ARECHAVALA-LOPEZ, P., CASTANHEIRA, M. F., VOLSTORF, J., HEINZPETER STUDER, B., A Global Assessment of Welfare in Farmed Fishes: The FishEthoBase. Fishes 4/2 (2019) 30. MDPI AG. Retrieved from http://dx.doi.org/10.3390/fishes4020030

${ }^{20}$ HUNTINGFORD, F.A. Implications of domestication and rearing conditions for the behaviour of cultivated fishes. J. Fish Biol. 65 (2004) 122-142. [Google Scholar] [CrossRef]

${ }^{21}$ BROWN, C., Fish intelligence, sentience and ethics. Anim. Cogn. 18 (2014) 1-17.; SNEDDON, L.U., The bold and the shy: Individual differences in rainbow trout. J. Fish Biol. 62 (2003) 971-975; YUE, S., MOCCIA, R.D., DUNCAN, I.J.H., Investigating fear in domestic rainbow trout, Oncorhynchus mykiss, using an avoidance learning task. Appl. Anim. Behav. Sci. 87 (2004) $343-354$. ${ }^{22}$ HelfMAN, G., COLLETTE, B.B., FACEY, D.E., BOWEN, B.W., The Diversity of Fishes: Biology, Evolution, and Ecology (Hoboken, NJ 2009).

${ }^{23}$ ASHLEY, P.J. Fish welfare: Current issues in aquaculture. Appl. Anim. Behav. Sci. 104 (2007) 199-235.

${ }^{24}$ SARAIVA, J.L., CASTANHEIRA, M.F., ARECHAVALA-LÓPEZ, P., VOLSTORF, J., STUDER, B.H., Domestication and Welfare in Farmed Fish. In Animal Domestication. IntechOpen (London 2018)

${ }^{25}$ SARAIVA, J. L., ARECHAVALA-LOPEZ, P., CASTANHEIRA, M. F., VOLSTORF, J., \& HEINZPETER STUDER, B., A Global Assessment of Welfare in Farmed Fishes: The FishEthoBase. Fishes, 4/2 (2019) 30. MDPI AG. DOI:
} http://dx.doi.org/10.3390/fishes4020030

68 Derecho Animal. Forum of Animal Law Studies, vol. 11/1 
Functioning of the European Union (TFEU). Thus, not only in terrestrial agriculture but also in fisheries the $\mathrm{EU}$ and its Member States are obliged to "pay full regard to welfare requirements of animals". ${ }^{26}$

Especially taking into account that the EU is putting in great efforts to increase its aquaculture production within the next years, ${ }^{27}$ and in light of growing evidence on the fishes' capacity to feel, the question arises to what extent a 'farmed' fish in Europe is currently protected by EU animal welfare legislation. Hereby, the present study aims to demonstrate whether the protection of conventionally 'farmed' fishes is sufficiently recognised in EU legislation, considering the different life stages of the fishes and taking into account the international animal welfare standards set out by the World Organisation of Animal Health (OIE) ${ }^{28}$

\section{Aquaculture in the European Union 1. EU aquaculture production}

The most common fishes being farmed in freshwater systems in the EU are rainbow trout, carps, sturgeon, tilapia but also pike, catfish, zander or whitefish. The most prominent 'farmed' fishes of marine aquaculture are Atlantic salmon, Gilthead sea bream, European sea bass, but also Atlantic bluefin tuna, meagre, cod, sea perch as well as flatfish species like turbot, common sole and Senegalese sole. ${ }^{29}$ Also, diadromous species like the European eel are farmed in the EU, "since attempts to reproduce eel in captivity have been unsuccessful so far, aquaculture production relies on catches of [wild] immature fish [es] that are ongrown in intensive rearing installations using recirculation systems, primarily in the Netherlands, Denmark and Italy". ${ }^{30}$

Currently, the European Union is promoting the expansion of the EU fish farming industry and thus funding projects such as DIVERSIFY to "explor[e] the biological and socio-economic potential of new/emerging candidate fish species", ${ }^{31}$ like greater amberjack, meagre, wreckfish or Atlantic halibut. These species have in common that they may reach high body weight - one quality that is obviously of particular interest for the fish producing industry.

Similarly, PERFORMFISH is a 7 million $€$ project funded by EU that aims to boost the aquaculture sector in Mediterranean countries. Its consortium is composed of 28 partners across the value chain and the ultimate goal is 'to ensure sustainable growth of the Mediterranean aquaculture industry, based on consumer perceptions and real market requirements. It aims to support fish farms that operate not only in ideal economic and environmental conditions but also in a socially and culturally responsible manner.' (http://performfish.eu/). However and even in such a large scale project, once again the welfare of farmed species is not clearly separated from health or considered only in a production perspective (http://performfish.eu/work-packages/). Although there are 7 mentions to the term 'welfare' throughout the outline of tasks, it is only mentioned assertively in point 4 of workpackage 3 . All of the remaining mentions in the public presentation of the project refer to production traits (growth and welfare, health and welfare, feed and welfare). Although it is positive that the issue is tackled, it should be accompanied by a sound and solid conceptual framework, in order to avoid 'bluewashing' (i.e. use of "welfare" solely as a marketing tool for the praise of public perception). Nevertheless, it should be clear that there is a strong correlation between welfare of farmed animals and the quality of fish products placed on the market - a rare case when the interest of the industry and the ethical standards underlying its activity walk closely together. ${ }^{32}$

Not only in terms of species diversity, but also regarding farming methods, "European aquaculture takes a variety of forms: extensive or intensive, in natural settings or tanks, in fresh water or sea water, in flow-through or recirculation systems, traditional or modern, classic or organic, sheltered or exposed, and so on" ${ }^{\prime 3}$. The type of farming method is dependent on the fish species reared and the grade of intensification.

Extensive aquaculture production is either conducted in freshwater or brackish water systems and represents a traditional farming method still found throughout Europe. The fishes are kept in a more natural

\footnotetext{
${ }^{26}$ Article 13 TFEU; GIMÉNEZ-CANDELA, M., Tratamiento jurídico de los peces en la UE y en España, dA. Derecho Animal (Forum of Animal Law Studies) 10/4 (2019) 43-59. DOI: https://doi.org/10.5565/rev/da.475; BAUER, H., Fishes - The Forgotten Sentient Beings, dA. Derecho Animal (Forum of Animal Law Studies 10/2 (2019) 72-77. DOI https://doi.org/10.5565/rev/da.427

${ }^{27}$ EU Commission Aquaculture High Level Event Report "Tapping into blue growth: the way forward for European aquaculture", 24 May 2016, Square Brussels meeting centre. 1-17.

${ }^{28}$ It should be noted that the present study only deals with finfish aquaculture, i.e. with the fishes as vertebrate animals kept in aquaculture. Invertebrates (also farmed in aquaculture) are not considered in this study at hand. Furthermore, this study does not analyse organic finfish production, but focuses on the biggest group of fishes affected in EU aquaculture, namely the conventionally 'farmed' fishes.

${ }^{29} \mathrm{https}: / /$ ec.europa.eu/fisheries/cfp/aquaculture/aquaculture_methods_en (12.06.2018).

${ }^{30} \mathrm{https}: / /$ ec.europa.eu/fisheries/marine_species/farmed_fish_and_shellfish/eel (12.06.2018).

${ }^{31} \mathrm{http} / / / \mathrm{www}$. diversifyfish.eu/about-diversify.html (12.06.2018).

${ }^{32}$ SARAIVA, J.L., ARECHAVALA-LOPEZ, P., Welfare of Fish-No Longer the Elephant in the Room. Fishes 4 (2019) 39.

${ }^{33} \mathrm{https}$ ://ec.europa.eu/fisheries/cfp/aquaculture/aquaculture_methods_en\#marine, (12.06.2018).
} 
environment in open freshwater ponds or brackish water lagoons in which natural vegetation is promoted by additional fertilisation. The fishes share their environment with other species, such as small molluscs or crustaceans or other fish species, and search for food in a natural way, partly being provided with additional food. From a conservational point of view, these extensive farming systems are considered important for preserving biodiversity. ${ }^{34}$

In contrast, intensive fish farming systems have been facing strong criticism for their negative impact on the environment due to pollution and the risk for disease transmission to wild fish populations. ${ }^{35}$ The most prominent example of intensive aquaculture is the farming of fishes in sea cages. These cages are essentially nets that are attached to the sea floor with a special floating frame in order to keep them at the surface. Sea cages are mostly located "in areas sheltered from excessive wave action, with sufficiently deep water and relatively low current speeds". ${ }^{36}$ Also, on land, intensive farming systems can be found either as open, flowthrough systems, mainly for trout fishes, or as closed recirculation systems, which have been used mainly in hatcheries - simply due to the fact that it is much easier in a closed system to control factors such as water quality or temperature which are essential for breeding. Only recently, these closed recirculation systems have become more and more attractive for rearing of on-grown fishes and are currently used, among others, for trout, eel or turbot. ${ }^{37}$ In these closed recirculation systems the fishes live in opaque, isolated tanks without any contact with their natural environment.

In Europe, it is estimated that $\sim 1000$ million trout and $\sim 440$ million individuals of Atlantic salmon are kept for the production of meat. ${ }^{38}$ Further official numbers of individuals from other fish species are not available since 'farmed' fishes are only registered in total weight [tonnes] and not counted as individuals. ${ }^{39}$

\section{EU Common Fisheries Policy and the welfare of 'farmed' fishes}

As described previously, currently the EU generates 'only' $20 \%$ of its total fish production from EU aquaculture. ${ }^{40}$ In order to increase this percentage and to be part of the so-called 'Blue Revolution', with Regulation (EU) No 1380/2013 a new Common Fisheries Policy (CFP) was enacted in 2013. Herewith, "[t] he Commission intends to boost the aquaculture sector", ${ }^{41}$ thus presenting 'Strategic Guidelines for the sustainable development of EU aquaculture'. Among others, administrative procedures for 'seafood' farmers should be facilitated; coordinated spatial planning of aquaculture plants should ensure sustainable development and growth within the EU; the reformed common market organisation and structuring of aquaculture should contribute to enhance competitiveness of EU aquaculture, especially due to its high quality, health and environmental standards, and an Aquaculture Advisory Council has even been established to support these objectives. ${ }^{42}$

The reformed Common Fisheries Policy aims to convert EU aquaculture into a sustainable and highquality sector by asking its Member States for multiannual national strategic plans and by producing guidelines which should strictly respect environmental issues. ${ }^{43}$

However, fish welfare does not seem to be one of the priorities within the reformed CFP. In fact, only recital 16 of the preamble of Regulation (EU) No 1380/2013 on the Common Fisheries Policy states that it should pay full regard to animal welfare, among others - but nothing more in detail. Following a Commission's Answer to a Written Parliamentary Question (E-012243/2011) in 2012, "animal welfare is not part of the objectives of the CFP", since "farmed fish [es] are covered under the scope of the following animal welfare legislation", ${ }^{44}$ namely: Council Directive 98/58/EC concerning the protection of animals kept for farming purposes; Council Regulation (EC) No 1/2005 on the protection of animals during transport; and Council Regulation (EC) No 1099/2009 on the protection of animals at the time of killing.

\section{Animal Welfare Legislation in the European Union}

\footnotetext{
${ }^{34}$ Ibid.

${ }^{35}$ E.g.: Greenpeace, Challenging the Aquaculture Industry on Sustainability (2008) 1-24.

${ }^{36} \mathrm{https}$ ://ec.europa.eu/fisheries/cfp/aquaculture/aquaculture_methods_en\#marine, 12.06.2018.

${ }^{37}$ Ibid.

${ }^{38}$ EU Commission (2017b) Animal Welfare in the European Union (Study PE 583.114) 49.

${ }^{39}$ This "might be considered as an indication of the status fish[es] have in today's society" (See: BERGQVIST, J., GUNNARSON, S., cit. 77).

${ }^{40}$ EU Commission (2017c) Welfare of farmed fish: Common practices during transport and at slaughter. Final report. 21.

${ }^{41} \mathrm{https}: / /$ ec.europa.eu/fisheries/cfp/aquaculture en, 12.06.2018.

${ }^{42}$ EU Commission (2013) Strategic guidelines for sustainable development of EU aquaculture, cit. 2-9

${ }^{43}$ Ibid.

${ }^{44}$ EU Commission's Answer to the Written Parliamentary Question E-012243/2011, 1 March 2012:

http://www.europarl.europa.eu/sides/getAllAnswers.do?reference=E-2011-012243\&language=EN 12.06.2018.

70

Derecho Animal. Forum of Animal Law Studies, vol. 11/1
} 
To the present day, the EU has produced a broad range of animal welfare rules and "(...) is widely respected in the world, not principally because of it is a large trading unit but because it has adopted many policies and much legislation for moral reasons" 45 - also regarding animal welfare. This becomes particularly clear with the introduction of Article 13 of the Treaty on the Functioning of the European Union (TFEU) in 2009. Hereby, the EU recognises animals as sentient beings and commits itself and its Member States to pay full regard to their welfare when formulating and implementing the Union's policies in certain key areas, such as agriculture or fisheries.

Looking at secondary EU legislation, the majority of these legislative provisions are laid down for terrestrial 'farm' animals.

For over 40 years now the EU has produced numerous legislative provisions in order to regulate the keeping, transport, and slaughter of 'farm' animals and not least to improve their welfare conditions, starting with the enactment of the first EU legislation on the protection of animals in slaughterhouses in 1974. This was followed, amongst others, by further EU legislations on the protection of animals during transport (1977) and finally in 1998 by Council Directive 98/58/EC on the protection of animals kept for farming purposes. ${ }^{46}$ Today, many of these early EU laws are no longer valid due to newly gained scientific knowledge, but are revised or replaced by new EU legislation. ${ }^{47}$ Even though aquatic 'farm' animals have taken a backseat in the welfare discussion for a very long time, slowly "concerns [are] raised by several citizens about animal welfare in fish farming [and thus] the European Commission would like to clarify that the health and welfare of farmed fish [es] is important for EU aquaculture". ${ }^{48}$ It is positive to consider the recently published EU Commission's report on fish welfare during transport and slaughter, which had already been formalised to be produced within the animal welfare strategy 2012-2015, indicating that fish welfare has finally found its way on the agenda of EU policy. However, it remains to be seen what this means indeed in practice for the 'farmed' fishes, especially when considering the European Union's recently reformed Common Fisheries Policy (CFP) - in which one searches in vain for detailed provisions regarding fish welfare.

\section{International Animal Welfare Standards - The World Organisation for Animal Health (OIE)}

In 2001 OIE's Member Countries recognised for the first time the need of improving international animal welfare by identifying it as a priority in the OIE Strategic Plan 2001-2005. As the OIE has been the leader in setting global animal health standards for more than 70 years, and due to the close linkage between animal health and welfare, the international community granted the mandate to the OIE "to take the lead in developing global standards and guidelines on animal welfare practices". ${ }^{49}$ Since then, the OIE has produced a number of standards and recommendations on animal welfare, the first being adopted in the OIE Terrestrial Animal Health Code in 2005. Following this, in 2008 the World Assembly of OIE Delegates also adopted standards on the welfare of 'farmed' fishes in the OIE Aquatic Animal Health Code. It contains, among others, general principles as well as special recommendations on the welfare of 'farmed' fishes during transport and slaughter.

Not being an enforcement body, the OIE "relies on an honour system of conduct by the official authorities responsible for animal health". ${ }^{50}$ In essence, OIE's codes and standards are recommendations without legal binding character but "based on the voluntary compliance by its Members". ${ }^{51}$ Accordingly, by accepting and adopting the OIE codes on animal health and welfare, each OIE member has committed itself to comply with these principles and standards.

\section{Fish ethology, cognition and sentience}

Victoria Braithwaite and Lynne Sneddon have been key advocates of the remarkable sentience and

\footnotetext{
${ }^{45}$ EU Commission (2017b) Animal Welfare in the European Union, cit., 30

4640 Years of Animal Welfare - EU Commission Infographic. See:

https://ec.europa.eu/food/sites/food/files/animals/docs/aw_infograph_40-years-of-aw.pdf, 12.06.2018.

${ }^{47}$ E.g. Council Regulation (EC) No 1/2005 on the protection of animals during transport, replacing Council directive 91/628/EEC of 19 November 1991 / Council Regulation (EC) 1099/2009 on the protection of animals at the time of killing, replacing Council Directive 93/119/EC of 22 December 1993 / N.B.: Council Directive 98/58/EC on the protection of animals kept for farming purposes has not been revised or adapted to newly gained scientific knowledge since its entry into force in 1998 .

${ }^{48} \mathrm{https}$ ://ec.europa.eu/fisheries/animal-welfare-eu-aquaculture_en, 12.06.2018.

${ }^{49}$ KAHN, S., VARAS, M., OIE animal welfare standards and the multilateral trade policy framework. OIE discussion paper (2014) 1. See:

www.oie.int/fileadmin/Home/eng/Animal_Welfare/docs/pdf/Others/Animal_welfare_and_Trade/A_WTO_Paper.pdf (13.04.2018).

${ }^{50} \mathrm{http}: / /$ www.fao.org/docrep/003/x7354e/X7354e06.htm (13.04.2018).

${ }^{51}$ Ibid.
} 
cognitive capabilities of fish ${ }^{52}$ - and they were one of the first showing that fishes do not simply react to aversive stimuli with reflexes, but that they indeed experience pain and fear. ${ }^{53}$ With their work, they made, among others, a significant contribution towards a better understanding of the inner life of fishes, as will be seen in the following.

Pain, which is defined as "aversive sensation and feeling associated with actual or potential tissue damage", ${ }^{54}$ can be distinguished in two different phases - the unconscious phase called nociception, and the conscious phase. ${ }^{55}$ Whereas nociception simply describes the automatic reflex response of the nervous system to a negative, noxious stimulus (like temperature, mechanical pressure or chemicals), the second phase implies that the pain signal is further conveyed via the spinal cord to the brain where it is transposed into the emotional feeling and experience of pain. ${ }^{56}$ In essence, the individual concerned becomes cognitively aware of the pain, which then can obviously lead to suffering. Fishes do not only possess numerous nociceptors that are necessary to detect negative stimuli and are distributed all over their body (especially around critical parts like eyes, mouth or fins), they also have the functional pathways transmitting the pain signal from the nociceptor to the brain. Like we do, fishes have A-delta and C-delta nerve fibres for the important pain stimuli transfer to the brain. ${ }^{57}$ With this discovery, finally the question of whether fishes have the anatomical features for pain detection was answered with yes, inter alia, by Victoria Braithwaite and Lynne Sneddon in 2003. ${ }^{58}$ They also demonstrated in experiments with rainbow trout, who were treated with aversive noxious stimuli like acidic vinegar or bee venom injected into their lips, that these fishes showed: (1) physiological reactions like an accelerated breathing rate ${ }^{59}$ and loss of appetite, which are also typical reactions to pain in mammals (including humans) and birds; ${ }^{60}$ (2) The fishes showed changes in their behaviour due to the painful stimulation, for example those fishes treated with the chemical substances rubbed their inflamed lip region over the ground of the tank indicating that they tried to get rid of this painful stimulus - just like we do when we start to scratch on itching bee stings; (3) The experiments showed an "impaired cognitive ability [of the fishes] caused by noxious stimulation", ${ }^{61}$ i.e. those fishes treated with the chemical substances were so distracted by pain that they were not able to show normal predator avoidance and fear behaviour when exposed to novel objects. ${ }^{62}$ Also, we know from our own experience that under heavy pain we are not able to concentrate on anything else and thus show impaired cognitive abilities, just like these fishes did in pain. Interestingly, when the 'test fishes' received painkiller they showed again the same normal avoidance behaviour as their 'untreated' companions of the control group. ${ }^{63}$ In other words, when relieved from the pain due to analgesics the fishes were no longer 'blinded by pain' but could concentrate again on the novel object and react accordingly. This led to the conclusion that the fishes indeed perceive and feel pain. Due to their different behavioural responses - depending on whether the fishes were in pain or received painkiller they "must be cognitively aware and experiencing the negative experiences associated with pain". ${ }^{64}$ Hence, fishes fulfil the criteria which are - according to EFSA (2009) - generally accepted to concede the capacity of feeling pain to animals. ${ }^{65}$ As reported by Lynne Sneddon (2013), fishes in pain are - like mammals or birds

\footnotetext{
${ }^{52}$ BRAITHWAITE, V.A. \& DROEGE, P., Why human pain can't tell us whether fish feel pain. Animal Sentience 3/3 (2016) 1-2; SNEDDON, L.U., LEACH, M.C., Anthropomorphic denial of fish pain. Commentary on Key on Fish Pain. Animal Sentience $3 / 28$ (2016)1-4.

${ }^{53}$ SNEDDON, L.U., BRAITHWAITE, V., GENTLE, M.J., Novel object test: examining nociception and fear in the rainbow trout. The Journal of Pain 4/8 (2003a) 431-440

${ }^{54}$ EFSA (2009) Scientific Opinion on general approach to fish welfare and to the concept of sentience in fish. The EFSA Journal 954, 12.

${ }^{55}$ BRAITHWAITE, V., Do fish feel pain? (New York 2010) 44.

${ }^{56}$ Ibid. 44-45.

${ }^{57}$ Ibid. 51-52; N.B.: At least these A-delta and C-fibres are found in Agnatha and teleost fish species; for other groups like sharks and rays there is less known due to the lack of research, see e.g.: EFSA (2009), Scientific Opinion on general approach to fish welfare and to the concept of sentience in fish. cit. 12-15; SNEDDON, L., Pain in aquatic animals. J. Exp. Biol. 218 (2015) 967-976.

${ }^{58}$ SNEDDON, L.U., BRAITHWAITE, V., GENTLE, M.J., Do fishes have nociceptors? Evidence for the evolution of a vertebrate sensory system. Proceedings of the Royal Society of London Series B - Biological Sciences 270/1520 (2003b) 1115-1121.

${ }^{59}$ Accelerated breathing can be measured in fishes by their gill cover movement/ventilation which is much quicker than in normal conditions, e.g. rainbow trout individuals treated with a noxious chemical substance showed an increased respiration rate for more than 3-6 hours after the painful stimulus event. See: SNEDDON, L.U., Do painful sensations and fear exist in fish? Animal Suffering: From Science to Law. International Symposium (2013) 97.

${ }^{60}$ BRAITHWAITE, V., Do fish feel pain? cit., 46-74.

${ }^{61}$ Ibid. 74.

${ }^{62}$ As described by Lynne Sneddon (2013), inter alia, "fear stimuli are psychological threats to the survival of the whole animal and fear motivates the animal to make an appropriate defensive response such as freezing, hiding or fleeing." In so-called predator tests, animals are exposed to 'predator-like' shapes or other 'predator-like' stimuli such as odour in order to analyse their "fight or flight response" and measure the animals' fear. See: SNEDDON, L.U., Do painful sensations and fear exist in fish? cit., 100.

63 Ibid. 69.

${ }^{64}$ BRAITHWAITE, Do fish feel pain? cit., 69.

${ }^{65}$ EFSA (2009), cit. 2-13.

72 Derecho Animal. Forum of Animal Law Studies, vol. 11/1
} 
- even "willing to pay a cost to access [a] pain relief". ${ }^{66}$ That is to say, when fishes were asked where to preferably spend their time, under normal circumstances they have chosen a friendlier chamber with environmental enrichment and the possibility of social interaction. But when the same fishes were subjected to a noxious, painful stimulus (such as acetic acid injected subcutaneously) they have changed their preferences, staying in a bright and barren chamber which contained analgesics in the water but no environmental or social enrichment. The fishes in pain forewent the more favourable enriched chamber in order to receive a pain relief. As Sneddon (2013) says, "[t] his is compelling evidence for a negative affective component when fish [es] experience a painful event", ${ }^{67}$ and thus can be understood as another proof for the conscious and subjective experience of pain in fishes. Consequently, when they are consciously feeling pain, shouldn't they be capable to suffer, too?

Suffering as well as any other feeling is always a subjective, personal experience and "no animal can directly communicate its experience to us". ${ }^{68}$ Without doubt, not only for fishes but for anybody else, it is difficult to describe scientifically how suffering, pleasure or any other emotion feels - same for defining sentience or consciousness. However, there is more and more evidence from the scientific side that fishes do have these capacities, too, and the fact that "mental experiences can be only truly accessed by their owners [regardless of human or non-human animals] does not make them less real (...)". ${ }^{69}$ Even though fishes lack a human-like neocortex, apparently other parts of the fish brain seem to be responsible for processing emotions and consciousness. ${ }^{70}$ On 7 July 2012, numerous international experts on neuroscience signed 'The Cambridge Declaration on Consciousness', in which they state that "[t]he absence of a neocortex does not appear to preclude an organism from experiencing affective states [but that] convergent evidence indicates that nonhuman animals have the neuroanatomical, neurochemical, and neurophysiological substrates of conscious states along with the capacity to exhibit intentional behaviours". ${ }^{71}$ For example, birds also lack a neocortex, but (luckily) we allow them to be sentient beings. In fact, they "appear to offer, in their behaviour, neurophysiology, and neuroanatomy a striking case of parallel evolution of consciousness" 72 - so why do we still deny the fishes being conscious and sentient beings?

The subjective experiences of fish that form their inner world or Umvelt ${ }^{73}$ are likely to be very different from our own, due to a divergent evolutionary pathway. Besides the five sensory systems that humans share with fish, these animals also present senses that are completely alien to us, e.g. hydrodynamic, electrical or magnetic sensing. ${ }^{74}$ The central integration of such stimuli combined with life in the aquatic environment, very different from life on land, results in extremely rich sensory worlds for fishes, that not only differ from species to species but also represent a challenge for human perception. Furthermore, this distance between the Umvelt of humans and fish creates a barrier that hampers the establishment of empathy - an essential requirement for compassion. ${ }^{75}$ Simultaneously, it may seem paradoxical for public perception that such different animals may rely on the same basic mechanisms regulating pain, cognition and sentience. Nevertheless, the overwhelming evidence towards the existence of advanced mental capabilities in fish should suffice to lend them the same ethical and legal protection as any other vertebrate. ${ }^{76}$

Remarkable observations have been made of fishes both in the lab and in their natural environment, demonstrating their great cognitive abilities:

\section{Memory and learning}

The popular image of fish and their 'three second memory' is fortunately fading away, much because the overwhelming amount of research and dissemination on their excellent use of memory. In fact,

\footnotetext{
${ }^{66}$ SNEDDON, L.U., Do painful sensations and fear exist in fish? cit., 99.

${ }^{67}$ Ibid. 99-100.

${ }^{68}$ SNEDDON, L.U., LEACH, M.C., Anthropomorphic denial of fish pain, cit. 1

${ }^{69}$ YUE COTTEE, S., Are fish the victims of 'speciesism'? A discussion about fear, pain and animal consciousness. Fish Physiology and Biochemistry (2012) 10.

${ }^{70}$ EFSA (2009), cit., 18-19; BRAITHWAITE, Do fish feel pain? cit. 99 -102; YUE COTTEE, S., Are fish the victims of 'speciesism'? cit. 12-13.

${ }^{71}$ The Cambridge Declaration on Consciousness. Publicly proclaimed Philip Low, David Edelman and Christof Koch at the Francis Crick Memorial Conference on Consciousness in Human and non-Human Animals, at Churchill College, University of Cambridge, UK on 7 July 2012 (2012) Online accessible: http://fcmconference.org/img/CambridgeDeclarationOnConsciousness.pdf

${ }^{72}$ Ibid.

${ }^{73}$ BETHOZ, A., Neurobiology of "Umwelt": How Living Beings Perceive the World. Springer Science \& Business Media (2008) 161

${ }^{74}$ For a review see, SARAIVA, J.L., CASTANHEIRA, M.F., ARECHAVALA-LÓPEZ, P., VOLSTORF, J., STUDER, B.H., Domestication and Welfare in Farmed Fish. In Animal Domestication. IntechOpen (London 2018); BROWN, C., Fish intelligence, sentience and ethics. Anim Cogn 18 (2015) 1-17. https://doi.org/10.1007/s10071-014-0761-0

75 SARAIVA, J.L., CASTANHEIRA, M.F., ARECHAVALA-LÓPEZ, P., VOLSTORF, J., STUDER, B.H., Domestication and Welfare in Farmed Fish. In Animal Domestication. IntechOpen (London 2018)

${ }^{76}$ BROWN, C. Fish intelligence, sentience and ethics. Anim. Cogn. 18 (2015) 1-17. https://doi.org/10.1007/s10071-014-0761-0
} 
many fishes have extraordinary social memory and are able to recognise conspecific ${ }^{77}$ and heterospecific individuals ${ }^{78}$, and make strategic use of that information ${ }^{79},{ }^{80}$. Many fish species are also excellent at navigation, with highly developed spatial memory ${ }^{81}$.

\section{Cooperation}

Several fishes have been demonstrated to have cooperative strategies, both with conspecifics ${ }^{82}$ and with other species: the most famous case of interspecific cooperation is probably the case of groupers and moray eels preying together and coordinated in coral reefs of the red sea ${ }^{83}$.

\section{$\underline{\text { Self-consciousness }}$}

Consciousness is a very broad concept and includes sentience, intelligence and awareness. It can be defined as awareness of internal and external stimuli while having some sense of self and selfcontextualization ${ }^{84} 85$. Although some forms of self awareness have been demonstrated in fish that may not require high-order consciousness ${ }^{86,87}$, a recent study has raised the possibility that some fish may even be self-conscious ${ }^{88}$, an ability that was only previously reported for mammals and a few species of birds.

\section{Fish have emotional states}

Fish have been demonstrated to have emotional-like states. For example, an experiment on gilthead seabream, one of the most farmed fish species in EU aquaculture, integrated behavioral, endocrine and neurophysiological data to conclude that mental states corresponding to anxiety/fear, depression/sadness, excitement/happiness and calm/relaxation do occur in this species, similarly to higher vertebrates. ${ }^{89}$ These emotional states in fish are functional, providing correct appraisal, flexibility and response mechanisms that ultimately enhance their fitness. ${ }^{90}$ Furthermore, and despite the fact that research has been focused on the negative states, there is also evidence for the elicitation of positive mental states in fish, which opens the road for positive welfare standards and assessment strategies for these animals. ${ }^{91}$

In conclusion, all these observations described above clearly give strong evidence that fishes are cognitively developed sentient beings. Even though most of these examples show other species than those typically farmed, they impressively demonstrate the great capacity of fishes, e.g. to solve problems, communicate with each other and to express their intentions, and last but not least to experience pain as proven in the early experiments of Braithwaite and Sneddon. In fact, these experiments were examined with rainbow trout individuals who are one of the most commonly 'farmed' fish species in the EU. ${ }^{92}$ Despite the fact that

\footnotetext{
77 GRIFFITHS, S.W., Learned recognition of conspecifics by fishes. Fish and Fisheries 4/3 (2003) 256-268

78 TEBBICH, S., BSHARY, R., GRUTTER, A., Cleaner fish Labroides dimidiatus recognise familiar clients. Animal Cognition 5/3 (2002) 139-145.

${ }^{79}$ AIRES, R. F., OLIVEIRA, G. A., OLIVEIRA, T. F., ROS, A. F., OLIVEIRA, R. F., Dear enemies elicit lower androgen responses to territorial challenges than unfamiliar intruders in a cichlid fish. PloS one 10/9 (2015).

${ }^{80}$ BSHARY, R., Machiavellian intelligence in fishes. Fish cognition and behavior (2011) 277-297.

${ }^{81}$ BROWN, C., Familiarity with the test environment improves escape responses in the crimson spotted rainbowfish, Melanotaenia duboulayi. Animal Cognition 4/2 (2001) 109-113.

${ }^{82}$ TABORSKY, M., Sneakers, satellites, and helpers: parasitic and cooperative behavior in fish reproduction. Advances in the Study of Behavior 23/1 (1994) e100.

${ }^{83}$ BSHARY, R., HOHNER, A., AIT-EL-DJOUDI, K., FRICKE, H., Interspecific communicative and coordinated hunting between groupers and giant moray eels in the Red Sea. PLoS biology 4/12 (2006).

${ }^{84}$ BROWN, C. Fish intelligence, sentience and ethics. Anim. Cogn. 18 (2015) 1-17. https://doi.org/10.1007/s10071-014-0761-0

${ }^{85}$ CHANDROO, K.P., YUE, S., MOCCIA, R.D., An evaluation of current perspectives on consciousness and pain in fishes. Fish Fish 5 (2004) 281-295

${ }^{86}$ OLIVEIRA, R. F., MCGREGOR, P. K., LATRUFFE, C., Know thine enemy: fighting fish gather information from observing conspecific interactions. Proceedings of the Royal Society of London. Series B: Biological Sciences, 265/1401 (1998) 1045-1049.

${ }^{87}$ SARAIVA, J.L., KELlER-COSTA, T., HUBBARD, P.C., RATO, A., CANÁRIO, A.V., Chemical diplomacy in male tilapia: urinary signal increases sex hormone and decreases aggression. Scientific reports 7/1 (2017) 1-9.

${ }^{88}$ KOHDA, M., HOTTA, T., TAKEYAMA, T., AWATA, S., TANAKA, H., ASAI, J.Y., JORDAN, A.L., If a fish can pass the mark test, what are the implications for consciousness and self-awareness testing in animals?. PLoS biology, 17/2 (2019).

${ }^{89}$ CERQUEIRA, M., MILLOT, S., CASTANHEIRA, M.F. et al. Cognitive appraisal of environmental stimuli induces emotion-like states in fish. Sci Rep 7 (2017) 13181. https://doi.org/10.1038/s41598-017-13173-x

${ }^{90}$ BRAITHWAITE, V.A., HUNTINGFORD, F., VAN DEN BOS, R. Variation in Emotion and Cognition Among Fishes. J. Agric. Environ. Ethics 26 (2013) 7-23. https://doi.org/10.1007/s10806-011-9355-x

${ }^{91}$ FIFE-COOK, I., FRANKS, B., Positive Welfare for Fishes: Rationale and Areas for Future Study. Fishes 4/2 (2019) 31. MDPI AG. Retrieved from http://dx.doi.org/10.3390/fishes4020031

${ }^{92}$ According to estimations, $\sim 1000$ million of rainbow trout individuals are farmed only in the EU. (See: EU Commission (2017b) 
science is still lacking to fully explain every process involved in the emotional experience of fishes, "the precautionary principle dictates that we should give the benefit of the doubts to fish[es]" 93 . Therefore, it is about time to overcome "the erroneous view that fish[es] have little awareness or cognitive ability" 94 and to finally grant them the protection they deserve as 'sentient beings' - as such they are also recognised by the EU in article 13 TFEU since 2009.

But how does this recognition manifest in secondary EU legislation and its practical implementation? Looking at the 'farmed' fishes and their huge number of individuals involved in aquaculture production what legal protection status is granted to them in fact, and how are they respected in EU animal protection laws during their different 'production' stages? The following section VI will try to bring light into this, also with reference to the international OIE standards on fish welfare.

\section{Comparison of EU legislation versus OIE's Aquatic Animal Health Code concerning fish welfare 1. Rearing of 'farmed' fishes 1.1. Specific animal welfare concerns and scientific opinion}

Like land 'farm' animals, also fishes are bred, reared and fattened under a great variety of farming and 'production' systems all around the world, and so also in the European Union. Hereby, 'farmed' fishes are the most exploited and divers group among 'farm' animals, including numerous finfish species and countless fish individuals. For example, alone $\sim 1000$ million trout individuals and $\sim 40$ million individuals of Atlantic salmon are currently kept only in the EU. ${ }^{95}$

As described in section II of this manuscript, the type of farming is not only dependent on the fish species (marine vs. freshwater), age and life stage respectively, but also on whether they are farmed under intensive or extensive production in closed, re-circulated or open water systems. ${ }^{96}$ Following, it is plausible that for different fish species "[d]ifferent production systems require different measures to control the welfare risks (...)"97 in order to ensure a good welfare state for the fishes. This is very important to keep in mind since 'farmed' fishes are exposed to numerous jeopardies during the rearing process, whereas some of them will be illustrated in the following:

\section{Diseases in 'farmed' fishes}

One of the major and probably most 'popular' welfare problems in finfish aquaculture is the widespread and frequent emergence of (infectious) diseases, which have increased due to the intensification of fish husbandry systems - like it had happened for terrestrial animals in intensive farming. ${ }^{98}$ That is to say that reasons for disease outbreaks are manifold, but can often be related to poor environmental conditions and management as well as to increased stress in the fishes. ${ }^{99}$ There is a great diversity of infectious and non-infectious diseases which range from fungal, bacterial and viral diseases to parasitic ones, ${ }^{100}$ and can easily lead to "an increased level of mortality within a population"101. A famous example are sea lice outbreaks in 'sea-farmed' salmon. Those ectoparasitic copepods (called sea lice) can severely damage the surface tissue in the infected salmon which obviously results in very poor welfare and suffering for the individual fish. ${ }^{102}$ But also other species like trout or carp can be seriously

\footnotetext{
Animal Welfare in the European Union, cit., 49).

${ }^{93}$ BALCOMBE, J., Cognitive evidence of fish sentience. Animal Sentience 3/2 (2016a) 1.

${ }^{94}$ EFSA (2004b) Scientific Report of the Scientific Panel on Animal Health and Welfare on a request from the Commission related to the welfare of animals during transport. The EFSA Journal 44 (2004) 10.

${ }^{95}$ EU Commission (2017b) Animal Welfare in the European Union, cit., 49.

${ }^{96}$ For detailed information on the different farming systems in the EU: see section II of this manuscript.

97 EFSA (2008a) Scientific Opinion of the Panel on Animal Health and Welfare on a request from the European Commission on Animal welfare aspects of husbandry systems for farmed Atlantic salmon. The EFSA Journal 736, 31.

${ }^{98}$ EFSA (2008b) Scientific Opinion of the Panel on Animal Health and Welfare on a request from the European Commission on animal welfare aspects of husbandry systems for farmed fish: carp. The EFSA Journal 843, 15.

${ }^{99}$ E.g. BERGQVIST, J., GUNNARSSON, S. (2013) Finfish Aquaculture, cit. 79.

${ }^{100}$ E.g. see: EFSA (2008a), cit., 21-23; EFSA (2008b), cit., Annex I, 43- 9; EFSA (2008c) Scientific Opinion of the Panel on Animal Health and Welfare on a request from the European Commission on animal welfare aspects of husbandry systems for farmed European seabass and Gilthead seabream. The EFSA Journal 844, 14-16; Chapter 1.3. article 1.3.1. of OIE Aquatic Animal Health Code for diseases listed for fishes by OIE.

${ }^{101}$ WALL, T., Disease and Medicines - the Welfare Implications. In BRANSON, E.J. (Ed.) Fish Welfare (Oxford 2008$) 195$.

102 EFSA (2008a), cit., 22; N.B.: Not least due to increased drug resistance issues, new methods have been developed to combat parasites in 'farmed' fishes, e.g. by using cleaner fishes like lumpfish and wrasses. However, these fishes also have specific animal welfare needs, which are apparently not met to a satisfying extent according to reports of high mortality. Followingly, these cleaner fishes used in aquaculture also must be protected to a sufficient level by EU legislation. There are no figures available on EU level regarding the numbers of cleaner fish individuals used but, for example, for Norway as main salmon producer in Europe $\sim 32$ million cleaner fishes were put in sea cages, in 2016 alone. See: $3^{\text {rd }}$ EU Platform Meeting on 21 June 2018, Presentation by Bente Bergersen,
} 
impaired in their welfare due to numerous diseases whereby "those diseases with chronic, often sub clinical effects are often of the greatest welfare significance" 103 - simply due to the prolonged and undetected course of disease. Despite the "significant welfare hazards" 104 due to the disease itself, another risk factor for poor fish welfare arises in this context, namely the "serious lack of available veterinary medicines licensed for use in farmed fish [es]" 105 . I.e. adequate treatment of the sick fishes is often limited, which in turn increases poor welfare effects for them. ${ }^{106}$

\section{Environmental conditions (abiotic)}

Fishes are in close physiological contact with their surrounding environment - especially through their gills and skin. ${ }^{107}$ Thus, water quality including e.g. oxygen content, temperature and other abiotic factors, play a vital role not only to fulfil the physiological needs of the fishes, but also to contribute to their wellbeing. As stated by EFSA, "water quality is essential for good welfare in fish [es] and several damaging effects of poor water quality on fish health were recognised" 108 . However, the optimal environmental conditions vary significantly between the different species. For example, high levels of dissolved oxygen are essential for the welfare (and survival) of trout ${ }^{109}$, as well as for Atlantic salmon $^{110}$, whereas carps can handle much better with low oxygen levels ${ }^{111}$ - all the more surprising that in carps "low oxygen is the most important cause of mortality (...) in every life stage" 112.

Even though oxygen is one of the most critical factors, there are many more influencing the welfare of fishes, like the concentration of ammonia, carbon dioxide, nitrite or heavy metals in the water which can turn toxic for them. ${ }^{113}$ For example, "sub-lethal concentrations of ammonia can damage the gills and also impair immune function leading to increased susceptibility to infectious disease" 114 . Also, the development of larvae and young fishes can be negatively affected, thus causing development disorders, deformities and even death. ${ }^{115}$ In this context, water temperature plays another important role as well as the light period and intensity to which the young fishes are exposed to. ${ }^{116}$ Furthermore, water flow and exchange rates respectively, as well as stocking densities affect the water quality and hence the welfare of the fishes. ${ }^{117}$ Environmental factors such as noise and vibrations in the water have also been reported for some fish species to affect them negatively. ${ }^{118}$

\section{Stocking density}

The stocking density has a crucial influence on the welfare of 'farmed' fishes. But due to the great variety of fishes 'used' in different aquaculture systems, it depends very much on their species-specific needs. ${ }^{119}$ For instance, some fish species living naturally in big social groups and shoals may prefer to live with more companions whereas "solitary living fish[es] may be stressed by, and turn aggressive in

\footnotetext{
Norwegian Food Safety Authority, https://webcast.ec.europa.eu/3rd-meeting-of-the-platform-on-animal-welfare, 22.06 .2018 (from 04:28:00).

${ }^{103}$ EFSA (2008b), cit. 14.

${ }^{104}$ Ibid. 15 .

${ }^{105}$ EFSA (2009h) Statement of EFSA prepared by the AHAW Panel on: knowledge gaps and research needs for the welfare of farmed fish. The EFSA Journal 1145, 4.; N.B.: "Over the last years there has been a significant reduction in the numbers of medicines available for use in aquaculture. (...) The reasons for the low numbers of medicines available are many and complicated. The cost of maintaining a licence, consumer safety issues and environmental considerations are some of the entirely valid reasons for loss of fish medicines." (see WALL, T., Disease and Medicines - the Welfare Implications, cit., 196-197).

${ }^{106}$ It should be mentioned that vaccination for preventing diseases has increased over the years, thus reducing to some extent the infectious disease outbreaks in concerned farms. Reviewed by BERGQVIST, J., GUNNARSSON, S., Finfish Aquaculture, cit., 79.

${ }^{107}$ EFSA (2008c), cit., 14.

${ }^{108}$ EFSA (2008a), cit. 10.

${ }^{109}$ EFSA (2008d) Scientific Opinion of the Panel on Animal Health and Animal Welfare on a request from the European Commission on the Animal welfare aspects of husbandry systems for farmed trout. The EFSA Journal 796, 11.

${ }^{110}$ EFSA (2008a), cit., 12.

${ }^{111}$ EFSA (2008b), Scientific Opinion of the Panel on Animal Health and Welfare on a request from the European Commission on animal welfare aspects of husbandry systems for farmed fish: carp, cit. 11.

${ }^{112}$ Ibid. 21.

${ }^{113}$ EFSA (2008a), cit., 14.

114 Ibid. 13.

115 Ibid. 10

${ }^{116}$ BRANSON, E.J., TURNBULL, T., Welfare and Deformities in Fish. In BRANSON, E.J. (Ed.) Fish Welfare (Oxford 2008) 202216.

${ }^{117}$ EFSA (2008d), Scientific Opinion of the Panel on Animal Health and Animal Welfare on a request from the European Commission on the Animal welfare aspects of husbandry systems for farmed trout., cit., Annex I, 39.

118 E.g. EFSA (2008b), cit., 11; EFSA (2008e) Scientific Opinion of the Panel on Animal Health and Welfare on a request from the European Commission on Animal Welfare Aspects of Husbandry Systems for Farmed European Eel. The EFSA Journal $809,8$.

${ }^{119}$ BERGQVIST, J., GUNNARSSON, S., Finfish Aquaculture, cit., 80. 
high densities (...)" ${ }^{120}$. Additionally, the available space and environmental conditions such as the carrying capacity of the water must also be taken into account when assessing the optimal stocking density. ${ }^{121}$ Like for terrestrial 'farm' animals, intra-specific aggression has been reported for 'farmed' fishes as well, which "(...) can cause poor welfare, causing for example fin damage and reduced access to food" 122 . Especially for salmon and trout, it has been reported that fin-chewing "is principally the result of high stocking density" ${ }^{23}$. Fins are not only essential for locomotion, but also fin damage can lead to "secondary bacterial infections [that occasionally] become so bad that whole cohorts of fish [es] need to be sacrificed" 124 . Apart from that, chewed fins cause pain for the respective fish since fins are sensitive tissue. ${ }^{125}$

\section{Fish feed}

A sufficient supply of adequate feed is one important pillar not only to reach optimal growth rates, but first and foremost to ensure the welfare of 'farmed' fishes ${ }^{126}$ - and this already from the very beginning as "inadequate feed formulation and quality problems can induce larval deformities and impaired growth" 127 , thus obviously causing poor welfare. As reported for seabream, for example, there are difficulties in finding suitable feed - accordingly, EFSA assessed "inadequate feed formulation [as] a highly scored hazard for a number of life stages and across production systems" ${ }^{128}$. Furthermore, adequate feeding methods are important in order to ensure that all individuals can get sufficient amount of food and to reduce aggressive behaviour between the individuals. But it must also be avoided to overfeed the fishes as it could again result in poor welfare since food left-overs could determine the water quality, and negative health impacts could occur in the fishes "due to lipid overload in organs such as liver" "29. Beside these "technical' aspects, it is essential for the welfare of fishes to take account of their species-specific feeding behaviour which will be further discussed under the aspect of 'behavioural needs', below in this section.

\section{Breeding and genetic selection}

Breeding fishes is a highly complex field which contains many risk factors and easily results in poor fish welfare. For example, a common problem already occurs at the stage of fish egg incubation due to inappropriate incubation temperature - with the result of deformities and other physiological abnormalities in the larval fishes. ${ }^{130}$ If breeding programmes are not properly structured, also inbreeding can occur which again increases the risk of development disorders and deformities in young fishes. ${ }^{131}$ However, as in any other 'farm' animal sector, also in aquaculture the fishes are selectively bred mainly with the focus on "(...) rapid growth, late sexual maturation, improved harvest quality and resistance to diseases" 132 . In order to reduce intra-specific aggression and to avoid cross-breeding between 'farmed' and wild fish populations, there are attempts towards "all-female populations" 133 - i.e. only female fishes should be reared for meat production - for example, by using 'triploid fishes' who are functionally sterile. ${ }^{134}$ But as reported for triploid salmon, they "(...) are more prone to develop

\footnotetext{
120 Ibid.

${ }^{121}$ Ibid.

122 EFSA (2008d), cit., 3.

${ }^{123}$ EU Commission (2017b) Animal Welfare in the European Union, cit., 50.

${ }^{124}$ BRAITHWAITE, V., Do fish feel pain? cit., 160.

${ }^{125}$ EU Commission (2017b) Animal Welfare in the European Union, cit., 50.

${ }^{126}$ In this context it is noteworthy that many 'farmed' fishes, especially of marine species, are carnivorous fishes who naturally prey for other fishes. I.e. in aquaculture, carnivorous fishes (like salmon, tuna, seabream and seabass) are fed on wild-captured fishes (as fish meal or oil). Not only has this feeding practice a negative ecological impact on wild and overfished fish populations, but it also implies a huge animal welfare problem for those wild fishes captured and killed on sea. E.g. see: BERGQVIST, J., GUNNARSSON, S., Finfish Aquaculture, cit., 90-91.

${ }^{127}$ EFSA (2008c), cit., 12.

${ }^{128}$ Ibid. 21.

${ }^{129}$ EFSA (2008d), cit., 14.

${ }^{130}$ E.g. skeletal deformities like gill cover defects or mouth/jaw deformities, swim bladder abnormalities, heart abnormalities, spinal deformities. See: BRANSON, E.J., TURNBULL, T., Welfare and Deformities in Fish, cit., 202-216; NOBLE, C., CANON JONES, H.A., DAMSGARD, B., FLOOD, M.J., MIDLING, K., ROQUE, A., SAETHER, B., YUE, S. (2012) Injuries and deformities in fish: their potential impacts upon aquacultural production and welfare. In VAN DE VIS, H., KIESSLING, A., FLIK, G., MACKENZIE, S. (Eds.) Welfare of Farmed Fish in Present and Future Production Systems. Springer Science+Business Media (Dordrecht. 1st ed. 2012) 67-89.

${ }^{131}$ E.g. EFSA (2008a), cit., Annex I, 21; EFSA (2008d), cit., 4; BERGQVIST, J., GUNNARSSON, S., Finfish Aquaculture, cit., 78.

132 EFSA (2008a), cit., 21.

133 Ibid. Annex I, 56.

${ }^{134}$ Triploids are fishes who contain three chromosome sets (two maternal and one paternal) instead of the normal two (diploid) chromosome set. See: EFSA (2008a), cit., Annex I p. 56.
} 
production disorders such as lenticular cataracts and spinal deformities, and are more sensitive to extreme environments compared with normal diploid salmon"135.

In some 'farmed' fish species, 'successful' breeding is still not possible in captivity and on a commercial basis, like it is the case for tuna and eels. ${ }^{136}$ I.e. originally free-living tunas and eels are captured from the wild in order to further fatten and slaughter them in EU aquaculture farms. Little is known about the welfare impact, but likely it turns out negative as these undomesticated, wild fishes "may not be adapted to farming conditions" 137 - not to mention the impact on wild fish populations when regularly baby and juvenile fishes are taken off the wild without giving the possibility to reproduce. ${ }^{138}$

\section{Handling practices}

In fish farming, there are many handling practices and procedures inflicted on the fishes on a routine basis that "can lead to injury, stress and increased disease incidence (...)" ${ }^{139}$. Among others, 'farmed' fishes are handled for sorting and size grading between their different life stages. I.e. in certain intervals they are separated according to their size, sex or stage of maturity into different groups. ${ }^{140}$ Grading is considered important in husbandry management, especially during the juvenile life stages "as it prevents the development of aggression and cannibalism (...)" 141 - but it also imposes extreme stress and risk of injury (of skin, scales or other tissue) onto the fishes as they are captured, handled and removed from water. ${ }^{142}$ Therefore, "[g]rading systems should be set up to minimise the time fish[es] are out of the tanks or cages, to ensure sufficient water quality is maintained and to minimise stress" 143 . Further handling involves vaccination programmes, on-farm transportation and transfer of the fishes into different tanks or cages. ${ }^{144}$

In the case of 'broodstock' fishes, they are additionally handled for stripping of eggs and sperm which is often performed manually. ${ }^{145}$ I.e. by pressing manually onto their abdomen, the 'broodstock' fishes release their eggs and sperm respectively. Obviously, this artificial 'spawning' outside the water causes extreme handling stress and risk to physical damage for the fishes. ${ }^{146}$ Therefore, EFSA states that "broodstock should be handled with the greatest care under anaesthesia in order to minimise physical damage and stress" 147 and recommends, for example for salmon males, "single stripping followed by slaughter" 148 due to the severe intervention in the fishes' integrity.

\section{Behavioural needs}

Probably fish behaviour and the behavioural needs that each individual fish has are still least studied and understood in fish farming - but nevertheless, "behaviour (...) is a key element of fish welfare" 149 . To the present day, research has been mainly focusing on how to avoid negative conditions and poor welfare, but the question about good welfare and what a fish indeed needs to flourish in his or her environment is still to be answered. ${ }^{150}$

Like terrestrial 'farm' animals, fishes show a great variety of behaviour which can easily be impaired by the respective husbandry system. ${ }^{151}$ And like terrestrial 'farm' animals, 'farmed' fishes also show abnormal behaviour and stereotypies, which are linked to poor welfare since clearly "(...) the development of stereotypes arises as a response to frustration, discomfort or a conflict of

\footnotetext{
${ }^{135}$ Ibid.; Lenticular cataracts are eye damages causing opaqueness or clouding of the eye lens. Eye damages can have detrimental effects on fish welfare due to reduced visibility, and thus increased behavioural and physiological stress (see: NOBLE, et al., Injuries and deformities in fish, cit. 72-73).

${ }^{136}$ EFSA (2009h), cit. 7.

${ }^{137}$ Ibid.

${ }^{138}$ E.g.: EFSA (2008e), cit., 7.

$\left.{ }^{139}\right)$ EFSA (2008a), cit., 19.

140 Ibid.

${ }^{141}$ EFSA (2008c), cit., 13.

142 EFSA (2008a), cit., 20.

${ }^{143}$ Ibid. 3.

${ }^{144}$ For welfare aspects during transportation, see section VI. 2 of this manuscript.

145 EFSA (2008c), cit., Annex I p. 46.

146 EFSA (2008b), cit., 41, 80.

${ }^{147}$ EFSA (2008a), cit., 19.

148 Ibid.

${ }^{149}$ MARTINS, C.I.M., GALHARDO, L., NOBLE, C., DAMSGARD, B., SPEDICATO, M.T., ZUPA, W., BEAUCHAUD, M., KULCZYKOWSKA, E., MASSABUAU, J.-C., CARTER, T., PLANELLAS, S.R., KRISTIANSEN, T., Behavioural indicators of welfare in farmed fish. In: VAN DE VIS, H., KIESSLING, A., FLIK, G. \& MACKENZIE, S. (Eds.) Welfare of Farmed Fish in Present and Future Production Systems. Springer Science+Business Media (Dordrecht. 1st ed. 2012) 21.

${ }^{150}$ See also section $\mathrm{V}$.

${ }^{151}$ MARTINS et al., Behavioural indicators of welfare in farmed fish, cit., 24. 
motivation"152. For example, some fish species conduct abnormal and stereotypic swimming as identified, inter alia, for Atlantic salmon who formed atypical circular shoaling in cages, or Atlantic halibut who showed stereotypic loops in vertical swimming at high stocking densities and due to inappropriate feeding. Halibut are flatfishes who feed normally at the bottom, but if they are only provided with floating food pellets under farming conditions they are hindered to express their normal foraging behaviour and thus can become chronically stressed which in turn reflects in stereotypic swimming. ${ }^{153}$

Since "intensively farmed fish [es] are kept under highly standardised conditions, which often mean a complete lack of enrichment" 154 , their freedom to express exploratory behaviour is obviously restricted if not completely impossible. For example, 'farmed' cod have been observed to bite and chew on the cage nets when they are confined without any enrichment material. ${ }^{155}$ Since "cod naturally spend much of their time close to the seafloor manipulating kelp and other things with their mouths"156, this "net manipulation behaviour' likely results from their unsatisfied motivation to explore a rich surrounding. Due to the lack of environmental enrichment, 'farmed' fishes are also compromised in expressing other behavioural needs, such as nest-building or normal spawning behaviour. In this context, it is reported for 'farmed' fish males of Mozambique tilapia that they build vacuum spawning nests when kept without proper substrate in order to fulfil their natural behaviour. ${ }^{157}$

Social behaviour as well as intra- and interspecific interaction between the fishes is dependent on the farming systems, and often the composition of fish individuals within a group is changed due to management practices such as size grading or sorting. This can increase the social stress within the new groups as hierarchies need to be fought out accordingly. Especially in farming conditions where other factors like space, feeding or water quality are not fulfilling the fishes' need, aggressive behaviour like fin biting among the individuals can become a serious welfare problem. ${ }^{158}$

Due to confinement, 'farmed' fishes are forced to adapt their swimming behaviour, inter alia, to the design and size of the cage and the stocking density. ${ }^{159}$ Hence, under current farming systems they are often not able to express their normal swimming behaviour - despite the fact that it plays an essential part for fishes as "it is intimately linked to their ability to develop, survive, grow and reproduce successfully" 160 . Accordingly, it should be thoroughly considered in husbandry systems in order to guarantee that the fishes can fulfil their behavioural needs. In this light, also the question should be raised how migratory species like salmon, eels or tuna who naturally undergo long journeys throughout their life cycle are affected in their welfare and mental state when being confined. There has not been a clear answer yet, ${ }^{161}$ but nevertheless wild tuna or eels are captured for further fattening in farms up to the present day.

\section{Conclusion}

Correct management of fish farms is more than challenging since multiple factors affect different fish individuals and species in different ways. Additionally, due to the sheer number of fishes reared it is practically impossible to recognise and check on every individual to ensure his or her individual wellbeing. Many of the routinely conducted farming practices contain a high risk of imposing stress, injuries and suffering on the single fishes. Therefore, it is essential to have only experienced and highly trained personnel being responsible for the fishes and their welfare.

\subsection{OIE recommendations concerning the protection of 'farmed' fishes during rearing}

The OIE Aquatic Animal Health Code does not give any recommendations on the protection of 'farmed' fishes during their rearing.

Chapter 7 on the welfare of 'farmed' fishes only contains detailed advice regarding transport, stunning, and killing of fishes for human consumption and for disease control purposes. However, in its

\footnotetext{
152 Ibid. 32.

153 Ibid.

${ }^{154}$ Ibid. 36.

${ }^{155}$ BRAITHWAITE, V., Do fish feel pain? 158.

${ }^{156}$ Ibid.

${ }^{157}$ MARTINS et al., Behavioural indicators of welfare in farmed fish, cit., 36.

158 Ibid. $27-28,36$.

${ }^{159}$ EFSA (2008a), cit., 9.

${ }^{160}$ PALSTRA, A.P., PLANAS, J.V., TAKLE, H., THORARENSEN, H., The Implementation of Swimming Exercise in Aquaculture to Optimise Production. Aquaculture Europe 40/1 (2015) 20.

${ }^{161}$ HUNTINGFORD, F.A., KADRI, S., Welfare and Fish. In: BRANSON, E.J. (Ed.) Fish Welfare (Oxford 2008) 20.
} 
introductory section 7.1. it is stated, inter alia, that "[t]he basic requirements for the welfare of farmed fish [es] include handling methods appropriate to the biological characteristics of the fish[es] and a suitable environment to fulfil their needs". ${ }^{162}$

\subsection{EU legislation on the protection of 'farmed' fish during rearing \\ 1.3.1 Council Directive 98/58/EC of 20 July 1998 concerning the protection of animals kept for farming purposes}

Council Directive 98/58/EC concerning the protection of animals kept for farming purposes ${ }^{163}$ lays down the rules on the welfare conditions for 'farm' animals in the European Union. Those rules represent the minimum standards under which 'farm' animals are allowed to be bred and kept at farms, as clearly stated by article 1 of the Directive. By the definition in article 2 'farmed' fishes are to be included in the Directive. However, only article 3 must be applied to them, in which EU Member States are obliged "to ensure that the owners or keepers take all reasonable steps to ensure the welfare of animals under their care and to ensure that those animals are not caused any unnecessary pain, suffering or injury". ${ }^{164}$

Explicitly, the fishes are excluded from article 4 and the annex in which further requirements are laid down on the farming conditions for animals.

Regarding compliance with Directive 98/58/EC, article 6 requires that official controls are conducted by the competent authorities in each Member State. Additionally, "whenever uniform application of the requirements of this Directive renders it necessary (...)", ${ }^{165}$ the EU Commission can take additional steps in order to "verify that the Member States are complying with the said requirements" 166 and to "make on-thespot checks to ensure that the checks are carried out in accordance with this Directive" 167 As provided by article 10, the Members States had to implement Directive 98/58/EC into national legislation at latest by 31 December 1999.

\subsubsection{European Convention for the protection of animals kept for farming purposes}

The European Convention for the protection of animals kept for farming purposes ${ }^{168}$ was adopted by the Council of Europe in 1976. It does not specify the animal species to which this convention shall apply, but only refers, among others, to "animals bred or kept for the production of food (...)", ${ }^{169}$ and thus also to 'farmed' fishes.

With the Farming Convention, the Council of Europe laid down general principles of animal welfare, ${ }^{170}$ which shall be implemented by each contracting party according to article 2 . Chapter II contains details on the implementation provisions of the Farming Convention.

\subsubsection{Council of Europe Recommendation concerning 'farmed' fishes}

The Council of Europe Recommendation concerning 'farmed' fishes ${ }^{171}$ contains various provisions on ownership and staff responsibilities, farming facilities, equipment, and management, but also on modification of genotypes and mutilation in fishes, emergency killing, and research.

\section{General provisions:}

As a general and guiding principle, article 2 of the COE Recommendation states that the biological characteristics and different species-specific needs of the fishes should be taken into account in husbandry practices, especially "with respect to the requirements for water conditions, social behaviour and environmental structures". ${ }^{172}$ In order to avoid "detrimental effects on their welfare, including health, [not only are to take] into account their biological characteristics [but also] the scientific

\footnotetext{
${ }^{162}$ Chapter 7.1 article 7.1.2. point 1 of the OIE Aquatic Animal Health Code.

${ }^{163}$ Hereinafter Directive 98/58/EC.

${ }^{164}$ Article 3 of Council Directive 98/58/EC.

${ }^{165}$ Article 7 point 1 of Council Directive 98/58/EC.

${ }^{166}$ Article 7 point 1 letter a of Council Directive 98/58/EC.

${ }^{167}$ Article 7 point 1 letter b of Council Directive 98/58/EC.

${ }^{168}$ Hereinafter the Farming Convention.

${ }^{169}$ Article 1 of the Farming Convention.

${ }^{170}$ See chapter I article 3-7 of the Farming Convention.

${ }^{171}$ Hereinafter as COE Recommendation.

${ }^{172}$ Article 2 of the COE Recommendation.

80 Derecho Animal. Forum of Animal Law Studies, vol. 11/1
} 
evidence and the practical experience available, and the farming system used". ${ }^{173}$

Ownership and staff responsibilities:

Regarding responsibilities, the owner and the person in charge have to take "every reasonable step (...) to safeguard the welfare, including health of such fish[es]". ${ }^{174}$ To achieve this, not only is a comprehensive training period considered essential for the responsible staff, but also continued training. ${ }^{175}$ In this context, a certificate of competence is suggested "at least for the stockman", ${ }^{176}$ i.e. for the person in charge of the fishes.

Furthermore, it is required that the owner employs enough trained and experienced staff who are also competent on the respective husbandry system ${ }^{177}$ as well as on handling practices. ${ }^{178}$ The personnel must be able to recognise the health state of the fishes and their behaviour as well as "appreciate the suitability of the total environment for the fishes' welfare, including health". ${ }^{179}$

Additionally, article 3 states that "the number of fish [es] and farm units (...) shall be such that, under normal circumstances, the stockman is able to ensure that the animals are properly looked after to safeguard their welfare, including health". ${ }^{180}$

Article 4 prohibits the use of fishes in public spectacle or demonstrations that are likely to negatively impact their welfare and health.

As required by article 5, the fishes should be checked a minimum of once per day, with "focus [of inspections] on factors affecting adversely the welfare of the fish [es], and signs of abnormal behaviour, injury, poor health or increased mortality". ${ }^{181}$ In cases of suspicion immediate action is required, and where necessary a veterinarian should be consulted. ${ }^{182}$ Also, "any dead or dying fish shall be removed as soon as possible in a way that does not adversely affect the welfare of those remaining". ${ }^{183}$

In order to avoid poor welfare, checks on the water quality must be conducted according to the speciesspecific needs, whereas the parameters for water quality are referred to water turbidity, oxygen and salinity content, temperature, and $\mathrm{pH}$ of the water. ${ }^{184}$

\section{Farming facilities and equipment:}

Regarding the farming facilities and equipment, article 6 requires that fish welfare, among others, should be taken into account when planning or modifying farms. In this context, new husbandry systems or designs "should be comprehensively and objectively tested from the point of view of fish welfare" 185 and only introduced onto the market when approved satisfactory in this respect. Effective alarm systems should be in place, especially when the welfare of the fishes depends on automatic farming systems. ${ }^{186}$ Regarding the selection and construction of the farming site, a sufficient flow-through of clean water is required in connection with the species-specific needs and the husbandry system in use, ${ }^{187}$ and in case of sea-cage farming it is "to avoid excessive damage to fish [es] under adverse sea conditions". ${ }^{188}$

Regarding the design, construction and maintenance of farming facilities and equipment, article 8 point 1 stipulates that it must be conducted in a way to:

- allow the fishes to fulfil their biological needs and ensure good welfare and health;

- facilitate the management of fishes;

- reduce the risk of injuries and stress of the fishes;

- avoid sharp corners, protrusions or any material possibly causing harm to the fishes;

- allow thorough checks on the fishes (acc. article 5.1);

- withstand the weather and environmental conditions;

\footnotetext{
173 Ibid.

${ }^{174}$ Article 3 point 1 of the COE Recommendation.

175 Article 3 point 2 of the COE Recommendation.

${ }^{176}$ Article 3 point 3 of the COE Recommendation.

${ }^{177}$ Article 3 point 4 of the COE Recommendation.

${ }^{178}$ Article 3 point 5 of the COE Recommendation.

${ }^{179}$ Article 3 point 4 letter $\mathrm{c}$ of the COE Recommendation.

${ }^{180}$ Article 3 point 6 of the COE Recommendation.

${ }^{181}$ Article 5 point 2 of the COE Recommendation.

${ }^{182}$ Article 5 point 3 of the COE Recommendation.

${ }^{183}$ Article 5 point 4 of the COE Recommendation.

${ }^{184}$ Article 5 point 5 of the COE Recommendation.

${ }^{185}$ Article 6 point 2 of the COE Recommendation.

${ }^{186}$ Article 7 point 1 of the COE Recommendation.

${ }^{187}$ Article 7 point 2 of the COE Recommendation.

${ }^{188}$ Article 7 point 3 of the COE Recommendation.
} 
- minimise the risk of escaping 'farmed' fishes;

- allow cleaning and disinfection in order to prevent or treat diseases if necessary;

- maintain good hygienic conditions as well as good water quality (incl. waste removal).

According to article 8 point 4 , the design, construction, placement and maintenance of feeding equipment must be conducted in a way to:

- keep the water contamination as low as possible;

- ensure that all fishes reach sufficient amount of food without undue competition between individuals;

- operate also under extreme weather conditions;

- allow monitoring of the amount of feed given to the fishes.

Furthermore, article 8 requires that "equipment used for size grading, netting and the mechanical transfer on-farm of fish[es] should be designed so that fish[es] are not injured during their operation". 189

\section{Management:}

In the following some examples are given on management practices that are required by the COE Recommendation. For instance, article 9 states that stress, aggression and cannibalism should be minimised due to management measures. In the case of size grading, "a minimum of handling and (...) stress ${ }^{\prime 190}$ is required.

Regarding the management of stocking density, several criteria must be fulfilled: ${ }^{191}$

- density of fishes according to their biological needs and environmental conditions (local farming conditions);

- density of fishes according to the husbandry system used, particularly with focus on water quality and feeding technology;

- density of fishes according to the animal welfare indicators like behaviour, stress level, injuries, appetite, growth, mortality and disease.

Among others, it is forbidden to routinely treat the fishes with medicine “(...) as part of a management system to compensate for poor hygienic conditions, poor management practices, or to mask signs of poor welfare such as pain and distress (...)". 192

Beside provisions given on feeding management, ${ }^{193}$ explanations and requirements regarding water quality and other physical parameters are also laid down in the COE Recommendation. ${ }^{194}$ Hereby, article 12 states that "[w] ater quality parameters shall at all times be within the acceptable range that sustains normal activity and physiology for a given species [and] take into account the fact that the requirements of individual species may vary between different life-stages e.g. larvae, juveniles, adults or according to physiological status e.g. metamorphosis or spawning". ${ }^{195}$ It is worth nothing the reference to appendices providing speciesspecific water quality parameters. ${ }^{196}$

With respect to oxygen concentration, article 12 also requires an adequate level according to the species, farming conditions and practices. ${ }^{197}$ In order to avoid toxic accumulation of ammonia and nitrite in the water, different measures are recommended, like "increasing flow rate, reducing feeding, biofiltration, reducing density or temperature". ${ }^{198}$ Regarding the harmful accumulation of carbon dioxide, there is a requirement to avoid it by for example "using aeration systems or by chemical means, according to the farming system used". ${ }^{199}$ Furthermore, "[w] here possible, $p H$ shall be kept stable, as all changes in $p H$ initiate complex water

\footnotetext{
${ }^{189}$ Article 8 point 5 of the COE Recommendation.

190 Article 9 point 1 of the COE Recommendation.

191 Article 9 point 2 of the COE Recommendation.

192 Article 9 point 5 of the COE Recommendation.

193 Article 11 of the COE Recommendation.

194 Article 12 of the COE Recommendation.

195 Article 12 point 1 of the COE Recommendation.

196 Ibid. Despite the reference to the appendices in the COE Recommendation, up to the present day the Standing Committee has not published any appendices in this context.

197 Article 12 point 3 of the COE Recommendation.

198 Article 12 point 4 of the COE Recommendation.

199 Article 12 point 5 of the COE Recommendation.

82 Derecho Animal. Forum of Animal Law Studies, vol. 11/1
} 
quality changes which may cause harm to the fish [es]", ${ }^{200}$

Article 13 lays down some rules regarding the breeding of fishes. Inter alia, only trained and competent personnel are allowed to undertake the stripping process. ${ }^{201}$ In this context, the COE Standing Committee stipulates that anaesthesia or sedation is used where necessary prior to stripping, ${ }^{202}$ but " [t] he number of times a fish is handled and exposed to sedation shall be minimised to limit injury and stress". ${ }^{203}$ Furthermore, article 17 prohibits conducting breeding practices (natural or artificial) that induce or could induce suffering or injury to the fishes concerned, ${ }^{204}$ but on the contrary encourages " $[t]$ he conservation or development of breeds or strains of fish [es], [who] would limit or reduce animal welfare problems (...)". 205

Article 14 sets up provisions for the handling of fishes, which should only be conducted when necessary - and then as short as possible and with the least stress for the handled fish, and also for the other fishes around. ${ }^{206}$ Beside the provision on appropriate handling equipment, it is furthermore stipulated that " $[t]$ he most preferable way is to handle fish [es] without taking them out of the water (e.g. size grading by machines carrying water along the run)". ${ }^{207}$ Where not possible, the COE Recommendation requires that handling outside the water must "be done in the shortest time possible and all equipment in direct contact with fish[es] should be moistened". 208

In any case, the COE Recommendation forbids lifting the fish at individual body parts such as the gill covers ${ }^{209}$ mutilating a fish, ${ }^{210}$ or putting live fishes in ice when it is done as an on-farm handling practice. ${ }^{211}$

According to article 17.1, "no animal shall be kept for farming purposes unless it can reasonably be expected, on the basis of its phenotype or genotype, that it can be kept without detrimental effects on its health or welfare". ${ }^{212}$

Further requirements are laid down in article 19 on emergency killing and in article 20 on research which should be promoted by the contracting parties of the COE Recommendation.

Supplementary provision article 2 requires, among others, that the COE Recommendation "(...) shall be completed with species-specific Appendices, as soon as adequate scientific knowledge or practical experience, in particular on the requirements for water quality, stocking density, feeding, social behaviour and environmental structures is available". ${ }^{213}$

\subsection{Critical assessment and possible recommendations for better protection of 'farmed' fishes during rearing}

On the international level, 'farmed' fishes are lacking any serious protection or consideration during husbandry and on-farm practices. That is to say that the OIE Aquatic Animal Health Code only mentions in its introductory chapter the need to take account of the biological and environmental needs of the fishes during handling but fails to give further guidance. However, within the European Union, they are protected during breeding and rearing by secondary EU legislation, namely by Council Directive 98/58/EC. According to its article 2 fishes "bred and kept for the production of food" 214 are included by definition, though they are only considered on a very basic level in article 3 , stating that:

"Member States shall make provision to ensure that the owners or keepers take all reasonable steps to ensure the welfare of animals under their care and to ensure that those animals are not caused any unnecessary pain, suffering or injury."

Article 3 can only be understood as a guiding principle since specific provisions on the protection of fishes during husbandry are lacking. However, article 3 clearly states that 'all reasonable steps' must be taken in order to safeguard the welfare of the 'farm' animals, including fishes, and to spare them from 'any

\footnotetext{
200 Article 12 point 6 of the COE Recommendation

201 Article 13 point 1 of the COE Recommendation.

202 Article 13 point 3 of the COE Recommendation.

203 Article 13 point 2 of the COE Recommendation.

${ }^{204}$ Article 17 point 1 of the COE Recommendation.

205 Article 17 point 2 of the COE Recommendation.

206 Article 14 point 1 of the COE Recommendation.

207 Article 14 point 2 of the COE Recommendation.

208 Ibid.

209 Ibid.

${ }^{210}$ Article 18 point 2 of the COE Recommendation.

211 Article 14 point 6 of the COE Recommendation.

212 Article 17 point 1 of the COE Recommendation.

213 Article 21 of the COE Recommendation.

${ }^{214}$ Article 2 point 1 of Council Directive 98/58/EC.
} 
unnecessary pain, suffering or injury'. These provisions are not only requested from the owners and keepers, but first and foremost each EU Member State is obliged to ensure the implementation of these provisions. Article 3 is directly addressed to the Member States, thus reflecting the legislative principle of a Directive. Nevertheless, following the wording of article 3 the principal objectives, namely 'to take all reasonable steps' to ensure the welfare of the animals and to avoid 'any unnecessary pain, suffering or injury', leave room for interpretation and can be read in several ways, depending on the consideration and willingness of those enacting, implementing, and enforcing the national laws.

EFSA clearly recommends that "[m]easures to improve welfare should be adapted to different production systems and should take into consideration the specific requirements of each life stage", 215 as well as during handling, "(...) efforts should be made to maintain the fish[es] in water of sufficient oxygen content, either by removing the fish[es] as quickly as possible or by introducing fresh, oxygen-rich water into the catchpit". ${ }^{216}$ Also, some detailed recommendations are included in the Scientific Opinions of EFSA, especially concerning carp husbandry. For example, EFSA clearly defined, among others, optimal oxygen levels for carp larvae and gave specific advice on the incubation of carp eggs. ${ }^{217}$ However, up to the present day EFSA's scientific opinions have not been considered in EU legislation - neither by including the fishes in article 4 , nor by expanding the annex of Directive 98/58/EC, nor by producing species-specific provisions despite the fact that these scientific opinions are aimed to "serve as the scientific basis for drafting and adoption of Community measures (...)". ${ }^{218}$ Furthermore, ignoring EFSA's recommendations clearly contradicts with the preamble of the Farming Directive, stating that:

“(...) those principles include the provision of housing, food, water and care appropriate to the physiological and ethological needs of the animals, in accordance with established experience and scientific knowledge." 219

Due to the lack of thorough consideration of the 'farmed' fishes in secondary EU legislation, the COE Recommendation concerning 'farmed' fishes becomes all the more important for the interpretation of article 3 of Directive 98/58/EC. On 5 December 2005 the Standing Committee of the European Convention for the Protection of Animals kept for Farming Purposes adopted this recommendation "containing detailed provisions for the implementation of the principles set out in Chapter I of the [EU Farming] Convention based on scientific knowledge (...)". ${ }^{220}$ Interestingly, COE recommendations must be accepted unanimously by the Standing Committee of the Farming Convention. ${ }^{221}$ This means on the one hand that the COE Recommendation can only be seen as the least minimum protection level for 'farmed' fishes, since all COE parties involved had to agree on the provisions laid down in the Recommendation. ${ }^{222}$ On the other hand, this unanimous approval indicates that not only “(...) all Member States have ratified the European Convention for the Protection of Animals Kept for Farming Purposes (...)", ${ }^{223}$ which has also been approved by the European Union, ${ }^{224}$ but also that each EU Member State has agreed on the implementation of this COE Recommendation concerning 'farmed' fishes. With reference to article 9 point 3 of the Farming Convention, "[a]s from the date when a recommendation becomes effective each Contracting Party shall either implement it or inform the Standing Committee by notification (...) why it has decided that it cannot implement the recommendation or can no longer implement it'. ${ }^{225}$ This indicates the binding character of the COE Recommendation for all Member States under international law, ${ }^{226}$ which is additionally highlighted by the following statement in the preamble of Directive 98/58/EC:

"(...) it is also necessary for the Community to make further provision for the uniform application of the Convention and its recommendations and for specific rules concerning the application of this

\footnotetext{
215 EFSA (2008a), cit. 31; also: EFSA (2008d), cit., 22.

216 EFSA (2008b), cit., 27.

217 Ibid. 26-27.

${ }^{218}$ Article 22 point 6 of Regulation (EC) No 178/2002.

219 Third paragraph of the preamble of Directive 98/58/EC.

${ }_{220}$ Paragraph (2) of the preamble of the COE recommendation concerning 'farmed' fish. As described in section VI. 1.3.3. of this manuscript, the COE Recommendation lays down numerous provisions for better welfare of 'farmed' fishes under husbandry practices.

${ }^{221}$ According to article 8 point 5 letter a of the Farming Convention.

${ }^{222}$ HIRT, A., MAISACK, C., MORITZ, J., Tierschutzgesetz - Kommentar. Verlag Franz Vahlen, 3. Edition (München 2016) 19/rec. 33.

223 First paragraph of the preamble of Directive 98/58/EC.

224 By Council Decision 78/923/EEC.

225 Article 9 point 3 of the Farming Convention.

${ }^{226}$ HIRT et al., Tierschutzgesetz - Kommentar, cit., 18-19/rec. 32.

84 Derecho Animal. Forum of Animal Law Studies, vol. 11/1
} 


\section{Directive. "227}

Clearly, the EU legislator hereby gives the same importance to the recommendations as to the Convention itself, and reaffirms their legally binding character by requesting their uniform application within the EU. Consequently, in order to 'take all reasonable steps' to ensure fish welfare and to comply with article 3 of Directive 98/58/EC, all EU Member States should have transposed at least the COE Recommendation into national law.

Looking closer at the fourth paragraph of the preamble of Directive 98/58/EC, another important issue is raised, namely the necessity for specific rules in order to implement this Directive uniformly. However, in the case of 'farmed' fishes the Directive is obviously missing its goal, since no further detailed provisions have been laid down for the husbandry conditions of fishes. In order to effectively ensure the welfare of fishes in aquaculture production, it would be necessary to consider them on a species-specific level:

"It is important to recognise that a fish is not just a fish. We have around 30000 species of fish[es] in the world, and there is probably a much larger difference between various fish species than between a bat and an elephant. Comparing salmon and sea bass is like comparing a tiger and a dog, or a pig and horse. (...)" 228

At least, article 2 of the COE Recommendation recognises the great variety of 'farmed' fishes by stating that "(...) in fish[es] pronounced interspecies differences exist with respect to the requirements for water conditions, social behaviour and environmental structures". ${ }^{22}$ Therefore, as supplementary provision the COE Recommendation requires in article 21 that:

"(...) it shall be completed with species-specific Appendices, as soon as adequate scientific knowledge or practical experience, in particular on the requirements for water quality, stocking density, feeding, social behaviour and environmental structures is available (...)"230

Even though "[t]he Council of Europe has begun to tackle this by approaching fish specialists and inviting them to prepare [these] species-specific information sheets", ${ }^{231}$ up to the present day not a single species-specific appendix on fish welfare has been published.

The EU legislator is bound by Directive 98/58/EC and its preamble to make further provisions and specific rules concerning its application. In order to help the Member States with the interpretation of article 3 of Directive 98/58/EC, species-specific rules are absolutely necessary for the protection of fishes kept for farming purposes. In this context, the often-heard argument that science is still lacking detailed information regarding fish welfare ${ }^{232}$ loses strength when taking account of the Commission Regulation (EC) No $710 / 2009^{233}$ regarding organic aquaculture production. That is to say that the preamble of Regulation (EC) 710/2009 states:

"Organic aquaculture animal production should ensure that species-specific needs of animals are met. In this regard husbandry practices, management systems and containment systems should satisfy the welfare needs of animals. (...) for reason of high animal welfare and health, maximum stocking densities should be laid down. Taking account of the broad variation of species with particular needs, specific provisions should be laid down." 234

And indeed, species-specific requirements on maximum stocking densities (even though indicated in $\mathrm{kg} / \mathrm{m}^{3}$ and not on individual fish level) are stipulated in its Annex XIIIa for numerous fish species. ${ }^{235}$

\footnotetext{
227 Fourth paragraph of the preamble of Directive 98/58/EC.

228 Interview with Dr Tore Kristiansen, project co-coordinator of the EU-funded COPEWELL project. See: https://cordis.europa.eu/news/rcn/125441_en.html, 30.05.2018.

229 Article 2 of COE Recommendation.

230 Article 21 of COE Recommendation.

231 BRAITHWAITE, V., Do fish feel pain? cit., 163.

232 E.g. EU Commission's Answer to the Written Parliamentary Question E-012243/2011, 1 March 2012. See: http://www.europarl.europa.eu/sides/getAllAnswers.do?reference=E-2011-012243\&language=EN, 12.06 .2018 .

${ }^{233}$ Commission Regulation (EC) No 710/2009 of 5 August 2009 amending Regulation (EC) No 889/2008 laying down detailed rules for the implementation of Council Regulation (EC) No 834/2007, as regards laying down detailed rules on organic aquaculture animal and seaweed production.

234 Paragraph 10 of the preamble of Commission Regulation (EC) 710/2009.

${ }^{235}$ Section 1 - 6 and section 9 of Annex XIIIa of Commission Regulation (EC) 710/2009. N.B.: Also, requirements regarding stocking
} 
Inevitably, the question arises of how it can be possible for the EU legislator to produce provisions on species level for 'organically farmed' fishes, but not for those being conventionally farmed - even though they are of the same species.

Looking at Member State level, the picture does not seem to be very different. In 2015 the European Commission attested in its overview report on the 'Implementation of the Rules on Finfish Aquaculture' that "(...) in the main producing countries, there are very few standards on fish animal welfare in the MS visited with the result that it is seldom included within the scope of official controls". ${ }^{236}$ This statement describes an alarming situation for the fishes involved: not only are existing laws insufficient and superficial, but these few laws are not even properly enforced - and all of this is against the backdrop of fishes being the most common 'farm' animals in the EU. In this context, it is hard to believe that the EU and its Member States indeed 'take all reasonable steps' to ensure the welfare of the fishes as required by Directive 98/58/EC. For instance, one could think that Germany, which is internationally recognised as a country with one of the highest animal welfare standards worldwide, would have implemented Directive 98/58/EC to its full extent, also in terms of fish welfare. But unfortunately, and as confirmed recently in an answer of the German government to a parliamentary question on 'animal welfare and aquaculture', there is no specific legislation on fish welfare during rearing, since the general provisions laid down in article 2 of the German Animal Welfare Act are considered appropriate in combination with the COE Recommendation. ${ }^{237}$ Indeed, the German Federal Ministry for Food, Agriculture and Consumer Protection announced the COE Recommendations as legally binding in the Federal Gazette No. 161 of 26 August 2006, ${ }^{238}$ but nevertheless failed to include any further provisions in the national 'Tierschutz-Nutztierhaltungsverordnung' ${ }^{239}$ which serves as transposition for Directive 98/58/EC. The fishes are completely excluded from this national order since by definition only warm-blooded 'farm' animals fall within its scope. ${ }^{240}$

The extremely stressful and (likely) painful practices of stripping 'broodstock' fishes are still allowed without anesthetizing the fish - even in organic aquaculture production. ${ }^{241}$ As reported by the EU Commission (2015), "the limited availability of veterinary medicinal products has led to suboptimal treatment of certain diseases and has potential to increase antimicrobial resistance", ${ }^{242}$ with the consequence that 'farmed' fishes are exposed to the risk of further pain and suffering when it is not possible to treat them appropriately and cure their diseases. Furthermore, there is a lack of fish experts and specialists working as official veterinarians, with " $[t]$ he consequence (...) that many inspectors found it difficult to recognize signs of fish disease" 243 - not to mention the difficulties in recognising the signs of fish welfare. In other words, one could summarise:

"If there is no new EU legislation on animal welfare, given the weak way in which Directive 98/58 is interpreted, animals such as (...) the main farmed fish species (...) will not be protected for most of their lives in much of the EU."244

Fishes are sentient beings - nowadays, this position is not only widely accepted by scientists (with few exceptions), ${ }^{245}$ but also "[t]he Commission acknowledges that there is now sufficient scientific evidence indicating that fish [es] are sentient beings and that they are subject to pain and suffering (...)". ${ }^{246}$ Indeed, since 2009 they are recognised as such by the EU in article 13 TFEU requiring that full regard shall be paid to their welfare when formulating and implementing EU policies. ${ }^{247}$ However, as seen above, reality paints a different picture, and the legal protection status of a 'farmed' fish lacks far behind the ambitions and ethical values reflected by article 13 TFEU. Even though " $t$ ] he concept of welfare applies to every animal (...) there

density and production systems are laid down for invertebrates, like shrimps, prawns, molluscs and echinoderms (section 7 - 8).

236 Ibid. 25

237 Antwort der Bundesregierung auf die Kleine Anfrage der Fraktion BÜNDNIS 90/DIE GRÜNEN. Drucksache 18/12194 (02.05.2017). Answer to question 7. See:

http://dipbt.bundestag.de/extrakt/ba/WP18/809/80961.html, 12.06.2018.

238 Vierte Bekanntmachung der deutschen Übersetzung von Empfehlungen des Ständigen Ausschusses des Europäischen Übereinkommens zum Schutz von Tieren in landwirtschaftlichen Tierhaltungen, veröffentlicht im Bundesanzeiger Nr. 161 vom 26. August 2006 (S. 5932).

${ }^{239}$ German Ordinance for the protection of 'production' animals used for farming purposes and other animals kept for the production of animal products, in the version published on 22 August 2006. Designation: TierSchNutztV.

240 Article 2 point 1 of TierSchNutztV.

241 See article 25h letter 1 of Commission Regulation (EC) No 710/2009.

242 EU Commission (2015) Overview Report: Implementation of the Rules on Finfish Aquaculture. p. I.

243 Ibid. 6.

${ }^{244}$ EU Commission (2017b) Animal Welfare in the European Union, cit., 56.

245 See supra section $\mathrm{V}$.

246 EU Commission's Answer to the Written Parliamentary Question E-1140/2009, 3 April 2009. See:

http://www.europarl.europa.eu/sides/getAllAnswers.do?reference=E-2009-1140\&language=HU (12.06.2018).

247 Article 13 TFEU.

86 Derecho Animal. Forum of Animal Law Studies, vol. 11/1 
is sometimes a tendency for the welfare of the individual to be considered less when the animals are numerous", ${ }^{248}$ as in the case of fishes. All the more and after twenty years of Directive 98/58/EC being in force, it is high time to finally include the fishes effectively in secondary EU legislation - in particular by developing provisions on species level in order to consider thoroughly the different species-specific needs of the countless fishes involved.

\section{Transport of 'farmed' fishes}

\subsection{Specific animal welfare concerns and scientific opinion}

Not only terrestrial 'farm' animals are subjected to live transport, but also 'farmed' fishes. According to Eurostat, around 27,230 tons of live fishes were exported from the EU to third countries, and 526,000 tons of live fishes were transported within the EU in 2017 alone. ${ }^{249}$ Regarding the transport distances, it is indicated for the year 2017 that live trout, for example, were transported from Spain to Italy ( 27,000 tons) and Germany ( $\sim 2,350$ tons) respectively. ${ }^{250}$ In 2005 , it was even reported that live fishes were transported from Spain to Romania (128 tons of live tuna) as well as to Turkey (4,300 tons of live fishes of different species), ${ }^{251}$ exposing those animals to extremely long-distance transports of several thousands of kilometres. Furthermore, 'farmed' fishes are commonly transported between different farming systems and according to their current life stage. For example, juveniles and young fishes ${ }^{252}$ are transferred from the land-based hatcheries into the cages for rearing, which are located either on land (e.g. in the case of freshwater species) or sea (in the case of marine species), ${ }^{253}$ whereas breeding fishes may be transported to the hatcheries for spawning there. ${ }^{254}$ Wild-captured fishes, like tuna or eels who are further reared in aquaculture production, are transported from their place of capture to the farming site. ${ }^{255}$ In some EU member states live fishes are still sold at markets, implying that the fishes have to be transported to these places beforehand. ${ }^{256}$ Finally, fishes who have reached slaughter weight and size are transported to the slaughterhouses and the processing facilities. ${ }^{257}$

Like terrestrial animals, fishes are transported by road, sea, and even by air. Hereby, the "road transport of farmed fish[es] is usually carried out in multiple purpose-built [water] tanks on a road haulage vehicle", 258 while additional oxygen as well as compressed air should be provided inside the tanks during transport. ${ }^{259}$ This is important especially in road transports as the animals are transported in closed systems without any water exchange on board. Additionally, the transport of juvenile fishes can also be conducted by putting them in oxygen-enriched sealed plastic bags (partly filled with water and atmospheric oxygen), which in turn are stored in insulated containers. ${ }^{260}$ Regarding the length of road transports, it has been reported that, for example, sea bream and sea brass juveniles are transported within Spain up to 12 hours, whereas when transported from Spain and France to Italy, it can even take up to 36 hours, in which the young fishes are non-stop inside the

\footnotetext{
${ }^{248}$ EU Commission (2017b) Animal Welfare in the European Union, cit., 49.

${ }^{249}$ Data extracted from Eurostat (http://ec.europa.eu/eurostat/data/database) on 30.04.2018. N.B.: It is noteworthy that: 1) the transport of live fishes is not placed in the same category as the transport of other live (terrestrial) animals within the Eurostat database, but is in the same category with other 'fish products', like fresh, chilled or processed, and thus dead fishes; 2) the numbers of transported fishes are not reported in the Eurostat database, but only the quantity is given per $100 \mathrm{~kg}$. Hence, it remains unclear how many individuals were transported indeed; 3) there is no indication on the means of transport (by road, sea or air) and on the purpose of these transports, i.e. no information is provided if the fishes are transported as juveniles from hatcheries to fattening farms or for breeding purposes or if they are transported for slaughter.

${ }^{250}$ Ibid.

${ }^{251}$ Ibid.

${ }^{252}$ In aquaculture and fisheries terminology, juvenile fishes are also called 'fry', 'fingerling' or in the case of salmon juveniles 'smolts'. ${ }^{253}$ E.g. EFSA (2009h), cit., 6; SOUTHGATE, P.J., Welfare of Fish During Transport. In: Branson, E.J. (Ed.) Fish Welfare (Oxford 2008) 185-187.

${ }^{254}$ Bocek, A. (undated) Water Harvesting and Aquaculture for Rural Development - Transporting Fish. International Center for Aquaculture and Aquatic Environments. Auburn University. p. 2.

${ }^{255}$ EFSA (2004b), Scientific Report of the Scientific Panel on Animal Health and Welfare on a request from the Commission related to the welfare of animals during transport. The EFSA Journal 44, 115-116.

${ }^{256}$ See section I.

${ }^{257}$ Except the fishes are killed on-spot, like tuna, seabream or seabass. For further information on slaughter of 'farmed' fishes see section 3 of section $\mathrm{V}$ of this manuscript.

${ }^{258}$ SOUTHGATE, P.J., Welfare of Fish During Transport, cit., 185.

259 DALlA VILlA, P., MAHAHRENS, M., VELARDE CALVO, A., DI NARDO, A., KLEINSCHMIDT, N., FUENTES ALVAREZ, C., TRUAR, A., DI FEDE, E., OTERO, J.L., MÜLlER-GRAF, C. (2009) Project to develop animal welfare risk assessment guidelines on transport. Technical Report submitted to EFSA - project developed on the proposal CFP/EFSA/AHAW/2008/02., p. 58.

${ }^{260}$ E.g. EFSA (2004b), cit., 115-116; GAYER, R., RABITSCH, A. \& EBERHARDT, U., Tiertransporte. Rechtliche Grundlagen, Transportpraxis, mit Prüfungswissen für den Befähigungsnachweis Tiertransport. Ulmer Verlag (2016) 132; DALLA VILLA et al., Project to develop animal welfare risk assessment guidelines on transport, cit., 61 .
} 
closed transport containers. ${ }^{261}$ But not only young fishes are shipped by road, fishes 'at slaughter age' are also transported by road, including long transport times. For example, in Germany common carps 'for slaughter' are transported more than eight hours in some cases, and in Poland transports for slaughter can reach over 12 hours for common carps and rainbow trout. ${ }^{262}$

Transport by sea takes place in so-called well-boats that are commonly used in marine aquaculture, "both for transporting fish to on-growing sites and also for moving harvest-sized fish [es] to central slaughter stations". ${ }^{263}$ These well-boats contain tanks or chambers that are embedded in the hull of the boat, which are filled either with re-circulated seawater (in a closed system) or with seawater being pumped through the chambers (in an open flow through system). ${ }^{264}$ The duration of these sea transports can easily exceed 24 hours in UK and Ireland, as reported for Atlantic salmon smolts who are brought by well-boats to sea cages for rearing and fattening. ${ }^{265}$ Regarding the transports for slaughter via well-boats, their duration can vary broadly, as seen for example in Ireland where these transports can take between 3-30 hours for Atlantic salmon 'for slaughter' ${ }^{266}$ For the UK it has been reported that Atlantic salmons are transported on average 24-28 hours before being slaughtered. ${ }^{267}$ Another method of sea transport is by towing the cages in which wild fishes have been caught to transport them to cages for further fattening. For example, in the case of tuna, these transports can last for several weeks from their place of capture until the fishes arrive at the 'fattening farms' ${ }^{268}$

Transport by air is not very common, ${ }^{269}$ but is sometimes used for young salmons who are transported over short distances from the land-based hatcheries to the rearing cages on sea. ${ }^{270}$ Here, the fishes are put in water tanks or buckets which are hung underneath the helicopter, often in very crowded conditions, as reported by EFSA (2004b). ${ }^{271}$

In any case, "transportation induces physiological stress", ${ }^{272}$ and "can have a detrimental effect on the welfare of the fish", ${ }^{273}$ According to EFSA (2004b), in cases of very bad transport conditions this could even result in $100 \%$ mortality of the fishes after transport. ${ }^{274}$ As in any other farming sector, in the aquaculture industry the transports are conducted as efficiently and cost-effectively as possible, which implies that fishes are often transported at high densities with thousands of individuals being affected in one single transport. ${ }^{275}$

During transport, the impacts on the welfare of the fishes are not only provoked by the transport itself, but also by related operations including "capture, loading, (...) unloading and stocking". ${ }^{276}$ Hereby, the following aspects must be taken particularly into account in order to avoid the fishes being exposed to additional pain, distress and suffering during transport:

\section{Handling stress during loading and unloading}

Following EFSA's opinion, "the initial loading of fish[es] into the [transport] container is the most stressful component of transport" 277 as the fishes are collected and captured out of their familiar environment, crowded, and then transferred into the transport tanks, often at high densities. These "multiple stressors within a short duration" 278 lead to acute stress, which could even imply immediate death, as well as to chronic stress and immune suppression, increasing their risk for disease and further

\footnotetext{
${ }^{261}$ EU Commission $(2017 \mathrm{c})$ Welfare of farmed fish: Common practices during transport and at slaughter. Final report, 94.

262 Ibid. 105, 107.

${ }^{263}$ SOUTHGATE, P.J., Welfare of Fish During Transport, cit., 186. N.B.: 'Harvest-sized' fishes are called in aquaculture terminology those fishes who have reached their slaughter weight and are thus 'ready for harvest', i.e. slaughter.

${ }^{264}$ SOUTHGATE, P.J., Welfare of Fish During Transport, cit., 186; DALLA VILLA et al., Project to develop animal welfare risk assessment guidelines on transport, cit., 60 .

${ }^{265}$ EU Commission (2017c) Welfare of farmed fish: Common practices during transport and at slaughter. Final report, 91.

${ }^{266}$ Ibid. 100; N.B.: The fishes are either transferred in an open or closed system via well-boat transport.

${ }^{267}$ Ibid.

${ }^{268}$ EFSA (2004b), cit., 116.

${ }^{269}$ In the case of 'farmed' fishes - e.g. only $1 \%$ of smolts is apparently transferred by helicopter to the sea cages (See: EU Commission (2017c) Welfare of farmed fish: Common practices during transport and at slaughter. Final report, 112). On the contrary, ornamental fishes are commonly transported by aircraft around the globe. See: WALSTER, C., The Welfare of Ornamental Fish. In: Branson, E.J. (Ed.) Fish Welfare. (Oxford 2008) 271-290.

${ }^{270}$ EFSA (2004b), cit., 116; SOUTHGATE, P.J., Welfare of Fish During Transport, cit., 185.

${ }^{271}$ Ibid. 116.

272 HUNTINGFORD, F.A., KADRI, S., Welfare and Fish, cit., 356.

${ }^{273}$ SOUTHGATE, P.J., Welfare of Fish During Transport, cit., 185.

${ }^{274}$ EFSA (2004b), cit., 15.

${ }^{275}$ E.g. TANG, S., THORARENSEN, H., BRAUNER, C.J., WOOD, C.M., FARRELL, A.P., Modelling the accumulation of $\mathrm{CO}_{2}$ during high density, re-circulation transport of adult Atlantic salmon, Salmo salar, from observations aboard a sea-going commercial live-haul vessel. Aquaculture 296 (2009) 102.

${ }^{276}$ ASHLEY, P.J., Fish welfare: Current issues in aquaculture. Applied Animal Behaviour Science 104 (2007) 208; DALLA VILLA et al., Project to develop animal welfare risk assessment guidelines on transport, cit., 61.

277 EFSA (2004b), cit., 117.

${ }^{278}$ DALLA VILLA et al., Project to develop animal welfare risk assessment guidelines on transport, cit., 62.

88 Derecho Animal. Forum of Animal Law Studies, vol. 11/1
} 
suffering. ${ }^{279}$ It has been reported that the fishes often need a prolonged period of post-transport recovery from severe transport stress. ${ }^{280}$

Depending on the handling and management, the fishes can suffer from injuries during transport procedures, for example through exceeding loading densities, motion of the transport vehicle, or simply through careless loading practices, "leading to descaling, fin erosion, snout abrasion and eye damage". ${ }^{281}$ These are particularly sensitive regions containing numerous nociceptors for detecting pain. ${ }^{282}$ Also, aggression among the fish individuals can increase under stressful conditions, ${ }^{283}$ for example when new groups of fishes are mixed together at high densities and with insufficient space inside the transport tanks.

Research on the psychological effect on the welfare of fishes during transport is lacking, but as stated by EFSA (2004b), "the behavioural response to being caught and carried is generally one of passive fear behaviour". ${ }^{284}$ For example, fishes under extreme stress react with the highest adreno-cortical stress response possible in their physiology, are are suffering seriously from stress and fear while at the same time may not show any active behavioural reaction. Thus, the "persons handling [them] may be unaware" 285 of their enormous suffering involved.

\section{Deteriorated water quality during transport}

During transport the fishes are confined in a small area within the transport container and often at very high loading densities due to economic reasons. This implies that for a large group of fishes only a relatively small amount of water is provided, in which "waste products from the fish [es] such as ammonia and carbon dioxide are likely to increase, as may the presence of organic material and suspended solids from faeces". ${ }^{286}$ As a consequence, the water quality easily changes for the worse, especially since "transportation of fish [es] is frequently carried out in 'static' water with very little chance of any water exchange". ${ }^{287}$ Like for any other vertebrates, those excretory products can become toxic for fishes at high concentrations. ${ }^{288}$ Considering that the fishes are in very close, direct contact with their surrounding environment through their gills and skin, poor water quality can result in poor welfare, and even death. ${ }^{289}$ Due to increased agitation and stress during loading and transport, the fishes show increased metabolic activity which in turn "will lead to further accumulation of ammonia and carbon dioxide which induce further deterioration of water quality". ${ }^{290}$ To counteract oxygen depletion, during transport and related operations ${ }^{291}$ 'static' water is often oxygenated by an external $\mathrm{O}_{2}$-source. However, excessive oxygenation of the water can even increase the toxicity effect of high carbon dioxide concentrations for the fishes, since too much oxygen in the water may reduce the fishes' ability to release their internal carbon dioxide from the blood into the water, possibly leading to hypercapnia ${ }^{292}$ and then to metabolic acidosis in the fishes. ${ }^{293}$ Furthermore, due to handling and loading stress the fishes not only show accelerated metabolic activity, but also "shed mucus (...), thereby [additionally] compromising water quality". 294

Especially during road and air transport, as well as during sea transports with closed wells, and with

\footnotetext{
${ }^{279}$ EU Commission (2017c) Welfare of farmed fish: Common practices during transport and at slaughter. Final report, 83.

${ }^{280}$ Ibid. 61

${ }^{281}$ SOUTHGATE, P.J., Welfare of Fish During Transport, cit., 191.

${ }^{282}$ See section V of this manuscript.

${ }^{283}$ EU Commission $(2017 \mathrm{c})$ Welfare of farmed fish: Common practices during transport and at slaughter. Final report, 82.

${ }^{284}$ EFSA (2004b), cit., 10 - 11.

285 Ibid.

${ }^{286}$ SOUTHGATE, P.J., Welfare of Fish During Transport, cit., 191.

${ }^{287}$ Ibid.

${ }^{288}$ EFSA (2004b), cit., 118.
}

${ }^{289}$ MACINTYRE, C.M., ELLIS, T., NORTH, B.P. and TURNBULL, J.F., The Influences of Water Quality on the Welfare of Farmed Rainbow Trout: a Review. In: Branson, E.J. (Ed.) Fish Welfare (Oxford 2008) 150.

${ }^{290}$ EFSA (2004b), cit., 118.

${ }^{291}$ Including lairage tanks at markets where live fishes are sold, e.g. in Poland, Czech Republic or Romania.

${ }^{292}$ Carbon dioxide reacts with the water and escapes from the water into the atmosphere, but in closed systems (e.g. transport tanks during road transport) the airspace above the water in the tanks is limited, thus leading to an increase in the ambient carbon dioxide concentration. As consequence, less carbon dioxide can escape from the water into the airspace which in turn prevents the fishes "to excrete [their own] endogenous carbon dioxide, leading to $\mathrm{CO}_{2}$ increases in the blood, known as hypercapnia" See: MACINTYRE, C.M., et al., The Influences of Water Quality on the Welfare of Farmed Rainbow Trout, cit., 163.

${ }^{293}$ EFSA (2004b), cit., 117-118; MACINTYRE, C.M., et al., The Influences of Water Quality on the Welfare of Farmed Rainbow Trout, cit., 163

${ }^{294}$ EU Commission (2017c) Welfare of farmed fish: Common practices during transport and at slaughter. Final report, 82; N.B.: Fishes are protected by a layer of mucus over their skin against external infection and to facilitate their movement in water - thus an intact mucus layer is very important for the fishes (e.g. see: HUNTINGFORD, F.A., KADRI, S., Defining, assessing and promoting the welfare of farmed fish. Scientific and Technical Review of the Office International des Epizooties 33/1 (2014) 235). 
increasing transport time, the deterioration of the water quality represents a serious welfare problem, since the fishes are carried in closed water systems with only little or no water exchange. ${ }^{295}$ For example, Robb (2008) mentions extreme cases in which "mortalities have been associated with well boat transports [and closed water systems] - [where] even entire shipments have been lost due to poor water quality control'. ${ }^{296}$

\section{Fasting and starvation prior and during transport}

Beside oxygenation, another strategy used to avoid, inter alia, those previously prescribed toxicity effects for transported fishes is to reduce their metabolic activity and thus their oxygen consumption, as well as the faecal contamination in the 'transport water'. Therefore, 'farmed' fishes are starved before and during transportation in order to "allow the gut to clear and thus decrease the bacterial and faecal load placed on any (...) transport system". ${ }^{297}$ Often, in commercial aquaculture, fasting and starvation periods far exceed what is actually needed for only emptying the fishes' intestine. ${ }^{298}$ As stated by EFSA, as well as in the recently published EU Commission report (2017), food withdrawal can reach up to seven days and more, ${ }^{299}$ exposing the fishes to unnecessary prolonged fasting and starvation. Taking into account that "food deprivation can result in the utilisation of body fat reserves and even functional tissue", ${ }^{300}$ this is likely to result in poor welfare. ${ }^{301}$

Beside these aspects described above, further environmental factors like temperature, light intensity, water flow, noises, and vibrations during transport can have severe effects on the well-being of the fishes. ${ }^{302}$ Thus, they must always be considered for the relevant fishes according to their different species' needs, number of individuals transported, as well as the length of journey.

\section{Conclusion}

A profound knowledge and experience in the people handling and transporting the fishes is needed in order to avoid unnecessary pain and suffering for the animals and "to provide a safe environment and minimise unnecessary stress or discomfort to the fish [es] before, during and after transport". ${ }^{303}$

\subsection{OIE recommendations concerning the protection of 'farmed' fishes during transport}

In the OIE Aquatic Animal Health Code, ${ }^{304}$ chapter 7.2. is dedicated to the welfare of 'farmed' fishes during transport, ${ }^{305}$ with the aim of reducing the effect of transport on their wellbeing. The provisions laid down refer to national and international transport of fishes by air, sea, or on land. ${ }^{306}$

Article 7.2.2. defines the responsibilities of the different parties involved in the transport of live fishes, but clearly puts in charge "all personnel handling fish [es] throughout the transportation process" to safeguard that "the potential impact on the welfare of fish[es]" 307 is taken into account.

Firstly, the competent authority in both the exporting and importing country is responsible for setting up minimum standards on the welfare of 'farmed' fishes, which should include pre- and post-checks, as well as checks during transport, a proper certification and record scheme, and training of personnel. Furthermore, the competent authorities are responsible for the enforcement of these standards.

Secondly, the 'fish farmers' (owners and managers at place of departure and place of destination) take

\footnotetext{
${ }^{295}$ As an exception is to name the sea transport with well-boats and open water systems in which sea water is pumped through the chambers in which the fishes are transported, thus providing them continuously with fresh seawater. See: SOUTHGATE, P.J., Welfare of Fish During Transport, cit., 186, 190-191.

${ }^{296}$ ROBB, D.H.F., Welfare of Fish at Harvest. In: BRANSON, E.J. (Ed.) Fish Welfare (Oxford 2008) 229.

${ }^{297}$ EFSA (2004b), cit., 116.

${ }^{298}$ LINES, J.A. \& SPENCE, J., Safeguarding the welfare of farmed fish at harvest. In: van de Vis, H. et al. (Eds.) Welfare of Farmed Fish in Present and Future Production Systems. Springer Science+Business Media (Dordrecht, $1^{\text {st }}$ ed. 2012) 165.

${ }^{299}$ EFSA (2009d) Scientific Opinion of the Panel on Animal Health and Welfare on a request from the European Commission on welfare aspect of the main systems of stunning and killing of farmed seabass and seabream. The EFSA Journal 1010, 10; EU Commission (2017c) Welfare of farmed fish: Common practices during transport and at slaughter. Final report, 86 - 111.

${ }^{300}$ EFSA (2009c) Scientific Opinion of the Panel on Animal Health and Welfare on a request from the European Commission on welfare aspect of the main systems of stunning and killing of farmed Atlantic salmon. The EFSA Journal 2012, 36.

${ }^{301}$ Further details on the welfare impact of fasting are described in section 3.1.1. of this manuscript, as more scientific information is available on fasting related to pre-slaughter operations.

302 EU Commission (2017c) Welfare of farmed fish: Common practices during transport and at slaughter. Final report, 82.

303 Ibid.

${ }^{304}$ Hereinafter referred to as 'Aquatic Code'.

${ }^{305}$ Chapter 7.2. provides only recommendations on the welfare of 'farmed' fishes during transport but does not consider how to control aquatic health risks related to fish transport, which is treated in chapter 5.5.

${ }^{306}$ Article 7.2.1. of Aquatic Code.

${ }^{307}$ Article 7.2.2. of Aquatic Code.

90 Derecho Animal. Forum of Animal Law Studies, vol. 11/1
} 
responsibility for the health condition of the fishes, including their fitness for transport at the start of the journey. They are also in charge of "the overall welfare of the fish[es] during the transport regardless of whether these duties are subcontracted to other parties". ${ }^{308}$ In this context, they must ensure that only trained and competent personnel conduct the loading and unloading activities in order to avoid injuries or additional stress for the fishes. The preparation of a contingency plan, which should also include the possibility of 'humane killing', lies within the responsibility of the owners and managers of fish farms, as well as the guarantee that the welfare of the fishes is secured at their place of destination.

Thirdly, together with the owners and managers, the transporters are in charge of a proper planning of the journey in order to comply with the health and welfare standards for fishes, by choosing a well-maintained, adequate vehicle, employing trained and competent people, having a contingency plan in case of emergency, and using adequate equipment for loading and unloading.

Fourthly, "the person in charge of supervising the transport" 309 , i.e. the driver, has to ensure all transport documentation as well as the practical enforcement of the welfare standards for fish transport.

Article 7.2.3. further defines the competence that each party should have. All people involved in fish transport should have obtained "an appropriate knowledge and understanding to ensure that the welfare of the fish [es] is maintained throughout the process", whereby one can be considered competent "through formal training and/or practical experience". This article also states that all parties involved in the transport of live fishes - competent authorities, 'fish farmers' and transport companies - are responsible to provide training to their personnel and staff working in this field. Hereby, species-specific knowledge should be addressed, as well as practical experience, on the following topics: ${ }^{310}$

- Fish behaviour, physiology, indicators of disease and poor welfare;

- Equipment operation and maintenance (regarding fish welfare and health);

- Water quality and exchange;

- (Species-specific) handling of live fishes during transport, loading and unloading;

- Inspection of live fishes during transport and management of critical situations, like changed water quality, adverse weather conditions, and emergencies;

- Humane killing;

- Logbook and record keeping.

Article 7.2.4. sets up the rules for planning the transport of live fishes, where preparations before the transport, journey route and time, as well as the purpose of the transport (e.g. for reasons of biosecurity/farming and processing/killing due to disease control) should be taken into account. Accordingly, the planning prior to transports should include: ${ }^{311}$

- Type of vehicle and transport equipment;

- Route plan considering distance, weather forecast and/or sea conditions;

- Nature and duration of transport;

- Assessment if fishes need to acclimatise to water quality beforehand;

- Need for care during transport;

- Emergency plan regarding fish welfare;

- Assessment of biosecurity issues (refer to chapter 5.5. of Aquatic Code).

Following this, specific recommendations are given on:

Vehicle and handling equipment:

The means of transport should be designed and used according to the species, size, weight, and number of fishes transported, and maintained in good working order. Also, an adequate circulation of water as well as a system for oxygenation should be ensured. Access to the fishes and inspection during transport must be ensured, and a transport logbook should be carried during the journey, including, inter alia, information on the transported fishes, contact information and mortalities. The handling equipment (e.g. nets, pumping devices and brailing devices) should be constructed in a way to handle the fishes without

\footnotetext{
${ }^{308}$ Article 7.2.2. Point 2 Letter a of Aquatic Code.

${ }^{309}$ Article 7.2.2. Point 4 of Aquatic Code.

${ }^{310}$ Article 7.2.3. Point 3 of Aquatic Code.

${ }^{311}$ Article 7.2.4. Point 1 of Aquatic Code.
} 
causing additional physical injuries. ${ }^{312}$

Water quality:

Water quality (including oxygen, carbon dioxide and ammonia level, $\mathrm{pH}$, temperature and salinity) during transport should be in accordance with the species-specific needs of the fishes transported. In this context, and depending on the journey length, equipment may be required to measure and maintain the water quality during transport. ${ }^{313}$

Preparation of fishes for transport:

Food withdrawal is recommended prior to transport and in accordance with the specific species and life stage of the fishes transported. Furthermore, the fishes should be checked on their stress coping ability before the transport by taking account of their health status, the previous handling, and the recent transport history of the respective fishes. ${ }^{314}$

It is clearly stated that only fishes who are fit for transport should be loaded. Indicators for unfitness include accordingly: ${ }^{315}$

- Clinical signs of disease;

- Significant physical injuries or abnormal behaviour, such as rapid ventilation or abnormal swimming;

- Recent exposure to stressors adversely affecting behaviour or physiological state, e.g. extreme temperatures or chemical agents;

- Insufficient or excessive length of fasting.

Species-specific recommendations:

Different species-specific behaviours and needs of the transported fishes must be taken into account during transport. Before transferring the fishes into a new environment, a physiological preparation, like food deprivation or osmotic acclimatisation, may be necessary for some fish species and some life stages. ${ }^{316}$

Contingency plans:

Contingency plans should be prepared for each transport considering the important adverse events on fish welfare during transport. Not only do the measures to be taken in such cases need to be defined, but also the responsibilities of all parties involved, including communications and record keeping. ${ }^{317}$

Further explanation on the documentation is given in article 7.2.5. of the Aquatic Code, where it states that the loading of fishes should not be undertaken before the completion of the required documentation. The accompanying documents (transport $\log$ ) should include details on the consignment, i.e. the date, time and place of loading, transported species and weight, ${ }^{318}$ as well as a transport plan, including route and expected duration of the journey, water exchanges, date and place of arrival, and contact information of the receiver. The transport log should be available for the dispatcher and the receiver as well as for the competent Aquatic Animal Health Service upon request.

Article 7.2.6 lays down the requirements for loading the fishes in order to avoid injuries and unnecessary stress for the fishes. Therefore, special attention has to be given to the crowding event prior to the loading as well as to the equipment used. Nets, pumps and pipe systems must be properly constructed without sharp bends or protrusions. Improper operation of the equipment, like overloading with fishes of incorrect size or number of individuals, must be addressed, as well as the quality of the water during transport. It is recommended to acclimatize some fish species prior to transport, especially if significantly different temperatures or other water parameters are to be expected during transport. Regarding the loading density, scientific data should be taken into account, and "should not exceed what is generally accepted for a given species and a given situation". ${ }^{319}$

Article 7.2.7. refers to the actual transport of fishes. In general, periodic inspections are required during

\footnotetext{
${ }^{312}$ Article 7.2.4. Point 2 of Aquatic Code.

${ }^{313}$ Article 7.2.4. Point 3 of Aquatic Code.

${ }^{314}$ Article 7.2.4. Point 4 Letter a and b of Aquatic Code.

315 Article 7.2.4. Point 4 Letter c of Aquatic Code.

${ }^{316}$ Article 7.2.4. Point 5 of Aquatic Code.

317 Article 7.2.4. Point 6 of Aquatic Code.

318 It is noteworthy that only the biomass load is required but not the number of fish individuals transported.

${ }^{319}$ Article 7.2.6. Point 3 of Aquatic Code.

92 Derecho Animal. Forum of Animal Law Studies, vol. 11/1
} 
the transport in order to ensure that the fishes are in an acceptable welfare condition. Also, the water quality should be monitored and adjusted to avoid extreme conditions for the fishes on-board. Since uncontrolled movements of the means of transport may cause stress and injury to the fishes, travelling should be conducted in a way to minimise these movements. In cases of sick or injured fishes, the vehicle operator (driver) must comply with the contingency plan, and - if necessary - emergency killing must be conducted humanely according to chapter 7.4. of the Aquatic Code.

With respect to unloading, article 7.2.8. refers to the "principles of good fish handling during loading", ${ }^{320}$ which should be applied equally to the unloading procedure. Additionally, this article states that the unloading should take place as soon as possible after arrival, but with sufficient time in order to avoid further harm to the fishes during the unloading procedure. Again, for some species it is recommended to give them time for acclimatisation, in case of significantly changes in water quality, such as temperature, salinity, or $\mathrm{pH}$. Dying or severely injured fishes must be removed and humanely killed under the provisions of chapter 7.4. of the Aquatic Code.

According to article 7.2.9. post-transport observations of the fishes are required after unloading by the person in charge at the place of destination. If fishes are observed with abnormal clinical signs, they should be isolated and checked by a veterinarian or qualified personal, or killed humanely in accordance with chapter 7.4. of the Aquatic Code. Furthermore, the evaluation of significant problems related to the transport is required in order to prevent reoccurrence.

\subsection{EU legislation on the protection of fishes during transport}

\subsubsection{Council Regulation (EC) No 1/2005 of 22 December 2004 on the protection of animals during transport and related operations}

The transport of vertebrate animals for economic purposes ${ }^{321}$ is regulated by Council Regulation (EC) No 1/2005 of 22 December 2004 on the protection of animals during transport and related operations. ${ }^{322}$ It is noteworthy that fishes are not mentioned in Regulation EC 1/2005. However, since they belong to the group of vertebrates, the transport of live fishes must be conducted in compliance with this Regulation. ${ }^{323}$ But, due to the lack of specific requirements for fish transports, only the general rules, which will be described in the following, apply to fishes.

Article 3 of Regulation EC 1/2005 sets up the general conditions for transporting live animals, including fishes. Hereby, as the principal rule it must be understood that "no person shall transport animals or cause animals to be transported in a way likely to cause injury or undue suffering to them". ${ }^{324}$ Among others, it requires all necessary arrangements to be made prior to the transport in order to minimise the duration of the journey and to comply with the needs of the animals concerned. ${ }^{325}$ The animals' fitness for transport must be ensured, as well as the safety of the animals during transport. ${ }^{326}$ The latter must be achieved by using "means of transport [that] are designed, constructed, maintained and operated so as to [also] avoid injury and suffering (...) of the animals" ${ }^{327}$ For the same purpose, the facilities for loading and unloading should be properly designed, constructed, maintained, and operated. ${ }^{328}$ Any personnel assigned to handle the fishes must be trained and competent to fulfil this task "without using violence or any other method likely to cause unnecessary fear, injury or suffering". ${ }^{329}$ Regarding the journey itself it is required that the transport is carried out without delay while checking on a regular basis and adequately maintaining the welfare conditions of the animals. ${ }^{330}$

Article 4 of Regulation EC 1/2005 states that the transport documents must be carried on board the means of transport and presented to the competent authority, if requested. Regarding the content of these documents, the following information must be given:

\footnotetext{
${ }^{320}$ Article 7.2.8. Point 1 of Aquatic Code.

${ }^{321}$ Article 1 point 5 of Council Regulation (EC) No 1/2005.

322 Hereinafter as Regulation EC 1/2005. letter (j) of Regulation EC 1/2005.

${ }^{324}$ Article 3 of Council Regulation (EC) No 1/2005.

325 Article 3 letter (a) of Council Regulation (EC) No 1/2005.

${ }^{326}$ Article 3 letter (b) and (c) of Council Regulation (EC) No 1/2005.

327 Article 3 letter (c) of Council Regulation (EC) No 1/2005.

328 Article 3 letter (d) of Council Regulation (EC) No 1/2005.

${ }^{329}$ Article 3 letter (e) of Council Regulation (EC) No 1/2005.

${ }^{330}$ Article 3 letter (f) of Council Regulation (EC) No 1/2005.
}

${ }^{323}$ See article 1 point 1 of Regulation EC 1/2005: "This Regulation shall apply to the transport of live vertebrate animals carried out within the Community (...)." According to article 2 letter (w) 'transport' is defined as "the movement of animals effected by one or more means of transport and the related operations, including loading, unloading, transfer and rest, until the unloading of the animals at the place of destination is completed". 'Transport' can be used synonymously to 'journey' according to the definition of article 2 
- the origin of the animals and their ownership;

- date, time and place of departure;

- place of destination; and

- expected duration of the journey.

Article 5 of Regulation EC 1/2005 requires, among others, that a natural person is responsible for the transport. Furthermore, the organisers have to ensure for each transport that, inter alia, "the welfare of the animals is not compromised by insufficient coordination of the different parts of the journey; and [that] the weather conditions are taken into account". ${ }^{331}$

Article 6 lays down the rules for transporters of vertebrate animals, thus including transporters of fishes. In cases of transporting the animals over $65 \mathrm{~km}$, the transporter (transport company) must be officially authorised in accordance with article 10(1), ${ }^{332}$ and article $11(1)^{333}$ for long journeys. ${ }^{334}$ For transports less than $65 \mathrm{~km}$ no authorisation is required. Regardless of the length of the transport, it is stipulated that "transporters shall transport animals in accordance with the technical rules set out in Annex I" ${ }^{335}$ However, an official certificate of competence is not required for the person in charge of the fishes during transport, but only training on the relevant provisions of annexes I and II, ${ }^{336}$ in case the transports exceed $65 \mathrm{~km} .{ }^{337}$

Furthermore, in the case of fish transport the "keepers of animals at the place of departure, transfer or destination shall ensure that the technical rules set out in Chapters I and III, section 1, of Annex I in respect of the animals being transported are met". ${ }^{338}$

In contrast to other 'farm' animals, no journey log is required for the long-distance transport of 'farmed' fishes. The organizer is not obliged to submit a proper planning of long distance transports of fishes to the competent authorities, ${ }^{339}$ and the competent authority is not obliged to verify if the planning of such long transports is realistic and in compliance with Regulation EC 1/2005. ${ }^{340}$ But, indeed, "the competent authority shall carry out at any stage of the long journey appropriate checks on a random or targeted basis to verify that declared journey times are realistic and that the journey complies with this Regulation (...)." 341342

In terms of official inspections, inter alia, article 27 states that “(...) inspections [on compliance with Regulation EC 1/2005] must be carried out on an adequate proportion of the animals transported each year within each Member State (...)" ${ }^{343}$ and the results of these inspections must be submitted to the European Commission on a yearly basis. ${ }^{344}$

Specifying the principal rules of article 3 and in connection with article 6 point 3 , annex I gives a variety of technical rules under which animals are either allowed or not allowed to be transported. As annex I does not give exhaustive specifications on the species included, in theory the provisions should also apply to fishes.

Further requirements on the means of transports are laid down in chapter II of annex I. The following examples can be understood as relevant, inter alia, for the transport of fishes: the design, construction, maintenance, and the operations of the transport vehicles must be conducted in a way to "avoid injury and suffering and to ensure the safety of the animals", ${ }^{345}$ as well as to "protect the animals from inclement weather, extreme temperatures and adverse changes in climatic conditions". ${ }^{346}$ Also, the means of transport shall "prevent the animals escaping or falling out and be able to withstand the stresses of movements", ${ }^{347}$ and be

\footnotetext{
${ }^{331}$ Article 5 point 3 letter (a) of Council Regulation (EC) No 1/2005.

${ }^{332}$ Article 10 point 1 lays down the administrative requirements which the competent authority has to take into account when granting authorisations for transporters regarding journeys under eight hours.

333 Article 11 point 1 lays down the requirements for long journeys transporter authorisations granted by the competent authority, whereas long journeys are defined as transports longer than eight hours (according article 2 letter (m) of Regulation EC 1/2005).

${ }^{334}$ Article 6 point 1 and 7 of Council Regulation (EC) No 1/2005.

${ }^{335}$ Article 6 point 3 of Council Regulation (EC) No 1/2005.

${ }^{336}$ Annex II does not apply to the transport of fishes according to article 5 point 4, article 8 point 2, article 14 point 1 and article 21 point 2. I.e. no journey log is required for long journeys of fishes.

${ }^{337}$ Article 6 point 4,5 and 7 of Council Regulation (EC) No $1 / 2005$.

${ }^{338}$ Article 8 point 1 of Council Regulation (EC) No 1/2005.

${ }^{339}$ Article 5 point 4 of Council Regulation (EC) No 1/2005.

${ }^{340}$ Article 14 of Council Regulation (EC) No 1/2005.

${ }^{341}$ Article 15 point 1 of Council Regulation (EC) No 1/2005.

${ }^{342}$ Regulation EC 1/2005 lays down further requirements regarding administrative procedures, which will not be further described in the following as they would go beyond the scope of this manuscript.

${ }^{343}$ Article 27 point 1 of Council Regulation (EC) No 1/2005.

${ }^{344}$ Article 27 point 2 of Council Regulation (EC) No 1/2005.

${ }^{345}$ Annex I chapter II section 1 point 1.1. letter (a) of Council Regulation (EC) No 1/2005.

${ }^{346}$ Annex I chapter II section 1 point 1.1. letter (b) of Council Regulation (EC) No 1/2005.

${ }^{347}$ Annex I chapter II section 1 point 1.1. letter (d) of Council Regulation (EC) No 1/2005 
accessible during transport "to allow [the animals] to be inspected and cared for". 348 Adequate space inside their compartment is required, as well as safety measures where there is transport in containers. ${ }^{349}$

Regarding the transport practices, some requirements of chapter III of annex I should also apply to fishes. For example, "certain categories of animals, such as wild animals, [should] become acclimatised to the mode of transport prior to the proposed journey". ${ }^{350}$ This could be interpreted in favour for the fishes, since they are usually not accustomed to close contact with humans. It is also stated that in case of longlasting loading, unloading operations over four hours, an authorised veterinarian should supervise these operations, and "particular precautions shall be taken to ensure that the welfare of the animals is properly maintained during these operations". ${ }^{351}$ In terms of loading and unloading facilities, they are to be built and used in such a way to "prevent injury and suffering and minimise excitement and distress during animal movement as well as to ensure the safety of the animals". ${ }^{352}$ Chapter III of annex I prohibits hitting the animals, including fishes, and handling them in such a way to inflict unnecessary pain or suffering on them, especially by putting pressure onto highly sensitive body parts. ${ }^{353}$ It should also apply to fishes that different fish species and individuals with significant variation in size and age are not allowed to be transported together. ${ }^{354}$

There are no further requirements on space allowances or for the conditions during the transport of live fishes. Only chapter V point 2.3. states that "[o]ther species [including fishes] shall be transported in accordance with the written instructions about feeding and watering and taking into account any special care required", ${ }^{355}$ but it is not further explained by whom these written instructions should be issued.

Additionally, it is also noteworthy that only articles 3 and 27 have to be complied with for "transport [s] carried out by farmers, of their own animals [including fishes], in their own means of transport for a distance of less than $50 \mathrm{~km}$ from their holding". ${ }^{356}$

\subsubsection{Council of Europe Recommendation concerning 'farmed' fishes}

The Council of Europe Recommendation contains only a few considerations on fish transport. Article 11 of the COE Recommendation requires that "the period during which fish[es] may be deprived of food prior to certain management procedures [including transport] (...) shall be kept as short as possible". ${ }^{357}$ Article 15 of the COE Recommendation lays down the requirements for the transport of fishes within a farm. Hereby, fishes are to be examined prior to their transport, whereas "unfit or unhealthy fish [es] shall not be transported, except for therapeutic reasons". ${ }^{358}$ In this context, article 19 states that if "treatment [of ill or injured fishes] is no longer feasible and transport would cause additional suffering, [then] they must be killed on the spot and without delay by a person properly trained and experienced (...)". ${ }^{359}$ Also, regular checks on the fishes are required by article 15, with special focus on the environmental conditions. Oxygen levels must be kept above the species-specific critical value, the level of carbon dioxide should be kept low, and "excessive changes in water temperature and $\mathrm{pH}$ [should be] avoided". ${ }^{360}$

\subsubsection{European Convention for the protection of animals during international transport}

The European Convention for the protection of animals during international transport applies to all vertebrates and thus also to fishes. ${ }^{361}$ It lays down the main principles, ${ }^{362}$ and, among others, provisions regarding the authorization of transporters, ${ }^{363}$ the design and construction of the transport vehicle, ${ }^{364}$ and on

\footnotetext{
348 Annex I chapter II section 1 point 1.1. letter (f) of Council Regulation (EC) No 1/2005.

${ }^{349}$ Annex I chapter II section 1 point 1.2. and section 5 of Council Regulation (EC) No 1/2005.

${ }^{350}$ Annex I chapter III section 1 point 1.1. of Council Regulation (EC) No 1/2005.

${ }^{351}$ Annex I chapter III section 1 point 1.2. letter (b) of Council Regulation (EC) No 1/2005.

${ }^{352}$ Annex I chapter III section 1 point 1.3. letter (a) of Council Regulation (EC) No 1/2005.

${ }^{353}$ Annex I chapter III section 1 point 1.8. letter (a) (b) and (d) of Council Regulation (EC) No 1/2005.

${ }^{354}$ Annex I chapter III section 1 point 1.12. letter (a) and (b) of Council Regulation (EC) No 1/2005.

${ }^{355}$ E.g. in chapter III section 2 of annex I, no provision can be applied to the fishes in a 'useful' way, in chapter V of annex I they are not considered at all.

${ }^{356}$ Article 1 point 2 letter (b) of Council Regulation (EC) No 1/2005.

${ }^{357}$ Article 11 of Council of Europe Recommendation concerning 'farmed' fish.

${ }^{358}$ Article 15 letter (a) of Council of Europe Recommendation concerning 'farmed' fish.

${ }^{359}$ Article 19 of Council of Europe Recommendation concerning 'farmed' fish.

${ }^{360}$ Article 15 letter (b) of Council of Europe Recommendation concerning 'farmed' fish.

${ }^{361}$ Article 2 point 1 of the European Convention for the protection of animals during international transport (revised).

${ }^{362}$ Article 4 of the European Convention for the protection of animals during international transport (revised).

${ }^{363}$ Article 5 of the European Convention for the protection of animals during international transport (revised).

${ }^{364}$ Article 6 of the European Convention for the protection of animals during international transport (revised).
} 
the transport phase itself, including preparation, planning and transport practices. ${ }^{365}$ This Convention does not apply to transports within the EU community territory,

\subsection{Critical assessment and possible recommendations for better protection of 'farmed' fishes during transport}

With Council Regulation (EC) No 1/2005, the EU has issued a comprehensive piece of secondary legislation on the protection of animals, containing numerous and complex rules. Regarding fishes, however, one tries unsuccessfully to find any specific provision therein. Noteworthily, the fishes are not even mentioned with one word - not in the preamble, nor in the regulation itself, nor in the annexes, despite the fact that fishes are supposed to be protected by this regulation as it covers all vertebrate animals. ${ }^{366}$ Only from their biological classification as vertebrates and the definition of 'animals' in article 2 does it become evident that the fishes are to be included in Regulation EC 1/2005. Due to the lack of precise requirements, only the basic and general principles are applicable for the transport of fishes, whereby "some (...) are neither appropriate nor necessarily properly implemented because they have been developed on the basis of approaches taken for terrestrial animals" ${ }^{\prime 67}$ This becomes obvious in article 3 of Regulation EC 1/2005, which lays down the general conditions for the transport of animals. Inter alia, it requires that "sufficient floor area and height is provided for the animals", ${ }^{368}$ and "water, feed and rest are offered to the animals at suitable intervals (...)". ${ }^{369}$ Both examples show the discrepancy between what the law demands and what would effectively protect the fishes during transport. Floor area and head space are irrelevant for the fishes since they need to be transported in water, whereas the density of fishes loaded within the water body and good water quality are much more important for them. ${ }^{370}$ As the example on feeding and watering shows, some provisions are even contradictory to their welfare as "feeding fish [es] prior to or during transport quickly leads to poor welfare and death of the transported animals, mainly because of changes in water quality in transport tanks". ${ }^{371}$ Consequently, the correct implementation and enforcement of this paragraph could very likely harm the fishes, causing them unnecessary suffering instead of protecting them. Regulation EC 1/2005 states that "transporters shall transport animals in accordance with the technical rules set out in Annex I", ${ }^{372}$ which contains more specific instructions on the transport conditions and practices. Regarding fish transport, however, annex I lacks any specification. ${ }^{373}$ On the contrary, confusing and imprecise wording can be found again. For example, animals (and thus including fishes) must be considered as unfit for transport if "they are unable to move independently without pain or to walk unassisted". ${ }^{374}$ Whereas the first part could be transferred to fishes - even though its practical application may appear difficult - with the second part of the provision it is not hard to see that this provision was meant for terrestrial animals. The same applies to chapter II of annex I, which requires, that the air quality inside all means of transport should be adequate for the relevant species on board. As stated by EFSA, "[l] ack of oxygen, which is seldom a problem during transport of land animals, is the greatest problem during the transport of fish [es] since disturbed fish [es] rapidly remove dissolved oxygen from the water within the transport containers". ${ }^{375}$ water quality (including oxygen concentration) would be the critical factor for fish transports instead of air quality. ${ }^{376}$

Fishes live in a completely different environment to land animals, and thus their needs during transport vary significantly. Regardless, the regulation does not take into account this important fact, nor does it give any specification on transport times or loading densities for fishes, despite EFSA's opinion that " $t$ ] he duration of transport, stocking densities and environmental conditions during process can result in deterioration in welfare, including the health, of the particular fish species". ${ }^{377}$ Regarding the transport times, recital 5 of the preamble of Regulation EC 1/2005 acknowledges that:

\footnotetext{
${ }^{365}$ Article 7-30 of the European Convention for the protection of animals during international transport (revised).

${ }^{366}$ Article 2 of Council Regulation EC 1/2005.

${ }^{367}$ EU Commission (2009a) Regulatory and legal constraints for European Aquaculture. Study report IP/B/PECH/NT/2008_176, p. 32.

368 Article 3 letter g of Council Regulation EC 1/2005.

369 Article 3 letter h of Council Regulation EC 1/2005.

${ }^{370}$ See section VI. 2.1 of this manuscript.

${ }^{371}$ EU Commission (2009a) Regulatory and legal constraints for European Aquaculture. Study report IP/B/PECH/NT/2008_176, cit.,

32 / See also section VI. 2.1 of this manuscript.

372 Article 6 point 3 of Council Regulation (EC) No 1/2005.

${ }^{373}$ See section VI. 2.3.1 of this manuscript.

${ }^{374}$ Annex I chapter I point 2 letter (a) of Council Regulation (EC) No 1/2005.

375 EFSA (2004b), cit., 14

${ }^{376}$ See section VI. 2.1 of this manuscript.

377 EFSA (2004a) Opinion of the Scientific Panel on Animal Health and Welfare on a request from the Commission related to the welfare of animals during transport. The EFSA Journal 44, 32.

96 Derecho Animal. Forum of Animal Law Studies, vol. 11/1
} 
"[f]or reasons of animal welfare the transport of animals over long journeys [i.e. more than 8 hours], including animals for slaughter, should be limited as far as possible."

Notwithstanding this, and as previously described, ${ }^{378}$ transports of fishes - including those for slaughter - can easily reach more than eight hours, in some cases even up to 30 hours. However, Regulation EC 1/2005 does not give any explanation on how such long transports should be organized in order to safeguard the welfare of the fishes during transport. On the contrary, it does not even require a proper planning of such long transports of fishes ${ }^{379}$ - which again could be understood as contradictory to recital 18 of Regulation EC 1/2005:

"Long journeys are likely to have more detrimental effects on the welfare of animals than short ones. Hence specific procedures should be designed to ensure better enforcement of the standards, in particular by increasing the traceability of such transport operations."

By implication the question arises of how this recital is considered for fish transports when the fishes are excluded from so many provisions, ${ }^{380}$ and effectively only the general rules of article 3 apply to them.

As all of these examples demonstrate, the EU legislator failed to respect the fishes and their specific welfare requirements during transport when adopting Regulation EC 1/2005. However, at the very beginning of its preamble, the first paragraph reads:

"The Protocol on protection and welfare of animals annexed to the Treaty requires that in formulating and implementing agriculture and transport policies, the Community and the Member States are to pay full regard to the welfare requirements of animals."

Herewith, the duty of the European Union and its members towards animals to fully take into account their welfare as a serious concern when balancing different interests and deciding on EU policies is clearly reaffirmed. ${ }^{381}$ Since the fishes are included by definition in Regulation EC 1/2005, this guiding principle should apply to them too. But, as described above, it did not find its way into the legislative text.

Regarding the training of personnel handling and transporting fishes, the final report on the welfare of 'farmed' fishes during transport and slaughter published by the EU Commission in 2017 indicates that only staff trained on fish welfare are employed in the assessed Member States. ${ }^{382}$ However, the content and scope of the training is not further specified. In this context, another enforcement problem of Regulation EC 1/2005 was drawn up in a study of the European Parliament on "Regulatory and Legal Constraints for European Aquaculture" from 2009, namely that "some training courses on animal welfare, as required for drivers, do not address the specific needs of the transport of fish [es]". ${ }^{383}$ According to article 6 point 4 of Regulation EC $1 / 2005$, the personnel responsible for the animals only need to be trained on the relevant aspects of annex I and II of the transport regulation. Since the fishes and their specific needs are not explicitly represented in annex I, and annex II does not apply to fish transports at all, the wording of article 6 point 4 could be understood that no specific training on fish welfare is required. But this would obviously not fulfil the aim of recital 1 , as well as of recital 14 , which reads:

\footnotetext{
${ }^{378}$ See section VI. 2.1 of this manuscript.

${ }^{379}$ According to article 5 point 4 of Council Regulation (EC) No $1 / 2005$, no journey log is required for long distance transports of fishes.

${ }^{380}$ E.g. no journey log and planning are required (article 5 point 4), and no official check is required prior to long journeys (article 14).

${ }^{381}$ Even though article 13 of the Treaty on the Functioning of the European Union has only entered into force on 1 December 2009 , its foundation was already laid down in 1992 with the 'Declaration on the protection of animals' in the Treaty of Maastricht. The next and very important step was made in 1997 with the 'Protocol on protection and welfare of animals' annexed to the Treaty of Amsterdam. With this protocol animal protection became a legal obligation for the EU and its members, and remarkably, therein animals have been recognised as sentient beings for the first time in EU legislation. Recital 1 of the Regulation EC 1/2005 refers to this protocol as article 13 TFEU has not been enacted in 2004. Accordingly, since 2009 recital 1 must be understood in the light of the legally binding article 13 TFEU in which the Union and its members not only have to pay full regard to animal welfare in agricultural and transport policies, but also in fishery policies. See: Treaty of Maastricht 1992 (92/C 191/01); Treaty of Amsterdam 1997; Lisbon Treaty 2009 - Treaty on the Functioning of the European Union.

${ }^{382}$ EU Commission (2017c) Welfare of farmed fish: Common practices during transport and at slaughter. Final report, 86-111. The following countries were assessed hereby: Ireland, United Kingdom, Spain, France, Italy, Greece, Denmark, Germany, Poland, Czech Republic (and Norway as non-EU country).

${ }^{383}$ EU Commission (2009a) Regulatory and legal constraints for European Aquaculture. Study report IP/B/PECH/NT/2008 176, cit. 33.
} 
"Poor welfare is often to lack of education. Therefore, training should be a prerequisite for any person handling animals during transport and training should be provided only by organisations approved by the competent authorities." 384

Since the fishes are included in Regulation EC 1/2005, specific obligatory training courses are to be offered EU-wide for those people involved in their handling and transport. The competent authorities of each Member State also have to ensure their proper implementation and enforcement. This statement is also supported by paragraph 10 of the preamble, in which the reason is given for changing the former EU directive on the protection of animals during transport ${ }^{385}$ into Regulation EC 1/2005:

"In the light of experience gained under Directive 91/628/EEC in harmonising Community legislation on the transport of animals, and the difficulties encountered due to the differences in transportation of that Directive at national level, it is more appropriate to set out Community rules in this field in a regulation." 386

A uniform application and enforcement of Regulation EC 1/2005 throughout the EU is known to be a big problem in other sectors of live animal transport, ${ }^{387}$ and it is to be expected also in the case of fish transports. Even an EU Commission study ${ }^{388}$ of 2011 concluded that regarding fish transports, "Regulation (EC) 1/2005 is still not fully implemented in all MS". ${ }^{389}$ Not only the great variety of fish species farmed and hence transported in aquaculture, but also the different transport methods and scales of businesses, combined with different 'motivation levels' of the responsible persons, can easily lead to different understanding of EU law - especially given that only a few, very basic rules exist on the protection of fishes during transport. This leaves a lot of room for interpretation and in turn hampers the harmonization of animal protection throughout the EU.

The recommendations of the OIE Aquatic Code on the welfare of 'farmed' fishes during transport could serve as a template. Unlike EU legislation, the OIE Code contains numerous comprehensive provisions. ${ }^{390}$ Admittedly, they are kept on a general basis, but at least they are relevant for aquatic animals and could be understood as guiding principles for further implementation of more specific legislation. Considering that those recommendations were adopted by the OIE members only in 2008, i.e. one year after the entry into force of Regulation EC 1/20005, all EU Members States (and thus the EU) committed themselves to comply with those standards as they are all OIE members. However, up to the present day there has been no move to transpose these soft law recommendations into legally binding EU law.

Paragraph 6 of the preamble of Regulation EC 1/2005 states that already in 2001:

"[t]he Council invited the Commission (...) to submit proposals for ensuring effective implementation and strict enforcement of existing Community legislation, improving the protection and welfare of animals as well as preventing the occurrence and spread of infectious animal diseases, and putting in place more stringent requirements so as to prevent pain and suffering in order to safeguard the welfare and health of animals during and after transport."

With regard to the fishes these requirements did not find their way into the legal wording of the 'new' transport regulation. Even though it can be assumed that the Council did not have in mind the fishes when addressing the EU Commission, this statement in recital 6 underlines the need for a thorough and reviewed legislation for all animals, including the fishes, in 2001 - and still today.

\section{Slaughter of 'farmed' fishes}

\subsection{Specific animal welfare concerns and scientific opinion}

\footnotetext{
${ }^{384}$ Recital 14 of Council Regulation (EC) No 1/2005.

${ }^{385}$ Directive 91/628/EEC.

${ }^{386}$ It is noteworthy that in comparison with Directive 91/628/EEC no big improvements have been made in Regulation EC 1/2005 regarding the protection status of the fishes during transport. That is to say that the fishes were already included as vertebrates in the former Directive (entered into force in 1993), obviously without any specific provisions for them. See: Council Directive 91/628/EEC of 19 November 1991 on the protection of animals during transport (end of validity: 04 January 2007).

${ }^{387}$ E.g.: Animals' Angels (2016) The Myth of Enforcement of Regulation (EC) No 1/2005 on the protection of animals during transport, Animals' Angels Press, Frankfurt a. M. p. 58 - 115.

388 See: EU Commission (2011) Study on the impact of Regulation (EC) No 1/2005 on the protection of animals during transport. Draft Final Report. SANCO/2010/D5/S12.574298.

${ }^{389}$ Ibid. 98 / E.g. in 2010 among 16 MS that only responded to the study's questionnaire, 7 MS had still not implemented rules on fish transport - after five years of Regulation EC 1/2005 being introduced, respectively after three years being in force.

${ }^{390}$ See VI. 2.2 of this manuscript.

98 Derecho Animal. Forum of Animal Law Studies, vol. 11/1
} 
When it comes to the act of slaughter, 'farmed' fishes "are subjected to a unique period of frequent and intense handling operations", 391 in which their welfare "is easily compromised by poor choice of handling and slaughter methods, lack of attention to detail and by unnecessary adherence to fish farming traditions", 392 keeping in mind "that actually killing the animal is the greatest insult to its welfare". ${ }^{393}$ Fishes are now considered as sentient beings with the capacity to feel pain and experience suffering, and during the last decades reasonable research has been conducted in the EU in terms of fish welfare during slaughter. However, Lines and Spence (2012) attest that "there is little evidence of improvement in slaughter methods on the majority of fish farms around the world". 394

\title{
3.1.1. Pre-slaughter operations
}

In the EU, the fishes must commonly go through a serious of stressful operations ${ }^{395}$ before their actual killing, including fasting periods, crowding, removal and handling procedures, as well as the transport to the slaughter or processing facilities.

\begin{abstract}
Fasting
Prior to slaughter, 'farmed' fishes are routinely deprived of food for several days. The aim is to empty their intestines to avoid faecal contamination in the subsequent processing of the dead fishes, with regard to food security and quality. ${ }^{396}$ In addition, due to food withdrawal the fishes decrease their metabolic activity and thus produce less ammonia and carbon dioxide which would be released in the water. ${ }^{397}$ Especially in the subsequent pre-slaughter operations such as crowding, the water quality can deteriorate significantly due to high density of fishes, who consume more oxygen than dissolved in the limited water column but at the same time excrete ammonia and carbon dioxide. This can lead to possible toxicity effects for the fishes. ${ }^{398}$

Due to the great diversity of the group of 'fish', the duration for emptying the gut differs between the species and also depends on the water temperature ${ }^{399}$ For example, salmons clear their guts completely within 72 hours according to scientific opinion, thus they should not be deprived of food longer than this time. ${ }^{400}$ However, it is reported for 'marketable' Atlantic salmon (i.e. salmon 'for slaughter') that they are even starved up to 14 days (336 hours). ${ }^{401}$ Seabreams and seabasses are usually deprived of food between 24 and 72 hours in commercial practice, but the starvation period "can be extended up to seven days [168 hours] according to the harvesting period". ${ }^{402}$ Common carps are often deprived of food between five to seven days (120 - 168 hours). ${ }^{403}$ In the wild fishes experience periods where food is scare or absent, but they have the choice to move and search for other food options - 'farmed' fishes do not. They are confined and strictly dependent on human provision of food. Particularly, considering that 'farmed' fishes are kept for fattening purposes, they are usually not used to food withdrawal, ${ }^{404}$ but on the contrary conditioned to being fed on a regular basis. As noted by Lines and Spence (2012), "the motivation to eat is clearly strong and as necessary to fish as to any other animal" and "excessive periods of fasting clearly infringe the principles of the five freedoms of animal welfare". ${ }^{405}$ From a scientific point of view, it is recommended to restrict the fasting period only to the time necessary to
\end{abstract}

\footnotetext{
${ }^{391}$ LINES, J.A., SPENCE, J., Safeguarding the welfare of farmed fish at harvest, cit., 163.

392 Ibid.

${ }^{393}$ ROBB, D.H.F., Welfare of Fish at Harvest, cit., 217.

${ }^{394}$ LINES, J.A., SPENCE, J., Humane harvesting and slaughter of farmed fish. Scientific and Technical Review of the Office International des Epizooties 33/1 (2014) 255-264

255.

${ }^{395}$ In aquaculture terminology also referred as "pre-harvest preparations", e.g. ROBB, D.H.F., Welfare of Fish at Harvest, cit.

396 LINES, J.A., SPENCE, J., Safeguarding the welfare of farmed fish at harvest, cit., 165.

${ }^{397}$ Ibid.

${ }^{398}$ EFSA (2009d), cit., 10. See also section VI. 2.1 of this manuscript.

399 Fishes (except tuna) are poikilothermic animals, i.e. they adapt their body temperature to their surrounding environment, respectively to the water temperature. Accordingly, the water temperature influences their metabolic rate, which in turn affects gut clearance, e.g. at lower temperatures it takes a longer time to empty the gut due to reduced metabolic rate.

${ }^{400}$ E.g. EFSA (2009c), cit.; ROBB, D.H.F., Welfare of Fish at Harvest.; LINES, J.A., SPENCE, J., Safeguarding the welfare of farmed fish at harvest, cit.

${ }^{401}$ Reported for salmon 'for slaughter' in Ireland. See: EU Commission (2017c) Welfare of farmed fish: Common practices during transport and at slaughter. Final report, 98.

402 EFSA (2009d), cit.

${ }^{403}$ EU Commission (2017c) Welfare of farmed fish: Common practices during transport and at slaughter. Final report.

${ }^{404}$ EFSA (2009d), cit.; LINES, J.A., SPENCE, J., Safeguarding the welfare of farmed fish at harvest, cit.

${ }^{405}$ LINES, J.A., SPENCE, J., Safeguarding the welfare of farmed fish at harvest, cit., 166.
} 
empty the gut of the relevant species. Regardless, "in commercial practice, a range of food withdrawal periods are to be found, often far longer than is necessary to simply empty the gut", ${ }^{406}$ for example for practical and technical reasons in large scale aquaculture systems, where catching and slaughter operations take a longer time due to the greater number of fishes involved. ${ }^{407}$

\section{Crowding}

Crowding describes the pre-slaughter practice of concentrating the fishes in the cages where they have been reared in order to increase the density of fishes for easier catching and removal to the subsequent slaughter operations. Depending on the farming method, the fishes are either crowded by lifting the cage net or by using additional nets to drive them into a certain section. As clearly stated by EFSA, crowding is a stressful procedure causing stress responses in fishes whereby "it is well known by those in the industry that when fish [es] are crowded too densely and too rapidly, they show escape behaviour, splashing and gasping". ${ }^{408}$ As physiological stress responses, increased levels of plasma cortisol, glucose, and lactate have been reported in different fish species as a consequence of crowding events. ${ }^{409}$ According to Lines and Spence (2012) effects on the physiology of the fishes can last for days after such crowding ${ }^{410}$ which shows the high impact of this procedure on the fishes. ${ }^{411}$ Even though most of these 'slaughter' fishes will obviously not survive the next days due to subsequent slaughter after crowding and capture, EFSA (2009d) mentioned that "in intensive flow-through tanks and cage systems, fish capture may take several days or even weeks", ${ }^{412}$ consequently exposing those fishes to a very prolonged period of stress. Beside increased stress due to high densities and duration, "the most common problem associated with crowding is shortage of oxygen" ${ }^{413}$ Not only are the fishes confined in a restricted amount of water, but they are also more active and stressed during crowding, which leads to a higher and quicker consumption of the dissolved oxygen in the water. Additionally, "the concentration of ammonia and other waste products also increase as less water is available per fish biomass". ${ }^{414}$

As already mentioned, different fish species respond in different intensities to the different crowding methods. For example, 'farmed' Atlantic bluefin tunas are very sensible to intense, rapid crowding. They easily panic and show strong attempts to escape, which can lead to poor welfare. Tunas are the only endothermic fish species and thus "due to their ability to conserve metabolic heat produced by the muscles, their body temperature can increase tremendously during struggling", ${ }^{415}$ meaning they can easily suffer from hyperthermia and exhaustion. Cods, for example, are at risk of swim bladder inflation if they are crowded too fast for adapting adequately to the pressure changes between the deeper water and the surface. ${ }^{416}$ Salmons and benthic species like halibuts avoid excessive sunlight but during crowding they are exposed to it when lifted to the surface. The fishes try to escape which increases their level of stress. ${ }^{417}$ As the different examples show, it is highly recommended that crowding, if not avoidable, is always conducted in a species-specific way in order to minimise the harm caused to the fishes involved.

In general, during and after crowding procedures, "fish[es] must be observed for signs of abnormal behaviour, such as moribundness, leaping out of the water, signs of asphyxia or inversion". ${ }^{418}$

\section{$\underline{\text { Removal }}$}

Another pre-slaughter operation is the removal of fishes in order to dislocate them for further procedures. Most commonly it is done by pumping systems or with nets.

\footnotetext{
406 Ibid. 165

${ }^{407}$ WAAGBO, R., JORGENSEN, S.M., TIMMERHAUS, G. BRECK, O., OLSVIK, P.A., Short-term starvation at low temperature prior to harvest does not impact the health and accurate stress response of adult Atlantic salmon. PeerJ 5 (2017) e3273.

${ }^{408}$ EFSA (2009d), cit., 13.

${ }^{409}$ Ibid.

${ }^{410}$ LINES, J.A., SPENCE, J., Safeguarding the welfare of farmed fish at harvest, cit., 166.

${ }^{411}$ Even though most of these 'slaughter' fishes will not survive the next days due to subsequent slaughter after crowding.

${ }^{412}$ EFSA (2009d), cit.

${ }^{413}$ LINES, J.A., SPENCE, J., Safeguarding the welfare of farmed fish at harvest, cit., 166.

${ }^{414}$ EFSA (2009d), cit., 13.

${ }^{415}$ EFSA (2009e) Scientific Opinion of the Panel on Animal Health and Welfare on a request from the European Commission on Species-specific welfare aspects of the main systems of stunning and killing of farmed tuna. The EFSA Journal 1072, 8.

${ }^{416}$ LINES, J.A., SPENCE, J., Safeguarding the welfare of farmed fish at harvest, cit., 166.

${ }^{417}$ ROBB, D.H.F., Welfare of Fish at Harvest, cit., 9; LINES, J.A., SPENCE, J., Safeguarding the welfare of farmed fish at harvest, cit., 166.

418 Ibid.
} 
In small-scale and extensive farms, often hand nets are used, whereas mechanical brailing ${ }^{419}$ is common in intensive farming systems. Some brail nets can keep a certain amount of water, called wet brailing, whereas in dry brails the fishes are removed without water. Even though the risk of injuries is lower in wet brailing, by hoisting the fishes with any type of net out of the water, "there are particular dangers to the fish [es] of bruising, crushing, puncture and abrasion injuries from contact with other fish [es], contact with the net and contact through the net with other hard surfaces". ${ }^{420}$ Frequently the brail nets are overloaded, with very high densities of fishes inside the nets, thus increasing the adverse effects such as abrasions, crush injuries, or other damages, due to exceeded weight put on the single fishes. Releasing the fishes from a brail net often means that the brail end is opened, so that the fishes are simply dropped on the hard ground, onto each other, or into water from a high altitude causing further welfare problems. ${ }^{421}$ Removing the fishes from the water to the air, as done in dry brailing for example, causes hypoxia and thus suffering to the fishes. According to EFSA's opinion, "it has been suggested that fish [es] should not be held out of water for longer than 10s as after that they will show aversive behaviour to the lack of oxygen", ${ }^{422}$ particularly in the case of trout, seabream and seabass. However, dry brailing is commonly used for operational and traditional convenience, as stated by Lines et al (2012).

Fish pumping is another method to remove fishes from the crowding unit to the point of slaughter and is mainly used in intensive farming systems. Different types of pumping systems exist, for example air lift, venturi and vacuum pumps. Air lift pumping runs with a compressor that blows compressed air into an underwater pipe connected to the area where the fishes are crowded. The emerging air lift draws water inside with the fishes at the same time. Venturi pumping requires large volumes of water that are pumped at high speed through a pipe sucking up the fishes via a second pipe from the crowding area. The third system is vacuum pumping, where strong suction is created by a vacuum chamber drawing the water and the fishes through the pipe. ${ }^{423}$ Vacuum pumps cannot generate an even, continuous water flow and thus the fishes struggle with the turbulent flow inside the pipe, which leads to exhaustion and an increasing risk of oxygen depletion. ${ }^{424}$ Due to inadequate pumping equipment and wrong construction, like sharp bends, the fishes can be trapped within the pipe system, collide at high speed with pipe walls, and/or can suffer from injuries, such as excessive scale loss. ${ }^{425}$ It is therefore recommended to check the fishes for recent injuries after pumping, to keep the pumping distances as short as possible, and to regularly check and maintain the pumping systems. ${ }^{426}$ Nevertheless, in some systems the fishes are pumped over one kilometre ${ }^{427}$ and stay inside the system for more than ten minutes. ${ }^{428}$ According to EFSA (2009a), rainbow trout for example are likely to be exposed to poor welfare during pumping procedures, which should be avoided.

\subsubsection{Stunning and killing methods}

EFSA stated in its 2004 Scientific Opinion on the welfare aspects of the main systems of stunning and killing the main commercial species of animals that "for many [fish] species, there is not a commercially acceptable method that can kill fish [es] humanely". ${ }^{429}$. Fishes are commercially killed in many ways, some of which may include prior stunning, some may not, but only "few of [these methods] would be considered acceptable for other vertebrates". 430

\section{Asphyxiation in air or ice}

Most fishes killed for human consumption, including 'farmed' fishes, are killed without prior stunning.

\footnotetext{
${ }^{419}$ A brail is a metal hoop (ca. $1 \mathrm{~m}$ in diameter) with a net tube hanging down from this hoop and with a free end attached to a rope which allows this end to be opened or closed. The brail net is mechanised, suspended from a small crane, which is used to drag the net through the crowded fishes, catching them. See definition: Robb, no. 348 above.

${ }^{420}$ LINES, J.A., SPENCE, J., Safeguarding the welfare of farmed fish at harvest, cit., 166.

${ }^{421}$ Ibid.; ROBB, D.H.F., Welfare of Fish at Harvest, cit., $226-227$.

${ }^{422}$ EFSA (2009d), cit., 14; EFSA (2009a) Scientific Opinion of the Panel on Animal Health and Welfare on a request from the European Commission on Species-specific welfare aspects of the main systems of stunning and killing of farmed rainbow trout. The EFSA Journal 1013, 11.

${ }^{423}$ EFSA (2009d), cit., 14; ROBB, D.H.F., Welfare of Fish at Harvest, cit., 226 - 228.

${ }^{424}$ Ibid.

${ }^{425}$ EFSA (2009a), no. 491 above, p. 11.

${ }^{426}$ EFSA (2009d), no. 351 above, p. 14.

${ }^{427}$ LINES, J.A., SPENCE, J., Safeguarding the welfare of farmed fish at harvest, cit., 164.

${ }^{428}$ ROBB, D.H.F., Welfare of Fish at Harvest, cit., 228.

${ }^{429}$ EFSA (2004a), cit., 23.

${ }^{430}$ LINES, J.A., SPENCE, J., Humane harvesting and slaughter of farmed fish, cit., 258.
} 
They are simply removed from the water and left to die by asphyxiation either in air or ice slurry. As clearly stated by EFSA, "exposure to air should be reduced to the minimum possible time and research employed to develop pre-slaughter and slaughter methods that avoid air exposure". ${ }^{431}$

Regardless, this method is widely used in the EU, for example for rainbow trout, seabream and seabass, as asphyxiation is very efficient in terms of efforts and costs. Asphyxiation on ice, live chilling, is also 'process-convenient' because the fishes are cooled and preserved in the ice at the same time. It has been shown that killing in ice slurry takes 14 minutes for rainbow trout, ${ }^{432}$ around 30 minutes for seabreams and seabasses, ${ }^{433}$ and for common carps up to 50 minutes. ${ }^{434}$ In the case of asphyxiation in air, it has been reported that seabasses suffocate in air up to two hours before they are finally dead, ${ }^{435}$ and for common carps it has been found that some individuals "left to asphyxiate in air took almost five hours to cease opercula (gill cover) movements". ${ }^{436}$

Live chilling is often described as a stunning method in which the fishes are placed from water into either solid ice or ice water slurry of $0-2^{\circ} \mathrm{C}$. Due to the extreme difference in temperature of at least $10^{\circ} \mathrm{C}$, the fishes experience a thermal shock. As poikilothermic animals (except tuna), fishes become almost paralysed by the sudden cold shock due to the rapid reduction of their body temperature which in turn reduces their metabolic rate significantly. ${ }^{437}$ As Lines and Spence (2014) suggest, the ability of fishes to show physical reactions may decrease quickly after the ice bath, but "brain activity indicates the potential for the continuation of consciousness for a substantial period", ${ }^{438}$ indicating that they continue to feel pain and suffering for a certain period of time without being able to demonstrate or show these negative feelings. According to EFSA (2009d), ice water slurries can lead to the death of Mediterranean fish species like seabream and seabass since they are normally used to live in much higher temperatures above $12^{\circ} \mathrm{C}$, but at the same time EFSA attests that "killing in ice does not result in immediate unconsciousness". ${ }^{439}$ Experiments with common carps, cods, Atlantic salmons, and other species showed stress responses to cold shocks, as reviewed by EFSA (2009). Also, seabass and seabream individuals show obvious struggling and active swimming when immersed in ice baths until they reach the point of immobilisation after several minutes. ${ }^{440}$ According to EFSA (2009f), "live chilling is an immobilisation method and not a stunning method since it does not induce unconsciousness". ${ }^{441}$

\section{Exsanguination or decapitation without prior stunning}

In some 'farmed' fish species, it is common practice to slaughter them by exsanguination or decapitation without prior stunning. The fishes are at full consciousness while they are killed. For example, often flat fish species like turbot are killed by cutting their gill arches followed by exsanguination. After cutting the fishes are left more than two hours, often in ice water slurry to let them bleed completely. Depending on the temperature, 60-90 minutes after the cut, responses in behaviour and even escape behaviour have been reported. ${ }^{442}$ Accordingly, EFSA (2009f) states that "existing methods of killing turbot, i.e. exsanguination and asphyxia on ice, involve prolonged periods of consciousness during which stress responses have been observed". ${ }^{443}$

As a slaughter method used in the retail sector, eels are killed, inter alia, by decapitation causing death by anoxia due to blood loss. It has been shown experimentally that in some beheaded eels their brain continues to function up to 13 minutes after decapitation. ${ }^{444}$ According to EFSA's opinion (2009g), this

\footnotetext{
${ }^{431}$ EFSA (2009d), cit., 32 /see also: EFSA (2009a), cit., 30.

${ }^{432} \mathrm{At}$ a temperature of $2{ }^{\circ} \mathrm{C}$ inside the ice slurry. See: ASHLEY, P.J., Fish welfare: Current issues in aquaculture, cit., 210.

${ }^{433}$ Time for killing for seabream between $\sim 20-35 \mathrm{~min}$, for seabass $23-34 \mathrm{~min}$, depending on season and temperature. See: EFSA (2009d), cit., 18.

${ }^{434}$ At a temperature of $0.6-1.8^{\circ} \mathrm{C}$ inside the ice slurry. See: LINES, J.A., SPENCE, J., Humane harvesting and slaughter of farmed fish, cit., 258

${ }^{435}$ EFSA (2009d), cit., 15.

${ }^{436}$ LINES, J.A., SPENCE, J., Humane harvesting and slaughter of farmed fish, cit., 258; also confirmed by: EFSA (2009b) Scientific of the Panel on Animal Health and Welfare on a request from the European Commission on Species-specific welfare aspects of the main systems of stunning and killing of farmed carp. The EFSA Journal 1013. p. 9.

${ }^{437}$ ROBB, D.H.F., Welfare of Fish at Harvest, cit., 233; LINES, J.A., SPENCE, J., Humane harvesting and slaughter of farmed fish, cit., 258.

${ }^{438}$ LINES, J.A., SPENCE, J., Humane harvesting and slaughter of farmed fish, cit., 258.

${ }^{439}$ EFSA (2009d), cit., 17.

${ }^{440}$ Ibid.; LINES, J.A., SPENCE, J., Humane harvesting and slaughter of farmed fish, cit., 258.

${ }^{441}$ EFSA (2009f) Scientific Opinion of the Panel on Animal Health and Welfare on a request from the European Commission on welfare aspect of the main systems of stunning and killing of farmed turbot. The EFSA Journal 1073, 20.

442 Ibid. 13.

${ }^{443}$ Ibid. 20.

444 VAN DE VIS, H., KESTIN, S., ROBB, D., OEHLENSCHLÄGER, J., LAMBOOIJ, B., MÜNKNER, W. KUHLMANN, H., 102 Derecho Animal. Forum of Animal Law Studies, vol. 11/1
} 


\section{"would appear to expose eels to considerable periods of suffering". ${ }^{445}$}

\section{Percussive stunning}

Percussive stunning is a method used to cause cerebral concussion and thus loss of consciousness by inducing a blow to the head of the animal. ${ }^{446}$ To result in immediate unconsciousness and insensibility, the blow must be rapid and strong enough as well as correctly located on the head. ${ }^{447}$

In the EU, percussive stunning is conducted either by automated equipment or manually. Both performances contain risks for poor welfare. In cases of manually stunning, the effectiveness of stunning depends very much on the operator and its abilities to conduct the blow. Additionally, manual stunning can lead to asphyxia for the fishes who are exposed to air during the handling procedure before stunning. ${ }^{448}$ According to EFSA, this is "the hazard causing the highest risk for poor welfare" ${ }^{449}$ in manual stunning. In automated percussive stunning systems, the main problem is due to the different sizes between individual fishes "causing a mis-stun in some fish, e.g. hitting [only] the snout on larger fish" ${ }^{450}$ instead of hitting the exact stunning location on the head.

The method of automated percussive stunning is used, inter alia, for salmons, whereas common carps are often manually percussive stunned. ${ }^{451}$ For common carps and other species like catfish, pangasius, and tilapia, it has been found that they show higher resistance to percussive stunning due to the shape of the head and the well-protected skull, which increases the risk of mis-stunning. ${ }^{452}$

After percussive stunning, it is recommended to control its effectiveness by checking the fishes for signs of consciousness, like rhythmic motion of the opercula, eye-roll-reflex, struggling, or other physical activities. ${ }^{453}$

\section{Carbon dioxide narcosis}

Carbon dioxide narcosis is a method that has been developed in commercial slaughter of 'farm' animals, including fishes (mainly Atlantic salmon and rainbow trout), with the advantage to industry in being able to stun a relatively big number of animals within a short period of time and with low labour and economic efforts.

In aquaculture, $\mathrm{CO}_{2}$-stunning is conducted by placing the fishes into water infused with carbon dioxide, creating an acidic mixture and causing a narcotic effect on the fishes. According to EFSA's Scientific Opinion (2009c), carbon dioxide is one of the stunning methods responsible for the poorest welfare, since "not only was it judged that exposure to the gas causes a strong adverse reaction [of the fishes] but it does not reliably result in unconsciousness". ${ }^{454}$ Firstly, fishes of different species show highly adverse swimming and escape behaviour directly after being exposed to $\mathrm{CO}_{2}$ enriched water, thus indicating high distress for them. ${ }^{455}$ Secondly, the fishes are not immediately unconscious but only narcotised by $\mathrm{CO}_{2}$. Often, they are falsely considered unconscious, while indeed only being immobilised due to the $\mathrm{CO}_{2}$ narcosis. In practice, they can still be conscious while being bled or eviscerated. ${ }^{456}$

Following EFSA (2009a), carbon dioxide “(...) should generally not be used for any species as alternative methods are available". ${ }^{457}$ In the EU, carbon dioxide narcosis is still commercially used as stunning method for salmons and rainbow trout. ${ }^{458}$

KLOOSTERBOER, K., TEJADA, M., HUIDOBRO, A., OTTERA, H., ROTH, B., SORENSEN, N.K., AKSE, L., BYRNE, H. \& NESVADBA, P., Is humane slaughter of fish possible for industry? Aquaculture Research 34 (2003) 215.

${ }^{445}$ EFSA (2009g) Scientific Opinion of the Panel on Animal Health and Welfare on a request from the European Commission on welfare aspect of the main systems of stunning and killing of farmed eel (Anguilla anguilla). The EFSA Journal $1014,15$.

${ }^{446}$ According to EFSA, "a cerebral concussion is generally agreed to be a traumatically induced derangement of the nervous system, resulting in an instantaneous diminution or loss of consciousness without gross anatomical changes in the brain". See: EFSA (2009g, no. 514 above, p. 10.

${ }^{447}$ EFSA (2004b), cit., 162; EFSA (2009a), cit., 14

${ }^{448}$ E.g. EFSA (2009b), cit., 20-21; EFSA (2009c), cit., 2.

${ }^{449}$ EFSA (2009c), cit., 2.

${ }^{450}$ Ibid.

${ }^{451}$ Ibid. 21; EFSA (2009b), cit., 20 - 21; LINES, J.A., SPENCE, J., Safeguarding the welfare of farmed fish at harvest, cit., 164-165.

${ }^{452}$ LINES, J.A., SPENCE, J., Safeguarding the welfare of farmed fish at harvest, cit., 167.

${ }^{453}$ LINES, J.A., SPENCE, J., Safeguarding the welfare of farmed fish at harvest, cit., 259.

${ }^{454}$ EFSA (2009c), cit., 3.

455 Ibid.; EFSA (2009a), cit., 3; EFSA (2009d), cit., 2.

${ }^{456}$ EFSA (2009c), cit., 3; EFSA (2009a), cit., 3.

${ }^{457}$ EFSA (2009a), cit., 30.

458 E.g. EU Commission (2018) Report from the Commission to the European Parliament and the Council on the possibility of introducing certain requirements regarding the protection of fish at the time of killing, p. 4; EFSA (2009c), cit., 20 / EFSA (2009a), cit., 16 - 17; ROBB, D.H.F., Welfare of Fish at Harvest, cit., 15 / LINES, J.A., SPENCE, J., Humane harvesting and slaughter of 


\section{Electrical stunning}

Another stunning method is the use of electricity. Depending on the correct application for each species, electrical stunning can cause immediate unconsciousness and insensibility. Electrical parameters such as voltage or electrical current need to be adapted species-specifically in order to effectively disrupt normal neural activity. ${ }^{459}$ If not applied correctly, fishes may only be paralysed by electrical stunning but continue to be conscious while being killed.

Either wet or dry electrical stunning systems are used in commercial practice. Wet stunning allows the fishes not to be exposed to air, and thus causes less stress for them. ${ }^{460}$ Hereby it is essential that the electric field in the water is homogeneous and in accordance with water conductivity as well as suitable for the fish species and number of individuals. Beside the additional stress factor of exposing the fishes to air, "the most common difficulty with dry stunning is to ensure that the fish [es] are not exposed to pre-stun shocks causes, for example, by entering the machine tail first or because spasms of the fish cause it to lose contact with the electrodes". ${ }^{461}$ Therefore, it is essential to ensure the adequate orientation of each fish entering the electrical field, with the head first in order to avoid that they "first will consciously feel the electricity for a few seconds before reaching the head", ${ }^{462}$ causing additional pain to them. To avoid the fishes returning to consciousness again, the electrical stunning needs to be long-lasting which, again, has to be defined species-specifically. ${ }^{463}$

Currently, electrical stunning within the EU is commercially used, for example, for Atlantic salmon, rainbow trout and common carp fishes. ${ }^{464}$

\section{Other killing methods}

In aquaculture practice, several species-related killing methods have been developed for 'farmed' fishes, like tunas or eels.

In the case of 'farmed' tunas, there are three slaughter practices in the EU which depend mainly on the size $^{465}$ of the fishes and the market destination of the 'end product': underwater shooting, also called lupara, surface shooting, and spiking or coring. ${ }^{466}$

Lupara, the shooting on the fish's head underwater, is the most common method in the EU to kill large tunas $(70-80 \%)$. If it is done correctly, this method is considered to cause less suffering to the animal compared to other methods, as the brain is destroyed immediately, and the fish is not handled in air beforehand. According to EFSA, "the only hazard is a missed shot that may (...) hit the head but not the brain", 467 obviously causing pain and suffering to the injured fish. As further stated, "lupara misshots are not uncommon (1-5\%)"468 on EU tuna farms.

The second method, surface shooting with a shotgun, is used for $20-30 \%$ of the large tunas in European aquaculture. According to EFSA (2009e), it takes approximately 10-15 minutes until a group of 30-70 tunas is killed by shooting them on the head from outside the water. To get the tunas close to the surface, they are crowded in a kind of slaughtering cage or seine net, which causes extreme stress for the fishes. Additionally, due to the shot tuna blood is released into the water, which leads to more stress and escape behaviour in the remaining individuals. ${ }^{469}$ As stated by EFSA (2009e), the fishes are also exposed to a high rate of mis-shots. ${ }^{470}$

The third killing method is called spiking or coring and used for small tuna of less than $50 \mathrm{~kg}$. They are killed by driving a spike into their head and thus destroying the brain. This leads to loss of consciousness within one minute if applied precisely. However, the fishes are exposed to severe pain and distress, as

farmed fish, cit., 259.

${ }^{459}$ LINES, J.A., SPENCE, J., Humane harvesting and slaughter of farmed fish, cit., 259.

${ }^{460}$ ASHLEY, P.J., Fish welfare: Current issues in aquaculture, cit., 260.

${ }^{461}$ EFSA (2009c), cit., 22.

462 Ibid. 37

${ }^{463}$ LINES, J.A., SPENCE, J., Safeguarding the welfare of farmed fish at harvest, cit., 168.

${ }^{464}$ EU Commission (2018) Report from the Commission to the European Parliament and the Council on the possibility of introducing certain requirements regarding the protection of fish at the time of killing, 4.

${ }^{465}$ EFSA classified tunas into two size groups, namely large tuna of more than $50 \mathrm{~kg}$ and small tuna under $50 \mathrm{~kg}$. See EFSA (2009e), cit., 10.

466 Ibid. 2, 10.

${ }^{467}$ Ibid. 12 .

${ }^{468}$ Ibid. 22.

${ }^{469}$ According to EFSA, it is possible that pheromones are emitted by the fishes when they are killed, and that these pheromones may cause distress and fear in their companions. See: EFSA (2009e), cit., 19-20.

${ }^{470}$ Ibid. 12-13, 19.

104 Derecho Animal. Forum of Animal Law Studies, vol. 11/1 
they are crowded for a long time (10 minutes to several hours), ${ }^{471}$ and then one by one hoisted and gaffed out of the water. This results in painful tissue damage as well as asphyxia. ${ }^{472}$ Another serious problem is mis-spiking, which causes additional pain and injuries due to tissue damage, including "superficial to deep lacerations of skin and bone layer with haemorrhage, skull fissure or fracture, brain contusion and haemorrhage, depending on the force and angle of the spike". ${ }^{473}$

In the case of the eels, there are, among others, two special killing methods are used that are known as salt or ammonia 'bath'. Eels are protected by a layer of mucus (slime) on their skin. In order to remove this, traditionally salt is poured onto the live eels who have been placed out of the water. The salt leads to the denaturation of the mucus proteins and thus to the destruction of the slime layer on the eel's skin. Damages or removal of skin parts can also be observed. It has been reported that eels desperately try to escape from the salt, taking a long time of possibly up to 25 minutes to become unconscious. Either the eels die as consequence from the salt bath or they are eviscerated while still being alive. ${ }^{474}$ Also with ammonia baths, eels are de-slimed by placing them in a $25 \%$ ammonia solution. The same strong escape behaviour is observed as with salt and involves severe pain and distress for the animals, as confirmed by EFSA (2009g). Additionally, "immediately after exposure to ammonia eels start to bleed from the gill openings and they take up to $15 \mathrm{~min}$ to die". ${ }^{475}$

\section{$\underline{\text { Conclusion }}$}

In summary, in each of the eight scientific opinions produced by EFSA ${ }^{476}$ severe risks are described for very poor welfare and suffering during the slaughter of 'farmed' fishes in the EU, underlining EFSA's general opinion that "many existing commercial killing methods expose fish[es] to substantial suffering over a prolonged period of time". 477

It is estimated that up to 128 billion fishes farmed in aquaculture were killed in $2011,{ }^{478}$ of whom billions were slaughtered in the EU within one year. ${ }^{479}$

\subsection{OIE recommendations concerning the protection of 'farmed' fishes during slaughter}

Chapter 7.3 of the OIE Aquatic Animal Health Code lays down the requirements that should be applied during the slaughter of 'farmed' fishes in order to safeguard minimum welfare aspects. ${ }^{480}$

As described in the introductory chapter 7.1 regarding the welfare of 'farmed' fishes, "these OIE recommendations (...) address the welfare of farmed fish [es] at a general level", due to the wide variety of fish species farmed, making it "not practicable to develop specific recommendations for each of those species". Consequently, the OIE recommendations concerning fish welfare during slaughter should be considered as the very basic welfare standards to comply with in aquaculture. In this context, it is noteworthy that the first article clearly states "as a general principle [that] farmed fish [es] should be stunned before killing, and [that] the stunning method should ensure immediate and irreversible loss of consciousness". ${ }^{481}$ It also requires in case of reversible stunning that the fishes need to be killed before returning to consciousness.

Recommendations are given not only for the actual killing, but also for prior activities like transport and holding of the fishes directly before slaughter. Where fishes need to be transported prior to slaughter, they must be transported in compliance with OIE standards on fish transport. ${ }^{482}$

Article 7.3.2 of Chapter 7.3 raises the importance of qualified personnel being in charge of the fishes during handling, stunning, and killing. To ensure the welfare of the fishes, not only are experience and competence required by the operators, but also an understanding of the animals' behavioural characteristics.

\footnotetext{
${ }^{471}$ See section VI. 3.1.1. of this manuscript regarding the poor welfare aspects of crowding.

472 EFSA (2009e), cit., 14.

473 Ibid. 15

${ }^{474}$ EFSA (2009g), cit., 12.

475 Ibid. (based on behavioural observations).

${ }^{476}$ EFSA (2009a-h)

${ }^{477}$ EFSA (2004a), cit., 22

$478 \mathrm{http}: / /$ fishcount.org.uk/fish-count-estimates\#farmedestimate (13.04.2018).

479 There is no figure available of the total number of 'farm' fishes killed per year within the EU since they are not counted as individuals but only in weight. However, the percentage of EU finfish aquaculture contributes approximately $5.5 \%$ to the global scale, thus estimating that several billions of fish individuals are slaughter every year, only in EU aquaculture production.

${ }^{480}$ According to the scope of Chapter 7.3 all fishes farmed for human consumption are included into these OIE recommendations, as well as 'farmed' fishes killed for disease control purposes. The latter case is not part of this manuscript, and thus will not be considered. Nevertheless, it is noteworthy that in the case of emergency slaughter, for most species EFSA attests a lack of methods that could be applied under animal welfare aspects.

${ }^{481}$ Article 7.3.1. of Aquatic Code.

${ }^{482}$ See Article 7.3.3., resp. Chapter 7.2. of Aquatic Code, and section VI. 2.2 of this manuscript.
} 
For safety reasons, in addition "training [for the personnel] should cover occupational health and safety implications of any [stunning and killing] methods used". ${ }^{483}$

Regarding the technical requirements related to the slaughter of fishes, the Aquatic Code sets general standards in article 7.3.4 for the facilities in which the fishes are kept prior to their killing. They should be designed for the specific species or group of fishes, as well as adequate in size for the number of fishes held there for a certain amount of time without compromising their welfare. Furthermore, this article states that "operations should be conducted with minimal injury and stress to the fish[es]". ${ }^{484}$ To achieve this, the following considerations may help according to article 7.3.4 point 4 :

- design and maintenance of nets and tanks minimising physical injuries;

- suitable water quality according to fish species and density;

- design and maintenance of equipment for transferring fishes (e.g. pumps, pipes) minimising injury.

- Article 7.3.5 considers the conditions under which fishes should be unloaded, transferred and loaded in order to minimise injury and stress to them:

- adequate water quality (e.g. temperature, oxygen and $\mathrm{CO}_{2}$ levels, $\mathrm{pH}$, and salinity);

- separation and humane killing of injured or moribund fishes (where possible);

- avoidance of stressful conditions for the fishes by short and infrequent periods of crowding;

- minimal handling of fishes during transfers, preferably without handling them out of the water;

- avoidance of handling stress by allowing the fishes to swim directly into a stunning device without handling (where feasible and when applicable);

- to handle fishes: use of equipment (e.g. nets, pumping and brailing devices) designed, constructed, and operated to minimise physical injuries (pumping height, pressure and speed are important factors to consider);

- before killing, no food deprivation for fishes longer than necessary (e.g. to clear the gut or to reduce undesirable organoleptic properties);

- contingency plans to address emergencies and minimise stress during unloading, transferrin, and loading fishes.

Regarding the stunning and killing methods, article 7.3.6 contains various considerations on the different practices.

In general, species-specific information should be taken into account for the chosen method (where available). Appropriate maintenance and operation of the equipment used for handling, stunning, and killing of fishes should be considered, as well as its adequate performance, which should be tested regularly.

Furthermore, article 7.3.6 point 1 states that "effective stunning should be verified by the absence of consciousness", and that where "a backup stunning system is necessary" 485 re-stunning should be repeated as soon as possible. In case of any delay in the slaughter process, the fishes should not be stunned in order to avoid them becoming conscious again during killing. According to the OIE Aquatic Code, signs of correct stunning include:

- loss of body and respiratory movement (loss in opercular activity);

- loss of visual evoked response (VER);

- loss of vestibulo-ocular reflex (VOR, eye rolling).

- Specific recommendations are given in Article 7.3.6 for the following slaughter methods:

- Mechanical stunning and killing methods (article 7.3.6 point 2), including percussive stunning, spiking, coring or shooting;

- Electrical stunning and killing methods (article 7.3.6 point 3);

- Other killing methods (article 7.3.6 point 4), including:

- chilling with ice in holding water,

- carbon dioxide in holding water,

- chilling with ice and $\mathrm{CO}_{2}$ in holding water,

- salt or ammonia baths,

- asphyxiation by removal from water,

- exsanguination without stunning.

\footnotetext{
${ }^{483}$ Article 7.3.2. of Aquatic Code.

${ }^{484}$ Article 7.3.4. Point 3 of Aquatic Code.

${ }^{485}$ Article 7.3.6. Point 1 Letter $\mathrm{c}$ and $\mathrm{d}$ of Chapter 7.3. of Aquatic Code.

106 Derecho Animal. Forum of Animal Law Studies, vol. 11/1
} 
These other killing methods are considered to result in poor welfare, and therefore should not be used (if feasible) according to the OIE recommendations of the Aquatic Code.

In terms of mechanical stunning, percussive stunning requires a blow onto the head "of sufficient force and delivered above or immediately adjacent to the brain in order to render immediate consciousness", 486 where it can be conducted either manually or by automated equipment. It is also required that the fish is removed quickly from the water, restrained and stunned quickly, following a check on the effectiveness of the stunning.

According to the OIE Aquatic Code, percussive stunning can be used for medium to large sized fishes, like carps and salmonids.

As disadvantages of percussive stunning, the following aspects are listed in article 7.3.7:

- hand operated equipment may be hampered by uncontrolled movement of the fishes;

- mis-stunning may result from a too-weak blow;

- injuries may occur;

- manual percussive stunning is only practicable for the killing of a limited number of fishes of a similar size.

Spiking or coring is described as an irreversible mechanical stun/kill method, in which "the spike should be aimed on the skull in a position to penetrate the brain of the fish", ${ }^{487}$ thus causing immediate unconsciousness. Like in percussive stunning, it is required that the fish is removed quickly from the water, restrained, and the spike is immediately inserted into the brain. It is also mentioned that spiking underwater avoids the fishes, like smaller tuna, being exposed to the air.

As disadvantages the following aspects are listed in article 7.3.7:

- inaccurate application may cause injuries;

- it is difficult to apply if fishes are agitated;

- it is only practicable for killing a limited number of fishes.

This mechanical stun/kill method is recommended for medium to large sized fishes, like tuna. For the killing of large sized fishes, the Aquatic Code recommends the free bullet stun/kill method. Therefore, the animals "may either be crowded in a net and shot in the head from the surface, or an individual fish may be killed by shooting in the head from under the water (commonly called lupara)", ${ }^{488}$ by positioning the animal correctly, carefully targeting the brain, and choosing the shortest shooting distance as possible. ${ }^{489}$

In this respect, the disadvantages listed in article 7.3.7 are the following:

- decision on right shooting distance;

- calibre needs to be adapted;

- excessive crowding and noise of guns may cause stress reaction;

- contamination of the working area due to release of body fluids may present a biosecurity risk;

- it may be hazardous to operators as well.

In terms of electrical stunning, its application requires "an electrical current of sufficient strength and duration, and suitable frequency to cause immediate loss of consciousness and insensibility of the fish [es]". 490 Furthermore, the electrical stunning device is required to be specifically constructed and used for the relevant fish species and its environment. According to the OIE recommendations, the fishes should be kept underneath the water surface and the electrical current should be uniformly distributed within the stunning tank. With semi-dry electrical stunning systems, the OIE Aquatic Code requires that the fishes "enter the device head first to ensure rapid and efficient stunning" ${ }^{491}$ Concerning fish welfare, it is also required that the electrical current is of sufficient strength, frequency, and duration in order to lead to immediate unconsciousness.

According to the OIE Aquatic Code, the electrical stunning method could be applied to small to medium sized fishes, like carps, eels or salmonids.

\footnotetext{
${ }^{486}$ Article 7.3.7. of Chapter 7.3. of Aquatic Code.

487 Ibid.

${ }^{488}$ Article 7.3.6. Point 2 Letter c of Chapter 7.3. of Aquatic Code.

${ }^{489}$ Article 7.3.7. of Chapter 7.3. of Aquatic Code.

${ }^{490}$ Article 7.3.6. Point 3 Letter a of Chapter 7.3. of Aquatic Code.

${ }^{491}$ Article 7.3.6. Point 3 Letter e of Chapter 7.3. of Aquatic Code.
} 
Regarding electrical stunning, the following disadvantages should be taken into account:

- it is difficult to standardise for all species;

- optimal control parameters are unknown for some species;

- it may be hazardous to operators as well.

With regard to semi-dry stunning, additional welfare concerns are mentioned in the OIE Aquatic Code:

- misplacement of the fishes may result in improper stunning;

- it is not suitable for mixed sizes of fishes.

\subsection{EU legislation on the protection of 'farmed' fishes during slaughter}

3.3.1. Council Regulation (EC) No 1099/2009 of 24 September 2009 on the protection of animals at the time of killing

Council Regulation (EC) No 1099/2009 of 24 September 2009 on the protection of animals at the time of killing ${ }^{492}$ is the relevant EU legislation regarding the protection of 'farmed' fishes during slaughter. Within this regulation only article 3(1) must be complied with for 'farmed' fishes, as it is clearly stated in article 1(1) that "however as regards fish [es], only the requirements laid down in Article 3 (1) shall apply". 493

Accordingly the only requirement for 'farmed' fishes is that they "shall be spared any avoidable pain, distress or suffering during their killing and related operations". ${ }^{494} 495$

\subsubsection{Council of Europe Recommendation concerning 'farmed' fish}

The COE Recommendation adopted in 2005 by the COE Standing Committee of the European Convention for the protection of animals kept for farming purposes does not contain any detailed provisions on the commercial slaughter and killing of 'farmed' fishes. Only recommendations on the emergency killing of fishes are laid down in article $19 .{ }^{496}$

Article 11 requires, inter alia, that the fishes are deprived from food only as little as possible before slaughter.

\subsection{Critical assessment and possible recommendations for better protection of 'farmed' fishes during slaughter}

The OIE standards of the Aquatic Animal Health Code set up general recommendations that should be met in order to ensure, inter alia, a minimum level of protection of 'farmed' fishes during slaughter and related operations. Also, paragraph (7) of the preamble of Council Regulation (EC) No 1099/2009 clearly states that "those international standards should be taken into account in this Regulation", even though only the OIE Terrestrial Animal Health Code is mentioned. Nevertheless, as all EU Member States are OIE members, they have not only accepted the Terrestrial Code, but also the Aquatic Code, including the recommendations on fish welfare during slaughter adopted in 2008. Council Regulation (EC) No 1099/2009 was adopted in 2009, only one year after the adoption of the Aquatic Code on fish welfare. However, it does not consider the recommendations of the Aquatic Code at all:

1) The effective and immediate stunning of 'farm' fishes is recommended in the OIE Aquatic Code, but not considered in Regulation EC 1099/2009.

2) Qualified personnel for pre-slaughter and killing operations are recommended in the OIE Aquatic Code, but not considered in Regulation EC 1099/2009.

3) Technical requirements according to species-specific needs are recommended in the OIE Aquatic Code, but not considered in Regulation EC 1099/2009.

\footnotetext{
${ }^{492}$ Hereinafter as Regulation EC 1099/2009.

${ }^{493}$ Article 1 (1) of Council Regulation (EC) No 1099/2009.

${ }^{494}$ According to Article 2 Letter b of Council Regulation (EC) No 1099/2009, related operations are defined as "operations such as handling, lairaging, restraining, stunning and bleeding of animals taking place in the context and at the location where they are to be killed".

${ }^{495}$ Article 3 Point 1 of Council Regulation (EC) No 1099/2009.

496 The practices used for emergency killing will not be further described in the following as they would go beyond the scope of this manuscript. 
4) Pre-slaughter conditions minimising injury and stress for the fishes are recommended in the OIE Aquatic Code, but not considered in Regulation EC 1099/2009.

5) Stunning and killing methods regarding appropriate equipment and effective stunning are recommended in the OIE Aquatic Code, but not considered in Regulation EC 1099/2009.

6) The end of specific slaughter methods is recommended in the OIE Aquatic Code, but not considered in Regulation EC 1099/2009.

Even without a legally binding character for the OIE standards, by adopting them the EU and its Member States have committed themselves to comply. As these OIE standards represent the lowest common denominator on fish welfare during slaughter between a diverse and big group of OIE members (currently 181 countries), and due to the great variation of fish species and their different needs, the recommendations are kept on a basic level. Nevertheless, they could be useful for policy makers, ${ }^{497}$ such as those in the EU who adopted Regulation EC 1099/2009, but missed the chance to implement the OIE standards on fish welfare during slaughter as basic principles within the 'Slaughter Regulation'.

On the contrary, Regulation EC 1099/2009 only lays down one requirement regarding the slaughter of 'farmed' fishes, namely in article 3(1):

\section{"Animals [including fishes] shall be spared any avoidable pain, distress or suffering during their killing and related operations." 498}

As shown previously, ${ }^{499}$ current practice of fish slaughter exposes the fishes to extreme distress, pain, and suffering, often over a long period of time. Hence, the question needs to be raised how article 3(1) shall be understood, and what does 'any avoidable pain, distress or suffering' ${ }^{500}$ mean legally speaking? Recital (2) of Regulation EC 1099/2099 could help with further interpretation:

“(...) Business operators or any person involved in the killing of animals [including fishes] should take the necessary measures to avoid pain and minimise the distress and suffering [including fear] of animals during the slaughtering or killing process, taking into account the best practices in the field and the methods permitted under this Regulation. Therefore, pain, distress or suffering should be considered as avoidable when business operators or any person involved in the killing of animals breach one of the requirements of this Regulation or use permitted practices without reflecting the state of art, thereby inducing by negligence or intention, pain, distress or suffering to the animals."

Since Regulation EC 1099/2009 does not require any specific rules for the slaughter of 'farmed' fishes, theoretically any kind of killing practice is currently allowed under EU law, provided that the fishes are spared any avoidable pain, distress or suffering ${ }^{501}$ and taking into account the best practices in the field. ${ }^{502}$ Consequently, current slaughter practices like asphyxiation in air, live chilling in ice, carbon dioxide narcosis, salt or ammonia baths, or exsanguination and decapitation without prior stunning should be forbidden by article 3(1) as they are scientifically proven to be extremely harmful to the fishes and could be avoided by alternative methods, also described in the species-specific EFSA reports. ${ }^{503}$ Especially in the case of asphyxiation and carbon dioxide narcosis, EFSA clearly recommends their ban for any species due to the poor welfare inflicted on the animals and the availability of alternatives. ${ }^{504}$ Regardless, "asphyxia in ice is still the

\footnotetext{
${ }^{497}$ FAVRE, D., An International Treaty for Animal Welfare. Animal Law Review 18 (2012) 252.

${ }^{498}$ It is noteworthy that nearly the same wording had already existed in the previously valid Council Directive 93/119/EC of 22 December 1993 on the protection of animals at the time of slaughter or killing, which was replaced by Regulation EC 1099/2009. Compare article 3 of Council Directive 93/119/EC of 22 December 1993 on the protection of animals at the time of slaughter or killing stating that "animals shall be spared any avoidable excitement, pain or suffering during movement, lairing, restraint, stunning, slaughter or killing".

${ }^{499}$ See section VI. 3.1. of this manuscript.

${ }^{500}$ According to the recital (2) of Regulation EC 1099/2009, fear is acknowledged as a form of suffering.

501 According to article 3 (1) of Regulation EC 1099/2009.

502 According to recital (2) of Regulation EC 1099/2009.

${ }^{503}$ In this context, already in 2003 van de Vis et al. attested that e.g. less inhumane methods are feasible for industry compared to $\mathrm{CO}_{2}$ stunning of salmons and the salt bathing of eels (see: VAN DE VIS et al., Is humane slaughter of fish possible for industry? Cit., 211 -220). However, these methods have not been banned by EU law, but are still found in practice nowadays.

${ }^{504}$ See: EFSA (2009a) Scientific Opinion of the Panel on Animal Health and Welfare on a request from the European Commission on Species-specific welfare aspects of the main systems of stunning and killing of farmed rainbow trout. The EFSA Journal 1013, 30; EFSA (2009b), EFSA (2009b) Scientific Opinion of the Panel on Animal Health and Welfare on a request from the European Commission on Species-specific welfare aspects of the main systems of stunning and killing of farmed carp. The EFSA Journal 1013, 23; EFSA (2009c), cit., 38 / EFSA (2009e), EFSA (2009e) Scientific Opinion of the Panel on Animal Health and Welfare on a request from the European Commission on Species-specific welfare aspects of the main systems of stunning and killing of farmed tuna. The
} 
most common slaughter method for European sea bass and gilthead sea bream" ${ }^{505}$ for example. Also, the other killing methods mentioned above are considered inhumane, but are still found to a certain extent within the EU. With reference to the OIE recommendations, article 7.3.6 of the Aquatic Code states that these killing methods should not be applied, and accordingly OIE standards are widely ignored in practice within the EU, especially in the case of seabream and seabass.

Furthermore, article 3(1) of Regulation EC 1099/2009 does not only refer to the actual killing, but also includes related operations. Hence, pre-slaughter practices like long-lasting fasting or crowding over several days and even weeks, causing avoidable distress and suffering to the fishes, should be forbidden by implication. Also, article 7.3.5 of the Aquatic Code clearly requires that stressful conditions, like crowding, should be kept as short as possible for the fishes and food should not be deprived longer than necessary to clear the gut. However, due to traditional and technical convenience, "in commercial practice a range of food withdrawal periods are to be found, often far longer than is needed to simply empty the gut", 506 and "fish capture [under stressful crowding conditions] may take several days or even weeks". ${ }^{07}$ Accordingly, OIE standards are clearly not met in these cases.

Asphyxiation, long-lasting fasting, and crowding periods, and all the other methods described previously ${ }^{508}$ are justified by cost and economic efficiency, whereas animal protection issues are widely neglected. ${ }^{509}$ In Regulation EC 1099/2009 this becomes obvious in paragraph (6) of the preamble, in which the reasons for ignoring EFSA's scientific opinions regarding fish slaughter are explained:

“(...) Recommendations [of EFSA] on farm fish[es] are not included in this Regulation because there is a need for further scientific opinion and economic evaluation in this field."

In this context, it is noteworthy that "[EFSA] recommendations to phase out the use of carbon dioxide for pigs and the use of waterbath stunners for poultry are not included in this Regulation [as well] because the impact assessment revealed that such recommendations were not economically viable at present in the $E U^{\prime \prime}{ }^{510}$ In other words, the EU legislator accepts economic interests to be more important than the protection of animals from pain, distress, or suffering, even when they could be avoided technically. ${ }^{511}$ Taking this statement into account, the interpretation of article 3(1) would probably lead to another outcome for the fishes: namely, that inhumane but avoidable methods, like asphyxiation, exsanguination without prior stunning, or long-lasting fasting and crowding periods, are acceptable due to the industry's economic necessity, and thus are apparently not violating EU legislation. But there are two arguments disproving that interpretation.

Firstly, from a technical point of view and as recently stated in the EU Commission's report on the possibility of introducing certain requirements regarding the protection of fishes at the time of killing, ${ }^{512}$ socioeconomic analysis showed that "improving welfare practices [during slaughter and related operations] is likely to have only a small impact on the cost price", 513 especially in scale economies, and "in the specific case of larger Atlantic salmon and rainbow trout farms it was [even] found that investment in improving welfare could lead to labour savings, and may outweigh the investment cost", ${ }^{514}$ implying that the economic impact should be acceptable for the aquaculture industry. ${ }^{515}$

Secondly, from a legal point of view, article 13 of the Treaty on the Functioning of the European Union (TFEU) stipulates that:

\footnotetext{
EFSA Journal 1072, 23.

${ }^{505}$ EU Commission (2018) Report from the Commission to the European Parliament and the Council on the possibility of introducing certain requirements regarding the protection of fish at the time of killing, 7.

${ }^{506}$ LINES, J.A., SPENCE, J., Humane harvesting and slaughter of farmed fish, 256.

${ }^{507}$ EFSA (2009d), cit., 11.

508 As seen in the previous section 3.1 there are many more practices on fish slaughter and related operations that are linked with substantial and often avoidable pain, distress, and suffering of the fishes.

${ }^{509}$ HIRT, A., et al., Tierschutzgesetz - Kommentar, cit., 1050/rec. 55.

${ }^{510}$ Recital (11) of Regulation EC 1099/2009.

${ }^{511}$ HIRT, A., et al., Tierschutzgesetz - Kommentar, cit., 1066/rec. 3.

512 EU Commission (2018) Report from the Commission to the European Parliament and the Council on the possibility of introducing certain requirements regarding the protection of fish at the time of killing, $8-14$.

513 Ibid. p. 13

${ }^{514}$ Ibid.

515 In this context, the EU Commission's report further found that "the production of sea bass and sea bream was also generally not profitable without subsidies during the period 2009 and 2013 in the major producing Member States" (see: COM report regarding the protection of fish at the time of killing, no. 527 above, p. 11). Taking into account that these two species are most commonly killed by asphyxia and thus are exposed to immense suffering, it is not acceptable at all that EU subsidies are paid to support such an inhumane practice. Hence, the question should be raised how these subsidies are in line with the European Fisheries Fund and its requirements laid down in Regulation EC 508/2014, and could be a topic for further studies.
} 
"in formulating and implementing the Union's agriculture, fisheries, transport, internal market, research and technological development and space policies, the Union and the Member States shall, since animals are sentient beings, pay full regard to the welfare requirements of animals, while respecting the legislative or administrative provisions and customs of the Member States relating in particular to religious rites, cultural traditions and regional heritage."

Article 13 TFEU is a cross-sectional clause and thus must be understood as a binding legal norm to be respected in conflicting EU policy areas. ${ }^{516}$ In fisheries policy, full regard must be paid to the animal welfare requirements. In order to comply fully with this provision, economic interests alone cannot be a justification to cause avoidable pain, distress, or suffering to the animals. ${ }^{517}$ As a consequence, the decision not to include EFSA's recommendations on fish slaughter is clearly disrespecting the principle of article 13 TFEU. Considering that less painful and economically moderate methods already exist, the decision is even more questionable.

Further scientific research on pre-slaughter management and killing practices is urgently needed and repeatedly demanded by EFSA in order to implement new methods on an EU-wide scale that will ensure at least a minimum protection level for fishes. Especially with the rapid growth of the aquaculture industry, new fish species are being introduced into the farming systems. This inflicts more animal welfare problems under current killing practices of 'farmed' fishes, as they are less understood in their behavioural and physiological needs. ${ }^{518}$ As explained in recital (11) of the Regulation EC 1099/2009, due to the lack of research on the stunning of fishes only the key principle, i.e. to spare 'farm' fishes from avoidable pain, distress, and suffering, should be applied to them. Before establishing separate standards on the protection of fishes at killing, further risk assessment studies should be performed by EFSA and socio-economic and administrative implications should be taken into account. ${ }^{519}$ Up to the present day, and nine years after adopting Regulation EC 1099/2009, no further scientific opinion on the protection of fishes during slaughter or killing has been published by EFSA.

Albeit with over three years of delay, in February 2018 there was finally published an EU Commission report on the possibility of introducing certain requirements regarding the protection of fish at the time of killing, taking into account the animal welfare aspects as well as the socio-economic impacts, as stated in recital (11) and required by article 27(1) of Regulation EC 1099/2009. ${ }^{520}$ Despite admitting serious animal welfare problems under the current fish slaughter practices and confirming non-compliance with OIE standards in part, the report concludes that "it is not appropriate to propose specific requirements on the protection of fish [es] at the time of killing", ${ }^{521}$ but suggests relying on voluntary animal welfare initiatives by the EU aquaculture industry

\section{Conclusion}

The European Union offers a broad range of animal welfare rules, especially concerning 'farm' animals. However, for the biggest group among them, the 'farmed' fishes, their legal protection status is lacking far behind the EU's ambitions. That is to say, 'farmed' fishes are currently only protected by the very basic and general principles laid down in secondary EU legislation which leave room for interpretation and are partly not applicable or even contradictory to the welfare of fishes. The simple reason for this is that EU animal protection laws are designed, above all, for terrestrial 'farm' animals.

The aquaculture sector is a relatively new industry, compared to land-based farming, and it is growing rapidly. Globally, "the aquatic food production has transitioned from being primarily based on wild fish [es] to culture of increasing numbers of farmed species", 522 reaching its turning point "in 2014 when the aquaculture sector's contribution to the supply of fish[es] for human consumption overtook that of wildcaught fish [es] for the first time". ${ }^{523}$ Within the EU, however, this sector was stagnating for more than a decade. The EU is trying to reverse this development and again become part of the 'Blue Revolution'. With the newly reformed Common Fisheries Policy and promotion campaigns for sustainable 'EU-farmed'

\footnotetext{
${ }^{516}$ HIRT, A., et al., Tierschutzgesetz - Kommentar, cit., 21/rec. 39.

517 Ibid. 22/rec. 41

${ }^{518}$ Ibid. 210/rec. 194

519 According to recital (11) of Regulation EC 1099/2009.

${ }^{520}$ According to article 27 (1) of Regulation EC 1099/2009 the report should have been submitted no later than 8 December 2014, but was only published on 6 March 2018, giving further rise to doubt on the importance given by EU Commission on this issue.

${ }^{521}$ EU Commission (2018) Report from the Commission to the European Parliament and the Council on the possibility of introducing certain requirements regarding the protection of fish at the time of killing, cit., 13.

522 FAO, The State of World Fisheries and Aquaculture 2016. cit., 2.

${ }^{523}$ Ibid.
} 
aquaculture products, first successes have already been seen: not least "(...) due to strong cooperation over the last years between the European Commission and national authorities to remove barriers to growth", 524 EU aquaculture is growing again, as recently stated by Commissioner Karmenu Vella in a speech about the current state of play of EU aquaculture. ${ }^{525}$ Whereas the "[m] omentum has built with changes in national laws", ${ }^{526}$ apparently the main protagonists, namely the 'farmed' fishes, and their welfare needs are not considered sufficiently within this process - neither on EU level nor on national or international level.

To the present day, 'farmed' fishes and terrestrial 'farm' animals are covered by the same EU legislation, namely under Council Directive 98/58/EC concerning the protection of animals kept for farming purposes, Council Regulation (EC) No 1/2005 on the protection of animals during transport, and Council Regulation (EC) No 1099/2009 on the protection of animals at the time of killing. Even though, 'farmed' fishes are also protected by the 'COE Recommendation', adopted by the Council of Europe in 2005, as well as by the OIE Aquatic Code, these legislative texts only contain minimum protection standards. They do not consider the fishes on a species-specific level and do not cover to a satisfying extent all areas in which 'farmed' fishes are subjected to potential welfare hazards. Moreover, these legislative texts appear too weak to be properly implemented in practice, not least due to their soft law character, at least in the case of the OIE Code. In fact, as found in the recent EU Commission's study on the welfare of 'farmed' fishes during transport and slaughter, several EU Member States have failed to comply with the requirements set up in the OIE Aquatic Code. ${ }^{527}$ In the light of the rapid growth of aquaculture industry and considering the enormous number of individuals involved, it is urgently necessary to elaborate adequate and effective laws taking account of the species-specific needs of the tens of billions of 'farm' animals kept underwater. But, as recently stated, not even for the slaughter of fishes will the EU Commission consider a revision of current EU legislation, since in their opinion "(...) the evidence suggests that it is not appropriate to propose specific requirements on the protection of fish[es]", ${ }^{528}$ despite the fact that science has demonstrated the great negative impact of many farming practices on the welfare of fishes, and despite the fact that the EU has also commissioned several research projects investigating into the welfare problems of fish farming. ${ }^{529}$

Fishes are sentient beings, and as such have been recognised by the EU since the introduction of article 13 TFEU in 2009 requiring that full regard shall be paid to their welfare when formulating and implementing EU policies. Even though we do not know how it feels like to be a fish, "their mental experiences (whatever they may be) are important from their perspective. Subsequently, being their stewards, it should also be important from our perspective as human caregivers". ${ }^{530}$ Therefore, it is high time to finally act and take a stand for the fishes, inter alia, by:

1) Revising current EU legislation in order to fully respect and acknowledge the different needs of aquatic 'farm' animals;

2) Producing species-specific rules and guidelines on fish welfare, including the different life stages, like breeding, rearing, handling, transport and slaughter; ${ }^{531}$

3) Investing into research projects which clearly focus on good welfare practices and consider the positive mental states of fishes (e.g. habitat enrichment, social interaction, foraging behaviour, swimming behaviour; impact of confinement for wild-caught fishes in aquaculture production); ${ }^{532}$

4) Implementing EU-wide uniform, obligatory certification and training courses on fish welfare and fish behaviour for the different stakeholders involved in fish farming, i.e. for farmers and their staff, transporters and drivers, slaughterhouse personnel and competent veterinary authorities;

\footnotetext{
${ }^{524} \mathrm{https} / /$ ec.europa.eu/fisheries/recovering-industry-and-valuable-source-healthy-food- $\% \mathrm{E} 2 \% 80 \% 93$-european-commission-callsregions-embrace_el (12.06.2018).

${ }^{525} \mathrm{https}$ ://ec.europa.eu/commission/commissioners/2014-2019/vella/announcements/eu-aquaculture-farmed-eu-regions_en (12.06.2018); N.B.: Karmenu Vella is the EU Commissioner for Environment, Maritime Affairs and Fisheries (DG MĀRE). ${ }^{526}$ Ibid.

${ }^{527}$ EU Commission (2017b) Animal Welfare in the European Union, cit., 7.

${ }^{528}$ EU Commission (2018) Report from the Commission to the European Parliament and the Council on the possibility of introducing certain requirements regarding the protection of fish at the time of killing, cit., 13.

529 E.g.: EFSA (2008a-e), EFSA (2009a-h); BENEFISH (https://cordis.europa.eu/project/rcn/84046_en.html, (12.06.2018); COPEWELL (https://cordis.europa.eu/result/rcn/186911_en.html, (12.06.2018).

${ }^{530}$ YUE COTTEE, S., Are fish the victims of ‘speciesism'? A discussion about fear, pain and animal consciousness. Fish Physiology and Biochemistry (2012) 14.

${ }^{531}$ In this context, cleaner fishes who are not primarily kept for food production but are also subjected to aquaculture practices should also be included.

532 So far, research has focused mainly on pain perception in fishes and the negative impact on fish welfare, but good welfare does not only mean the absence of pain, disease, and suffering, but also includes the individual needs of animals to express their innate behaviour and to live a flourishing life.
}

112 Derecho Animal. Forum of Animal Law Studies, vol. 11/1 
5) Increasing official controls by creating expert groups within the competent veterinary authorities, at least in areas with a substantial number of fish farms;

6) Banning of certain practices, like selling of live fishes to private or untrained people;

7) Immediate banning of particularly cruel slaughter practices, like asphyxiation, $\mathrm{CO}_{2}$ narcosis, salt/ammonia baths, exsanguination, and decapitation without prior stunning;

8) Promoting fish welfare and raising awareness among the different stakeholders (i.e. aquaculture industry, consumers, competent authorities) throughout the EU and on international level;

9) Finally by also including wild fishes who are overexploited in wild-captive fisheries into thorough welfare considerations. ${ }^{333}$

Acknowledging that the EU seems to be at the forefront - compared to other regions where fish welfare has not even entered the political discussion yet - it would be all the more essential to finally take the next step by granting the fishes a legal protection status adequate to their needs and effective in practice. This would not only strengthen the EU's image as a first mover concerning animal welfare legislation and set an important example to the international community, but first and foremost it would help the fishes, the EU's most common but forgotten 'farm' animals.

\section{References}

- AIRES, R. F., OLIVEIRA, G. A., OLIVEIRA, T. F., ROS, A. F., OLIVEIRA, R. F., Dear enemies elicit lower androgen responses to territorial challenges than unfamiliar intruders in a cichlid fish. PloS one 10/9 (2015).

- ASHLEY, P.J., Fish welfare: Current issues in aquaculture. Applied Animal Behaviour Science 104 (2007) 199-204

- BALCOMBE, J., Cognitive evidence of fish sentience. Animal Sentience 3/2 (2016a) 3 pp.

- BAUER, H., Fishes - The Forgotten Sentient Beings, dA. Derecho Animal (Forum of Animal Law Studies 10/2 (2019) - DOI https://doi.org/10.5565/rev/da.427

- BERGQVIST, J., GUNNARSSON, S., Finfish Aquaculture: Animal Welfare, the Environment, and Ethical Implications. Journal of Agricultural and Environmental Ethics 26. (2013) 75-99

- BETHOZ, A., Neurobiology of "Umwelt": How Living Beings Perceive the World. Springer Science \& Business Media (2008) 161

- BRAITHWAITE, V., Do fish feel pain? Oxford (2010)

- BRAITHWAITE, V.A., HUNTINGFORD, F., VAN DEN BOS, R. Variation in Emotion and Cognition Among Fishes. J. Agric. Environ. Ethics 26 (2013) 7-23. https://doi.org/10.1007/s10806-011-9355-x

- BRAITHWAITE, V. \& DROEGE, P. (2016) Why human pain can't tell us whether fish feel pain. Commentary on Key on Fish Pain. Animal Sentience 3 (3). 2 pp.

- BRANSON, E.J., TURNBULL, T., Welfare and Deformities in Fish. In BRANSON, E.J. (Ed.) Fish Welfare (Oxford 2008) 202-216

- BROOM, D.M., Indicators of poor welfare. The British Veterinary Journal 142/6 (1986) 524-526

- BROWN, C., Fish intelligence, sentience and ethics. Anim Cogn 18 (2015) 1-17. https://doi.org/10.1007/s10071-014-0761-0

- BROWN, C., Familiarity with the test environment improves escape responses in the crimson spotted rainbowfish, Melanotaenia duboulayi. Animal Cognition 4/2 (2001) 109-113.

- BSHARY, R., Machiavellian intelligence in fishes. Fish cognition and behavior (2011) 277-297.

- BSHARY, R., HOHNER, A., AIT-EL-DJOUDI, K., FRICKE, H., Interspecific communicative and coordinated hunting between groupers and giant moray eels in the Red Sea. PLoS biology 4/12 (2006).

- CERqueIRA, M., Millot, S., CASTANHEIRA, M.F. et al. Cognitive appraisal of environmental stimuli induces emotion-like states in fish. Sci Rep 7 (2017) 13181. https://doi.org/10.1038/s41598-017-13173-x

- CHANDROO, K.P., YUE, S., MOCCIA, R.D., An evaluation of current perspectives on

\footnotetext{
${ }^{533}$ Not only for human consumption, but also for fish farming wild-captive fisheries play an important role: many 'farmed' fishes, especially of marine species, are carnivorous fishes who feed on other fishes. In aquaculture production these carnivorous fishes, like salmon, tuna, seabream and seabass, are fed on wild-captured fishes (in form of fish meal or oil). Not only has this feeding practice a negative ecological impact on wild (and overfished) fish populations, but it also implies a huge animal welfare problem for those wild fishes captured and killed on sea, e.g. see: BERGQVIST, J., GUNNARSSON, S., Finfish Aquaculture, cit., 90-91.
} 
consciousness and pain in fishes. Fish Fish 5 (2004) 281-295

- DAlla VILla, P., MAHAhRENS, M., VELARDE CALVO, A., DI NARDO, A., KLEINSCHMIDT, N., FUENTES ALVAREZ, C., TRUAR, A., DI FEDE, E., OTERO, J.L., MÜLLER-GRAF, C. (2009) Project to develop animal welfare risk assessment guidelines on transport. Technical Report submitted to EFSA - project developed on the proposal CFP/EFSA/AHAW/2008/02. 143 pp.

- DUNCAN, I.J., Science-based assessment of animal welfare: Farm animals. Revue scientifique et technique (International Office of Epizootics) 24/2 (2005) 483

- DUNCAN, I., DAWKINS, M., The problem of assessing "well being" and "suffering" in farm animals. In Indicators Relevant to Farm Animal Welfare (Dordrecht 1983) 13-24

- FAVRE, D., An International Treaty for Animal Welfare. Animal Law Review 18 (2012) 237-280

- FIFE-COOK, I., FRANKS, B., Positive Welfare for Fishes: Rationale and Areas for Future Study. Fishes 4/2 (2019) 31. MDPI AG. Retrieved from http://dx.doi.org/10.3390/fishes4020031

- FRANKS, B., GRAHAM, C., VON KEYSERLINGK, M.A.G., Is Heightened-Shoaling a Good Candidate for Positive Emotional Behavior in Zebrafish? Animals 8 (2018) 152

- FRASER, D., WEARY, D.M., PAJOR, E.A., MILLIGAN, B.N., A scientific conception of animal welfare that reflects ethical concerns. Animal welfare, 6 (1997) 187-205.

- GAYER, R., RABITSCH, A. \& EBERHARDT, U., Tiertransporte. Rechtliche Grundlagen, Transportpraxis, mit Prüfungswissen für den Befähigungsnachweis Tiertransport. Ulmer Verlag (2016) $312 \mathrm{pp}$.

- GIMÉNEZ-CANDELA, M., Tratamiento jurídico de los peces en la UE y en España, dA. Derecho Animal (Forum of Animal Law Studies) 10/4 (2019) DOI: https://doi.org/10.5565/rev/da.475

- GRIFFITHS, S.W., Learned recognition of conspecifics by fishes. Fish and Fisheries 4/3 (2003) 256-268

- HelfMan, G., COLlette, B.B., FACEY, D.E., BOWEN, B.W., The Diversity of Fishes: Biology, Evolution, and Ecology (Hoboken, NJ 2009)

- HIRT, A., MAISACK, C., MORITZ, J., Tierschutzgesetz - Kommentar. Verlag Franz Vahlen, 3. Edition (München 2016)

- HUNTINGFORD, F.A. Implications of domestication and rearing conditions for the behaviour of cultivated fishes. J. Fish Biol. 65 (2004) 122-142

- HUNTINGFORD, F.A., KADRI, S., Welfare and Fish. In: Branson, E.J. (Ed.) Fish Welfare (Oxford 2008) 19-31

- HUNTINGFORD, F.A., KADRI, S., Defining, assessing and promoting the welfare of farmed fish. Scientific and Technical Review of the Office International des Epizooties 33/1 (2014) 233-244

- KAHN, S. \& VARAS, M. (2014) OIE animal welfare standards and the multilateral trade policy framework. OIE discussion paper. $10 \mathrm{pp}$.

- KOHDA, M., HOTTA, T., TAKEYAMA, T., AWATA, S., TANAKA, H., ASAI, J.Y., JORDAN, A.L., If a fish can pass the mark test, what are the implications for consciousness and self-awareness testing in animals?. PLoS biology, 17/2 (2019).

- LINES, J.A., SPENCE, J., Safeguarding the welfare of farmed fish at harvest. In: van de Vis, H. et al. (Eds.) Welfare of Farmed Fish in Present and Future Production Systems. Springer Science+Business Media (Dordrecht, $1^{\text {st }}$ ed. 2012) 163-172

- LINES, J.A., SPENCE, J., Humane harvesting and slaughter of farmed fish. Scientific and Technical Review of the Office International des Epizooties 33/1 (2014) 255-264

- MACINTYRE, C.M., ELLIS, T., NORTH, B.P. and TURNBULL, J.F. (2008) The Influences of Water Quality on the Welfare of Farmed Rainbow Trout: a Review. In: Branson, E.J. (Ed.) Fish Welfare (Oxford 2008) 150-184

- MARTINS, C.I.M., GALHARDO, L., NOBLE, C., DAMSGARD, B., SPEDICATO, M.T., ZUPA, W., BEAUCHAUD, M., KULCZYKOWSKA, E., MASSABUAU, J.-C., CARTER, T., PLANELLAS, S.R., KRISTIANSEN, T., Behavioural indicators of welfare in farmed fish. In: van de Vis, H., Kiessling, A., Flik, G. \& Mackenzie, S. (Eds.) Welfare of Farmed Fish in Present and Future Production Systems. Springer Science+Business Media (Dordrecht. 1st ed. 2012) 21-45

- NOBLE, C., CANON JONES, H.A., DAMSGARD, B., FLOOD, M.J., MIDLING, K., ROQUE, A., SAETHER, B., YUE, S. (2012) Injuries and deformities in fish: their potential impacts upon aquacultural production and welfare. In van de Vis, H., Kiessling, A., Flik, G. \& Mackenzie, S. (Eds.) Welfare of Farmed Fish in Present and Future Production Systems. Springer Science+Business Media (Dordrecht. 1st ed. 2012) 67-89 
- OLIVEIRA, R. F., MCGREGOR, P. K., LATRUFFE, C., Know thine enemy: fighting fish gather information from observing conspecific interactions. Proceedings of the Royal Society of London. Series B: Biological Sciences, 265/1401 (1998) 1045-1049.

- PAlSTRA, A.P., PlANAS, J.V., TAKLE, H., THORARENSEN, H., The Implementation of Swimming Exercise in Aquaculture to Optimise Production. Aquaculture Europe 40/1 (2015) 20-22

- ROBB, D.H.F., Welfare of Fish at Harvest. In: Branson, E.J. (Ed.) Fish Welfare (Oxford 2008) 217242

- SARAIVA, J.L., ARECHAVALA-LOPEZ, P., Welfare of Fish-No Longer the Elephant in the Room. Fishes 4 (2019) 39.

- SARAiva, J. L., ARECHAVAlA-LOPEZ, P., CASTANHEIRA, M. F., VOLSTORF, J., HEINZPETER STUDER, B., A Global Assessment of Welfare in Farmed Fishes: The FishEthoBase. Fishes, 4/2 (2019) 30. MDPI AG. Retrieved from http://dx.doi.org/10.3390/fishes4020030

- SARAIVA, J.L., CASTANHEIRA, M.F., ARECHAVALA-LÓPEZ, P., VOLSTORF, J., STUDER, B.H., Domestication and Welfare in Farmed Fish. In Animal Domestication. IntechOpen (London 2018)

- SARAIVA, J.L., KELlER-COSTA, T., HUBBARD, P.C., RATO, A., CANÁRIO, A.V., Chemical diplomacy in male tilapia: urinary signal increases sex hormone and decreases aggression. Scientific reports 7/1 (2017) 1-9.

- SNEDDON, L.U., The bold and the shy: Individual differences in rainbow trout. J. Fish Biol. 62 (2003) 971-975.

- SNEDDON, L.U., Pain in aquatic animals. Journal of Experimental Biology 218 (2015) 967-976

- SNEDdon, L.U., BRAithWAite, V. and GENTLE, M.J., Novel object test: examining nociception and fear in the rainbow trout. The Journal of Pain 4/8 (2003a) 431-440

- SNEDDON, L.U., BRAITHWAITE, V., GENTLE, M.J., Do fishes have nociceptors? Evidence for the evolution of a vertebrate sensory system. Proceedings of the Royal Society of London Series B - Biological Sciences 270/1520 (2003b) 1115-1121

- SNEDDON, L.U., LEACH, M.C., Anthropomorphic denial of fish pain. Commentary on Key on Fish Pain. Animal Sentience 3/28 (2016) 1-4

- SPRUIJT, B.M., VAN DER BOS, R., PIJLMAN, F.T., A concept of welfare based on reward evaluating mechanisms in the brain: Anticipatory behaviour as an indicator for the state of reward system. Applied Animal Behaviour Science 72/2 (2001)145-171

- SOUTHGATE, P.J., Welfare of Fish During Transport. In: Branson, E.J. (Ed.) Fish Welfare (Oxford 2008) 185-194

- TABORSKY, M., Sneakers, satellites, and helpers: parasitic and cooperative behavior in fish reproduction. Advances in the Study of Behavior 23/1 (1994) e100.

- TANG, S., THORARENSEN, H., BRAUNER, C.J., WOOD, C.M., FARRELL, A.P., Modelling the accumulation of $\mathrm{CO}_{2}$ during high density, re-circulation transport of adult Atlantic salmon, Salmo salar, from observations aboard a sea-going commercial live-haul vessel. Aquaculture 296 (2009) 102-109

- TEBBICH, S., BSHARY, R., GRUTTER, A., Cleaner fish Labroides dimidiatus recognise familiar clients. Animal Cognition 5/3 (2002) 139-145.

- VAN DE VIS, H., KESTIN, S., ROBB, D., OEHLENSCHLÄGER, J., LAMBOOIJ, B., MÜNKNER, W. KUHLMANN, H., KLOOSTERBOER, K., TEJADA, M., HUIDOBRO, A., OTTERA, H., ROTH, B., SORENSEN, N.K., AKSE, L., BYRNE, H. \& NESVADBA, P., Is humane slaughter of fish possible for industry? Aquaculture Research 34 (2003) 211-220

- WAAGBO, R., JORGENSEN, S.M., TIMMERHAUS, G. BRECK, O., OLSVIK, P.A., Short-term starvation at low temperature prior to harvest does not impact the health and accurate stress response of adult Atlantic salmon. PeerJ 5 (2017) e3273.

- WALL, T., Disease and Medicines - the Welfare Implications. In BRANSON, E.J. (Ed.) Fish Welfare (Oxford 2008) 195-201

- WALSTER, C., The Welfare of Ornamental Fish. In: Branson, E.J. (Ed.) Fish Welfare. (Oxford 2008) 271-290

- YUE COTTEE, S., Are fish the victims of 'speciesism'? A discussion about fear, pain and animal consciousness. Fish Physiology and Biochemistry (2012) 12 pp.

- YUE, S., MOCCIA, R.D., DUNCAN, I.J.H., Investigating fear in domestic rainbow trout, Oncorhynchus mykiss, using an avoidance learning task. Appl. Anim. Behav. Sci. 87 (2004) 343- 
354.

\section{LEGAL REFERENCES}

\section{European Union :}

- Consolidated Version of the Treaty on the Functioning of the European Union (2016/C 202/1). Online accessible: https://eur-lex.europa.eu/legal-content/EN/TXT/?uri=OJ:C:2016:202:TOC

- Treaty of Amsterdam amending the Treaty on European Union, the Treaties Establishing the European Communities and Certain Related Acts (1997/C340/1). Online accessible: https://eurlex.europa.eu/legal-content/EN/ALL/?uri=OJ\%3AC\%3A1997\%3A340\%3ATOC

- Treaty on European Union (Maastricht text), July 29, 1992 (1992/C191/1). Online accessible: https://eur-lex.europa.eu/legal-content/EN/TXT/?uri=OJ\%3AC\%3A1992\%3A191\%3ATOC

- COUNCIL REGULATION (EC) No 1/2005 of 22 December 2004 on the protection of animals during transport and related operations and amending Directives 64/432/EEC and 93/119/EC and Regualtion (EC) No 1255/97.

- Online accessible: http://eur-lex.europa.eu/legal-content/en/ALL/?uri=CELEX:32005R0001

- COUNCIL REGULATION (EC) No 1099/2009 of 24 September 2009 on the protection of animals at the time of killing.

- Online accessible: http://eur-lex.europa.eu/legal-content/EN/ALL/?uri=CELEX:32009R1099

- COUNCIL DIRECTIVE 98/58/EC of 20 July 1998 concerning the protection of animals kept for farming purposes.

- Online accessible: http://eur-lex.europa.eu/legal-content/EN/TXT/?uri=celex:31998L0058

- COMMISSION REGULATION (EC) No 710/2009 of 5 August 2009 amending Regulation (EC) No 889/2008 laying down detailed rules for the implementation of Council Regulation (EC) No $834 / 2007$, as regards laying down detailed rules on organic aquaculture animal and seaweed production.

- Online accessible: https://eur-lex.europa.eu/legal-content/EN/ALL/?uri=celex:32009R0710

- REGULATION (EC) No 178/2002 of the European Parliament and of the Council of 28 January 2002 laying down the general principles and requirements of food law, establishing the European Food Safety Authority and laying down procedures in matters of food safety. Online accessible: https://eur-lex.europa.eu/legal-content/EN/TXT/?uri=CELEX\%3A32002R0178

- REGULATION (EU) No 1380/2013 of the European Parliament and of the Council of 11 December 2013 on the Common Fisheries Policy, amending Council Regulation (EC) No 1954/2003 and (EC) No 1224/2009 and repealing Council Regulations (EC) No 2371/2002 and (EC) No 639/2004 and Council Decision 2004/585/EC. Online accessible: http://eurlex.europa.eu/LexUriServ/LexUriServ.do?uri=OJ:L:2013:354:0022:0061:EN:PDF

- REGULATION (EU) No 508/2014 of the European Parliament and of the Council of 15 May 2014 on the European Maritime and Fisheries Fund and repealing Council Regulations (EC) No 2328/2003, (EC) No 861/2006, (EC) No 1198/2006 and (EC) No 791/2007 and Regulation (EU) No 1255/2011 of the European Parliament and of the Council. Online accessible: https://eurlex.europa.eu/legal-content/EN/TXT/?uri=uriserv:OJ.L_.2014.149.01.0001.01.ENG

- COUNCIL DIRECTIVE 93/119/EC of 22 December 1993 on the protection of animals at the time of slaughter or killing (end of validity: 31 December 2012).

- Online accessible: https://eur-lex.europa.eu/legal-content/EN/ALL/?uri=celex:31993L0119

- DIRECTIVE 91/628/EEC of 19 November 1991 on the protection of animals during transport (end of validity: 04 January 2007). Online accessible: https://eur-lex.europa.eu/legalcontent/EN/TXT/?uri=celex\%3A31991L0628

- COUNCIL DECISION 78/923/EEC of 19 June 1978 concerning the conclusion of the European Convention for the protection of animals kept for farming purposes. Online accessible: https://eurlex.europa.eu/legal-content/EN/ALL/?uri=CELEX\%3A31978D0923

\section{Council of Europe:}

- EUROPEAN CONVENTION FOR THE PROTECTION OF ANIMALS DURING INTERNATIONAL TRANSPORT, adopted by Council of Europe on 13 December 1968. CETS No. 065. Revised on 6 November 2003. CETS No. 193. Online accessible: 
https://www.coe.int/en/web/conventions/full-list/-/conventions/treaty/065

- EUROPEAN CONVENTION FOR THE PROTECTION OF ANIMALS KEPT FOR FARMING PURPOSES, adopted by the Council of Europe on 10 March 1976. CETS No. 087. Online accessible: https://www.coe.int/en/web/conventions/full-list/-/conventions/treaty/087

- RECOMMENDATION CONCERNING FARMED FISH, adopted by the Standing Committee of the European Convention for the Protection of Animals kept for Farming Purposes on 5 December 2005. Online accessible: https://www.coe.int/t/e/legal_affairs/legal_cooperation/biological_safety_and_use_of_animals/Farming/Rec\%20fish\%20E.asp

\section{OIE Recommandations:}

- WORLD ORGANISATION FOR ANIMAL HEALTH (OIE) Aquatic Animal Health Code. $20^{\text {th }}$ edition, 2017. Online accessible: http://www.oie.int/standard-setting/aquatic-code/

- WORLD ORGANISATION FOR ANIMAL HEALTH (OIE) Terrestrial Animal Health Code. $26^{\text {th }}$ edition, 2017. Online accessible: http://www.oie.int/standard-setting/terrestrial-code/

\section{National Animal Welfare Legislation:}

- TIERSCHUTZGESETZ (TierSchG) - German Animal Welfare Act, in the version published on 18 May 2006 and latest revised on 29 March 2017 (BGBI. I S. 1206, 1313).

- VERORDNUNG ZUM SCHUTZ LANDWIRTSCHAFTLICHER NUTZTIERE UND ANDERER ZUR ERZEUGUNG TIERISCHER PRODUKTE GEHALTENER TIERE BEI IHRER HALTUNG (Tierschutz-Nutztierhaltungsverordnung - TierSchNutztV) - German Ordinance for the protection of 'production' animals used for farming purposes and other animals kept for the production of animal products, in the version published on 22 August 2006 and latest revised on 30 June 2017.

\section{DOCUMENTS}

- ANIMALS' ANGELS (2016) The Myth of Enforcement of Regulation (EC) No 1/2005 on the protection of animals during transport. A documentation. Animals' Angels Press, Frankfurt a. M. $200 \mathrm{pp}$.

- DEUTSCHE BUNDESREGIERUNG (2017) Antwort der Bundesregierung auf die Kleine Anfrage der Fraktion BÜNDNIS 90/DIE GRÜNEN. Drucksache 18/12194 (02.05.2017). Online accessible: http://dipbt.bundestag.de/extrakt/ba/WP18/809/80961.html (accessed on 12.06.2018)

- EFSA (2004a) Opinion of the Scientific Panel on Animal Health and Welfare on a request from the Commission related to the welfare of animals during transport. The EFSA Journal 44, $36 \mathrm{pp}$.

- EFSA (2004b) Scientific Report of the Scientific Panel on Animal Health and Welfare on a request from the Commission related to the welfare of animals during transport. The

- EFSA Journal 44, 181 pp.

- EFSA (2008a) Scientific Opinion of the Panel on Animal Health and Welfare on a request from the European Commission on Animal welfare aspects of husbandry systems for farmed Atlantic salmon. The EFSA Journal 736, $172 \mathrm{pp}$.

- EFSA (2008b) Scientific Opinion of the Panel on Animal Health and Welfare on a request from the European Commission on animal welfare aspects of husbandry systems for farmed fish: carp. The EFSA Journal 843, 128 pp.

- EFSA (2008c) Scientific Opinion of the Panel on Animal Health and Welfare on a request from the European Commission on animal welfare aspects of husbandry systems for farmed European seabass and Gilthead seabream. The EFSA Journal 844. 129 pp.

- EFSA (2008d) Scientific Opinion of the Panel on Animal Health and Animal Welfare on a request from the European Commission on the Animal welfare aspects of husbandry systems for farmed trout. The EFSA Journal 796, 138 pp.

- EFSA (2008e) Scientific Opinion of the Panel on Animal Health and Welfare on a request from the European Commission on Animal Welfare Aspects of Husbandry Systems for Farmed European Eel. The EFSA Journal 809, 84 pp.

- EFSA (2009) Scientific Opinion on general approach to fish welfare and to the concept of sentience in fish. The EFSA Journal 954, 27 pp.

- EFSA (2009a) Scientific Opinion of the Panel on Animal Health and Welfare on a request from the 
European Commission on Species-specific welfare aspects of the main systems of stunning and killing of farmed rainbow trout. The EFSA Journal 1013. 55 pp.

- EFSA (2009b) Scientific Opinion of the Panel on Animal Health and Welfare on a request from the European Commission on Species-specific welfare aspects of the main systems of stunning and killing of farmed carp. The EFSA Journal 1013. $37 \mathrm{pp}$.

- EFSA (2009c) Scientific Opinion of the Panel on Animal Health and Welfare on a request from the European Commission on welfare aspect of the main systems of stunning and killing of farmed Atlantic salmon. The EFSA Journal 2012, 77 pp.

- EFSA (2009d) Scientific Opinion of the Panel on Animal Health and Welfare on a request from the European Commission on welfare aspect of the main systems of stunning and killing of farmed seabass and seabream. The EFSA Journal 1010, $52 \mathrm{pp}$.

- EFSA (2009e) Scientific Opinion of the Panel on Animal Health and Welfare on a request from the European Commission on Species-specific welfare aspects of the main systems of stunning and killing of farmed tuna. The EFSA Journal 1072. $53 \mathrm{pp}$.

- EFSA (2009h) Statement of EFSA prepared by the AHAW Panel on: knowledge gaps and research needs for the welfare of farmed fish. The EFSA Journal $1145.9 \mathrm{pp}$.

- EU COMMISSION (2009a) Regulatory and legal constraints for European Aquaculture. Study report IP/B/PECH/NT/2008_176, 102 pp.

- EU COMMISSION (2011) Study on the impact of Regulation (EC) No 1/2005 on the protection of animals during transport. Draft Final Report. SANCO/2010/D5/S12.574298

- EU Commission (2013) Strategic guidelines for sustainable development of EU aquaculture. COM (2013) 229 final. 2.

- EU COMMISSION (2015) Implementation of the rules on finfish aquaculture. Overview report. 43 pp.

- EU COMMISSION (2016) Aquaculture High Level Event Report "Tapping into blue growth: the way forward for European aquaculture". DG Maritime Affairs and Fisheries, Unit A.2 - Common Fisheries Policy and Aquaculture. 17 pp.

- EU COMMISSION (2017a) The ABC of EU law. By Klaus-Dietrich Borchardt. DG for Communication. $152 \mathrm{pp}$.

- EU COMMISSION (2017b) Animal Welfare in the European Union. Study PE 583.114.

- EU COMMISSION (2017c) Welfare of farmed fish: Common practices during transport and at slaughter. Final report. 78 pp.

- EU COMMISSION (2018) Report from the Commission to the European Parliament and the Council on the possibility of introducing certain requirements regarding the protection of fish at the time of killing. $15 \mathrm{pp}$.

- EUROGROUP FOR ANIMALS (undated) Fish Welfare. Building a Europe that cares for all animals. Position paper. Available online: http://www.eurogroupforanimals.org/wpcontent/uploads/Fish-Welfare-Eurogroup-for-Animals.pdf [accessed on 12.06.2018]

- FAO (2016) The State of World Fisheries and Aquaculture 2016. Contributing to food security and nutrition for all. Rome. $200 \mathrm{pp}$.

- GREENPEACE (2008) Challenging the Aquaculture Industry on Sustainability. Amsterdam. 24 pp. 